\title{
EVALUATION OF DRIVER VISUAL DEMAND ON THREE-DIMENSIONAL RURAL HIGHWAY ALIGNMENTS
}

\author{
By \\ Wen Long He \\ Bachelor of Engineering, Beijing Polytechnic University, \\ Beijing, China, 1993
}

A thesis

Presented to Ryerson University

In partial fulfillment of the requirement of degree of

Master of Applied Science

In the Program of

Civil Engineering

Toronto, Ontario, Canada, 2004

CWen Long He 2004 
UMI Number: EC53465

\section{INFORMATION TO USERS}

The quality of this reproduction is dependent upon the quality of the copy submitted. Broken or indistinct print, colored or poor quality illustrations and photographs, print bleed-through, substandard margins, and improper alignment can adversely affect reproduction.

In the unlikely event that the author did not send a complete manuscript and there are missing pages, these will be noted. Also, if unauthorized copyright material had to be removed, a note will indicate the deletion.

\section{$\mathrm{UMI}$}

UMI Microform EC53465

Copyright 2009 by ProQuest LLC

All rights reserved. This microform edition is protected against unauthorized copying under Title 17, United States Code.

ProQuest LLC

789 East Eisenhower Parkway

P.O. Box 1346

Ann Arbor, MI 48106-1346 


\section{Author's Declaration}

I hereby declare that I am the sole author of the thesis.

I authorize Ryerson University to lend this thesis to other institutions or individuals for the purpose of scholarly research.

Signature

I further authorize Ryerson University to reproduce this thesis by photocopying or by other means, in total or part, at the request of other institutions or individuals for the purpose of scholarly research.

Signature 


\section{Borrowers}

Borrowers undertake to give proper credit for any use made of the thesis.

Ryerson University requires the signatures of all persons using or photocopying this thesis.

Please sign below and give address and date.

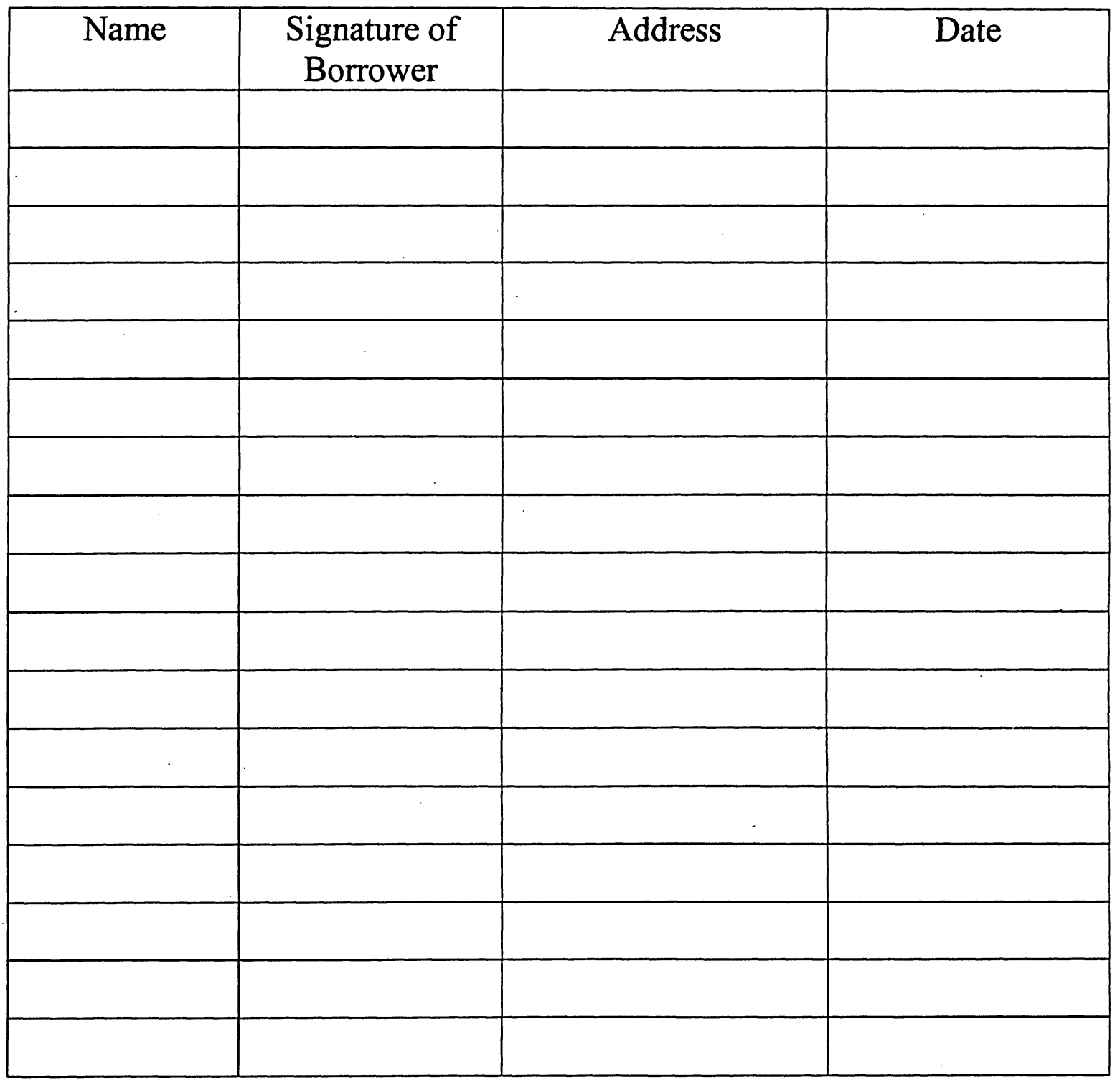




\title{
EVALUATION OF DRIVER VISUAL DEMAND ON THREE-DIMENSIONAL RURAL HIGHWAY ALIGNMENTS
}

\author{
By \\ Wen Long He \\ Master of Applied Science in Civil Engineering \\ Department of Civil Engineering \\ Ryerson University, Toronto \\ 2004
}

\begin{abstract}
This research focuses on evaluating driver visual demand on three-dimensional (3D) highway alignments consisting of combined horizontal and vertical alignments which is an important part of highway design consistency research. Using a driving simulator, ten hypothetical 2D and 3D alignments for two-lane rural highways were developed, following the standard guidelines of the Transportation Association of Canada (TAC) and the American Association of State Highway Transportation Officials (AASHTO). Fifteen driver subjects drove in the simulator. The data relating to visual demand information were processed and analyzed using Microsoft Excel and the SAS statistical software. The results indicated that visual demand on 3D curves varies widely with the inverse of radius of horizontal curvature and the inverse of $\mathrm{K}$ value of vertical curvature. Age played another important role on visual demand. Models for evaluating visual demand on 3D highway alignments were developed for curves and tangents. The models developed in this study have been applied to horizontal and 3D alignments to carry out a design consistency evaluation. In addition, GIS virtual reality technique was applied to present the visual demand results for a real highway on the 3D visualization model. 3D visualization not only offers a better understanding of driver workload along the highway, but also represents an important tool to effectively manage information.
\end{abstract}




\section{ACKNOWLEDGEMENTS}

I would like to thank my supervisor, Dr. Said Easa, for suggesting the idea of this thesis. He offered me strong support, freedom of research and excellent guidance throughout the entire project. He provided useful advice and gave effective suggestions and innovative concepts in developing the final models in my study. I am also indebted to Dr. Easa for allowing me to carry out the experiments using the driving simulator at his Human Factor's lab.

I would like to thank Dr. Paul Milgram, Professor of Mechanical and Industrial Engineering Department, University of Toronto, for his active guidance and support in learning to use the visual occlusion device and simulator. I am also grateful to Dr. Kathryn Woodcock, Dr. Ali Mekky and Dr. Lamya Amleh, members of my thesis defense committee, for their thoughtful and diligent comments on my thesis.

There are not enough words to express my gratitude to my wife for sacrificing her needs and time to support me throughout the successful completion of this research project. 


\section{TABLE OF CONTENTS}

Abstract iv

Acknowledgement v v

List of Tables $\quad$ ix

List of Figures $\quad$ xi

$\begin{array}{lll}\text { Chapter } 1 \quad \text { INTRODUCTION } & 1\end{array}$

1.1 Background 1

1.2 Thesis Organization 3

$\begin{array}{lll}\text { Chapter } 2 & \text { LITERATURE REVIEW }\end{array}$

2.1 Highway Design Consistency 6

2.1.1 Cross Section Consistency 7

2.1.2 Operating Speed Consistency 7

2.1.3 Alignment Geometry Consistency 11

2.1.4 Driver Workload Consistency 12

$\begin{array}{lll}2.2 & \text { Driver workload } & 13\end{array}$

2.3 Visual Occlusion Method

$\begin{array}{ll}\text { 2.3.1 Background } & 16\end{array}$

2.3.2 Development of Visual Occlusion Apparatus 24

2.3.3 Comparison and Validation of Driving Environments 26

2.4 Three-Dimensional Highway Alignment Research 27

$\begin{array}{ll}2.5 & \text { Challenge and Hypothesis } \\ \end{array}$

$\begin{array}{lll}\text { Chapter } 3 & \text { SIMULATION PILOT STUDY } & 31\end{array}$

3.1 Methodology 31

3.1.1 Road Design Variables $\quad 31$

3.1.2 Test Alignments in Simulation Scenarios 32

3.1.3 Process 32

3.2 Data Extraction $\quad 32$

3.3 Data Analysis and Validation $\quad 34$

3.4 Statistical Analysis and Comparison 36 
$\begin{array}{lll}\text { Chapter } 4 \text { SIMULATION EXPERIMENT } & 40\end{array}$

4.1 Apparatus 40

4.1.1 Driving Simulator $\quad 40$

4.1.2 Data Definition of 3D Highway Alignments 41

4.1.3 STISIM Data Input Files $\quad 45$

4.1.4 STISIM Data Output Files $\quad 46$

4.1.5 Visual Occlusion Device $\quad 47$

4.1.6 Linking of Devices 49

$\begin{array}{lll}4.2 & \text { Methodology } & 49\end{array}$

4.3 Experimental Design $\quad 51$

4.3.1 Road Variables Calculation $\quad$. 54

4.3.2 Developing Hypothetical Scenarios in STISIM 55

4.4. Experimental Process $\quad 58$

$\begin{array}{lll}\text { Chapter } 5 & \text { ANALYSIS RESULTS } & 61\end{array}$

$\begin{array}{lll}5.1 & \text { Analysis Procedures } & 61\end{array}$

5.2 Calibrated Visual Demand Models 63

5.2.1 Curve Models $\quad 63$

$\begin{array}{ll}\text { 5.2.2 Tangent Models } & 67\end{array}$

5.3 Discussion of Visual Demand on Curves 68

5.3.1 Effect of 3D Curvature 68

5.3.2 Effect of Age $\quad 72$

5.3.3 Comparison with On-road Test $\quad 73$

5.3.4 Model Verification and Comparison $\quad 75$

5.4 Discussion of Visual Demand on Tangents 83

5.41 Effect of 3D Curvature $\quad 84$

5.4.2 Effect of Age $\quad 85$ 
6.1 Description of Test Alignments $\quad 86$

$\begin{array}{llr}6.2 & \text { Results } & 89\end{array}$

6.2.1 Result for 2D Horizontal Alignment $\quad 89$

$\begin{array}{ll}\text { 6.2.2 Result for 3D Alignment } & 90\end{array}$

$\begin{array}{lll}6.3 & \text { Discussion } & 92\end{array}$

$\begin{array}{lll}6.4 & \text { GIS Visualization } & 96\end{array}$

6.4.1 Background $\quad 96$

6.4.2 Visualization of 3D Highway Alignments 97

6.4.3 Visualization of Driver Visual Demand 98

$\begin{array}{lll}\text { Chapter } 7 & \text { CONCLUSIONS AND RECOMMENDATIONS } & 101\end{array}$

$\begin{array}{lll}7.1 & \text { Conclusions } & 101\end{array}$

$\begin{array}{lll}7.2 & \text { Recommendations } & 102\end{array}$

$\begin{array}{lr}\text { REFERENCES } & 109\end{array}$

$\begin{array}{lll}\text { Appendix A Characteristics of Tested Alignments } & 110\end{array}$

$\begin{array}{lll}\text { Appendix B Details of the Driving Simulator } & 121\end{array}$

$\begin{array}{lll}\text { Appendix C Forms for Pilot Study and Experiment } & 125\end{array}$

$\begin{array}{lll}\text { Appendix D Summary Output and Results } & 129\end{array}$ 


\section{LIST OF TABLES}

Table 1 Equations for Estimating Operating Speed on Varies Types of Speed-Limiting Curves (Fitzpatrick 1999) 10

Table 2 Review of Objectives, Subjects and Results of Previous Research

Table 3

Geometry of Horizontal and Vertical Curves Used in Pilot Study and Simulation Experiment

Table 4 Test Alignments for the Simulation

Table 5 Average Visual Demand for Single Curves

Table 6 Average Visual Demand from the TTI Occlusion Field Study (Shafer et al. 1995)

Table 7 Average Visual Demand from the TTI Occlusion Field Study (Fitzpatrick et al. 1999)

Table 8

Models Developed in the Pilot Study

Table 9

Spreadsheet for Calculating Road Parameters

Table 10

Table 11

Sample of *.DAT File for Visual Demand Data Collection

Visual Demand on 3D Alignments with different $\mathrm{R}$ and $\mathrm{K}$

Table 12

Table 13

Parameter Estimates on VDF of Curves

66

Table 14

Parameter Estimates on VDF on Tangents

68

Comparison of this Study and Previous Studies

Table 15

Information of Individual Observation Elements (Horizontal Curves)

Table 16 Information of Individual Observation Elements (Subject age $=30$ )

Table 17 Information of Individual Observation Elements (Subject age $=61$ )

Table 18

Test Alignment 7

Table 19

Detail Geometric Information on 2D Test Alignment

Table 20

Detail Geometric Information on 3D Test Alignment

Table 21

Operating Speed and Visual Demand for 2D Test Alignment

Table 22

Table 23 Operating Speed and Visual Demand for 3D Test Alignment

Visual Demand Information along the Highway Alignment

Table 24 Detail Geometric Information on Test Alignment - 1

Table 25

Detail Geometric Information on Test Alignment - 2

Detail Geometric Information on Test Alignment - 3

Table 27

Detail Geometric Information on Test Alignment - 4

Detail Geometric Information on Test Alignment - 5

Detail Geometric Information on Test Alignment - 6

Table 29

Table 30

Detail Geometric Information on Test Alignment - 7

Detail Geometric Information on Test Alignment - 8

Detail Geometric Information on Test Alignment - 9 
(for 2D horizontal curves, only considering $1 / R$ )

Täble 35 Model developed on Average VD during Pilot Study (for 2D curves, and 3D horizontal overlapping sag curves, only considering 1/R)

Table 36 Model developed on Average VD during Pilot Study (for 2D horizontal curves, and 3D horizontal overlapping sag curves, considering $1 / \mathrm{R}$ and $1 / \mathrm{K}$ )

Table 37 Model developed on Average VD during Pilot Study (for 2D curves, and 3D horizontal overlapping crest curves, considering 1/R)

Table 38 Model developed on Average VD during Pilot Study (for

2D curves, and 3D horizontal overlapping crest curves, considering $1 / \mathrm{R}$ and $1 / \mathrm{K}$ )

Table 39 Model developed on Individual VD during Pilot Study (for horizontal overlapping sag curves, considering Age, 1/K and 1/R)

Table 40 Model developed on Individual VD during Pilot Study (for horizontal overlapping crest curves, considering Age, 1/K and 1/R)

Table 41 Correlation Coefficient Analysis Result for Curve Models

Table 42 Model developed on VDF for 2D \& 3D Curves during Experimentation

Table 43 Model developed on VDH for 2D \& 3D Curves during Experimentation

Table 44 Model developed on VD30 for 2D \& 3D Curves during Experimentation

Table 45

Model developed on VDF for Tangents during Experimentation 


\section{LIST OF FIGURES}

Figure 1 Organization of the thesis 4

Figure $2 \quad$ Device for controlling Driver Vision (Senders et al. 1967) 18

Figure 3 Driving Simulator at Ryerson University (Easa and Ganguly 2004) 18

Figure $4 \quad$ Definitions of Pulse Timing Parameters (Milgram et al. 1984) 26

Figure $5 \quad$ Comparison of Visual Demand Regression Equations 28

Figure 6 Roadway Scene of STISIM Simulator 41

Figure $7 \quad$ The Geometry of Constant Grade and Vertical Curve 43

Figure $8 \quad$ An Example of 3D Combined Alignment 44

Figure 9 Linkage of Devices for Visual Demand Experiment 50

Figure $10 \quad$ Flow Chart Showing Various Steps of the Experimentation

Figure 11 Variability of Visual Demand on a Test Alignment 64

Figure 12 Sketches Showing Characteristics of Vertical Curve Types 64

Figure 13 Sensitivity of VDF with varying Inverse of $\mathrm{K}$ of the Vertical Curve (Radius $=600 \mathrm{~m}$, Subject age $=60$ ) 69

Figure 14 Sensitivity of VDF with varying Inverse of $\mathrm{K}$ of the Vertical Curve (Radius $=300 \mathrm{~m}$, Subject age $=30$ )

Figure 15 Sensitivity of VDF with varying Inverse of $\mathrm{K}$ of the Vertical Curve (Radius $=300 \mathrm{~m}$, Subject age $=60$ )

Figure 16 Sensitivity of VD with varying Inverse of Radius

$(\mathrm{K}=40$, Subject age $=60)$

Figure 17 Sensitivity of VD with varying Age (Radius $=300 \mathrm{~m}, \mathrm{~K}=60$ )

Figure 18 Comparison of Simulator Study and On-Road Study and

Test Track 75

Figure 19 Comparative Study on Goodness of Fit (2D Horizontal Curves) 77

Figure 20 Comparative Study on Goodness of Fit

(Sag and Crest Curves, Subject age $=30$ )

Figure 21 Comparative Study on Goodness of Fit

(Sag and Crest Curves, Subject age $=61$ )

80

Figure 22 Comparative Study for a specific Curves Combination

(Test Alignment 7)

Figure 23 Sensitivity of VD on Tangents with varying Preceding

Curve Radius (Subject age $=30 \mathrm{~s}$ )

Figure 24 Sensitivity of VD with varying Subject Age (Radius $=600 \mathrm{~m}$ ) 85

Figure 25 Sketches showing Plan View of 2D Test Alignment 87

$\begin{array}{lll}\text { Figure } 26 & \text { Sketches showing Plan View of 3D Test Alignment } & 87\end{array}$

Figure 27 Difference of Speed Profile for 2D Test Alignment 93

Figure 28 Difference of Visual Demand Profile for 2D Test Alignment 93

Figure 29 Difference of Speed Profile for 3D Test Alignment 95

Figure 30 Difference of Visual Demand Profile for 3D Test Alignment 95

Figure 31 3D Visualization Model of Highway Alignment 98 
Figure 32 3D Visualization Model of Visual Demand on Highway

Alignment

Figure 33 Sketches showing Vertical Profile of Test Alignment - 1

Figure 34

Sketches showing Horizontal Curves of Test Alignment - 2

Figure 35

Sketches showing Vertical Profile of Test Alignment - 3

113

Figure 36

Sketches showing Vertical Profile of Test Alignment - 4

Figure 37

Sketches showing Vertical Profile of Test Alignment - 5

Figure 38 Sketches showing Vertical Profile of Test Alignment - 6

Figure 39 Sketches showing Vertical Profile of Test Alignment - 7

Figure 40 Sketches showing Vertical Profile of Test Alignment - 8

Figure 41 Sketches showing Vertical Profile of Test Alignment - 9

Figure 43 STISIM Simulator at Human Factors Lab in Ryerson University

Figure 44 Visual Occlusion Spectacles, ToTal Control Computer, Pulse Generator and Black Control Box

Figure 45

ToTal Control Computer for Visual Occlusion Control

Figure 46 Switch Pedal and Pulse Generator 


\section{Chapter 1 INTRODUCTION}

\subsection{Background}

As safety is the most important goal of transportation engineering, both for the public and for highway professionals, researchers and designers are constantly trying to develop and apply tools and techniques that improve road safety. Highway geometric design is an important area of transportation engineering. Many geometric design policies have been framed, revised and published by organizations such as the American Association of State Highway and Transportation Officials (AASHTO 2001) and the Transportation Association of Canada (TAC 1999). Highway safety is the primary goal of these design guides.

Collision statistics show that about $90 \%$ of road collisions are caused by driver error. Driving can be regarded as an information processing and decision making task (Rockwell 1972). Ideally, driving should be error-free, but in reality, errors occur and can lead to vehicle damage, injuries or fatalities (Senders et al. 1967). In Canada and the United States, the concept of design consistency has been introduced to improve highway design and to maximize safety. The concept of design consistency was initially employed to evaluate speed consistency. The concept of driver mental workload consistency is also relevant because it has been found that a sudden change in visual demand is a significant cause of driver error and can cause a collision (Lamm 1995).

Before a set of ideal design consistency standards can be established, driver mental workload in all highway environments must be studied. There are five broad categories of workload measurement techniques: (1) primary task measures, (2) secondary task 
measures, (3) physiological measures, (4) subjective measures, and (5) visual occlusion measures (Hicks et al. 1979). The visual occlusion method for determining visual demand is currently the main approach to workload measurement. Due to limitations in the techniques, equipment, and presentation methods available, visual demand research to date has investigated only two-dimensional (2D) highway alignments, either for simple horizontal alignments (Senders 1967, Godthelp 1972, Shafer 1995, Mourant 1997, and Tsimhoni 1999) or for complex horizontal alignments (Easa and Ganguly 2004).

As a result, existing visual demand models may be limited in scope when applied on rolling or mountainous terrain. One obvious limitation of current 2D visual demand models is that the models do not address the effect of vertical alignment that overlaps with horizontal alignment. Since the early 1990s, Easa and his research team have found more indications that suggested that the $3 \mathrm{D}$ nature of highway alignment design makes many issues highly complex and not suitable for study using traditional methods based on 2D separate horizontal and vertical alignments. Research issues for 3D highway alignment studies include sight distance analysis, horizontal curve perception, and vehicle stability (Easa et al. 2002, Hassan et al. 1998, Easa and Gauguly 2004).

This research was undertaken as partial fulfillment of a M.A.Sc. degree. The objectives of this research were:

(1) To measure driver visual demand on 3D highway alignments using the visual occlusion method under a driving simulator environment.

(2) To evaluate the effect of vertical alignment overlapping with horizontal alignment.

(3) To examine the effect of individual differences such as a driver's age and other potentially important factors. 
(4) To develop visual demand models for curves and tangents on 3D highway alignments.

(5) To develop an advanced virtual reality technique that presents complex visual demand information collected along highway alignments.

\subsection{Thesis Organization}

The work for this thesis followed the steps shown in Figure 1:

Chapter 2 Literature Review: The literature review focused on an in-depth study of relevant methods and analysis in the areas of highway design consistency, driver workload and visual demand determination. A detailed review. of the visual occlusion method is presented, including relevant models, previous studies, visual occlusion apparatus, and comparison and validation of the driving environments. A review of 3D highway alignment research is also presented, followed by the research challenge and hypothesis.

Chapter 3 Simulation Pilot Study: A Pilot Study was conducted to test the hypothesis of this research. Nine 3D and one 2D highway alignments were designed using TAC and AASHTO standards. The curves on the alignments include 3D horizontal curves overlapping crest vertical curves and overlapping sag vertical curves, and 2D horizontal curves. Three drivers representing young, middle-aged and old drivers participated in the scenarios. The visual occlusion method was used to determine driver visual demand. The Pilot Study showed that the experimentation procedure adopted for this research worked well. 


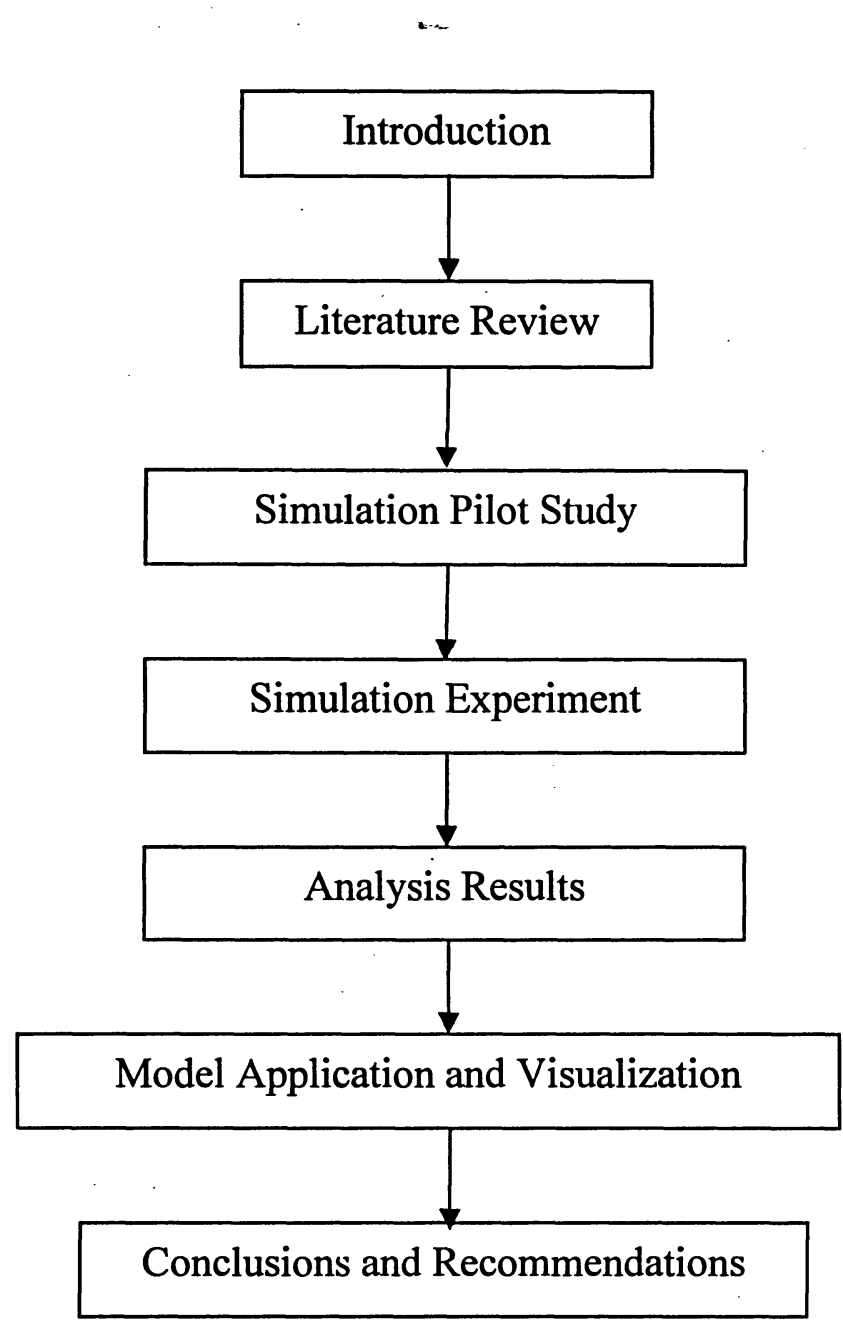

Figure 1 Organization of the thesis

Chapter 4 Simulation Experiment: The simulation experiment is the core of this research. This chapter explains the details of the experimental design, including the apparatus, hardware integration, experimental design, and process adopted. Fifteen drivers were invited to participate in the simulation experiment using the 2D and 3D alignments described in the Chapter 3.

Chapter 5 Analysis Results: This chapter describes the procedures used to extract and interpret the data from the simulation results and to develop the 
visual demand models. Visual demand models for curves and tangents are developed.

Chapter 6 Model Application and Visualization: This chapter deals with the application of this visual demand measurement and the models developed in this research to compute the visual demand on 2D and 3D alignments. A design consistency evaluation with respect to operating speed and workload was carried out. Then, the 3D Analysis Package in Geographic Information System (GIS) was used to develop 3D visualization modeling to present the results of the visual demand measurement. A real highway in the State of Georgia (U.S.A.) was implemented using the driving simulator. The results were presented on the highway network model.

Chapter 7 Conclusions and Recommendations: This chapter summarizes and discusses the research findings, and presents recommendations for future research. 


\section{Chapter 2 LITERATURE REVIEW}

For many years, researchers have recognized that there is a relationship between the geometric features of a highway and its safety and efficiency. Important geometric features include the horizontal and vertical alignment of the roadway, lane width, median, shoulders, curbs, etc. As these features are visible to drivers and affect driving performance, a consideration of human factors in highway design is essential.

\subsection{Highway Design Consistency}

Design consistency implies that the design of a road does not violate either the expectation of the driver or the ability of the driver to guide and control the vehicle in a safe manner (Glennon 1978). Maintaining roadway design consistency is important because drivers are believed to make fewer errors at geometric features that conform with their expectations than at features that violate their expectations (Post 1981). An inconsistent design can be defined as "a geometric feature or combination of adjacent features that have such unexpectedly high driver workload that motorists may be surprised and possibly drive in an unsafe manner (Messer 1980)." Researchers have found a strong relationship between design consistency and road safety. Highly inconsistent design that produces a sudden change in roadway characteristics can lead to human errors and subsequently to collisions (Lamm et al. 1995).

The TAC design guide has a revised chapter on Design Consistency by Easa (2004). The chapter introduces a number of procedures for the consistency evaluation and divides design consistency measures into two categories: system consistency and local consistency. System consistency measures (among elements) include cross section 
consistency, operating speed consistency, alignment geometry consistency, and driver workload consistency. Local consistency measures (within individual elements) include design-speed margin consistency and vehicle stability consistency. When designing a highway, designers must ensure consistency at both the system and the local levels. Cross section and operating speed consistency are the primary measures in any consistency evaluation. Alignment geometry consistency and driver workload consistency are important supplementary measures.

\subsubsection{Cross Section Consistency}

For a given classification of roadway under the same or similar terrain conditions, cross section elements should be the same. After establishing the cross section dimension, the lane widths, shoulder widths, and clear zones should all be consistent. The same principle should be applied to other features of the cross section, such as marker posts and roadside barriers. If a sudden change in the cross section is unavoidable (such as a signalized intersection, a narrow two-lane road, a narrow bridge) the designer should try the best to mitigate the negative influence of the unexpected features or should redesign the road to maintain design consistency.

\subsubsection{Operating Speed Consistency}

The concept of design speed has been the primary quantitative method for ensuring consistency and safe operating speeds along rural highways. Speed inconsistencies are, however, often observed on highways (Krammes 1995). The concept of design speed cannot completely co-ordinate individual geometric features on an alignment because the tangent issue is not considered. 
Leisch et al. (1977) started to use an operating speed profile to identify undesirably large speed differences when evaluating geometric design consistency. A procedure was suggested to estimate average running speed for passenger cars and trucks.

Lamm et al. (1988) developed a linear regression model for the prediction of operating speed. The model considers highway geometry and traffic volume, as follows $\left(r^{2}=0.84\right)$

$$
\mathrm{V}_{85}=34.7-1.005 * \mathrm{DC}+2.081 * \mathrm{LW}+0.174 * \mathrm{SW}+0.0004 * \mathrm{AADT}
$$

where

$\mathrm{V}_{85}=85$ percentile operating speed,

$\mathrm{DC}=$ degree of curve,

$\mathrm{LW}=$ lane width,

$\mathrm{SW}=$ shoulder width,

$\mathrm{AADT}=$ annual average daily traffic, and

$\mathrm{r}^{2}=$ coefficient of determination.

Choureiti et al. (1994) pointed out that curvature change rate (CCR), which is defined as the absolute sum of the angular change per unit length of a highway section, can be used to predict operating speed and to determine the speed inconsistency on a horizontal alignment. Choureiti et al. then established linear regression relationships between the 85th percentile operating speed and design parameters for different lane widths.

Many factors influence operating speed, including pavement condition, radius of horizontal curvature, sight distance, length of the curve, superelevation rate and side friction factor (Gibreel. et al. 1999). Most previous research work has focused on 
establishing the relationship between operating speed and 2D horizontal geometric features. Hassan and Easa (2000) developed an operating speed model based on observation of a specific highway in Ontario and validated their model by comparing the operating speed profile with the results of field measurements. Unlike the traditional 2D method, the authors analyzed sight distance using a 3D approach during both daytime and nighttime. Tire friction and vehicle stability were also considered for model verification.

Easa (2003) recommended that the system consistency of existing or proposed alignments should be evaluated using the operating speed method. In this method, it is suggested that the speed difference between two consecutive elements should not be more than $20 \mathrm{~km} / \mathrm{h}$. If the speed difference exceeds $20 \mathrm{~km} / \mathrm{h}$, the designer should make adjustments to the design. Ideally, the speed difference should be within $10 \mathrm{~km} / \mathrm{h}$.

To evaluate speed consistency for a proposed new road, it is necessary to predict operating speeds. The new TAC Design Guide recommends a series of regression equations for $2 \mathrm{D}$ and $3 \mathrm{D}$ highway conditions. Table 1 summarizes these regression equations for various types of curves. The TAC Design Guide suggests that the $85^{\text {th }}$ percentile speed observed on long tangents of two-lane rural highways ranges from 94 to $104 \mathrm{~km} / \mathrm{h}$. Therefore, a rounded value of $100 \mathrm{~km} / \mathrm{h}$ is a good estimate for the desired speed $\left(V_{\mathrm{f}}\right)$ on long tangents of two-lane rural highways. A long tangent is one that is long enough for the driver to accelerate to a desired speed for some distance. It can be checked by $\mathrm{TL}_{\mathrm{c}}$ :

$$
\begin{aligned}
& T L_{c}=X_{1 a}+X_{1 d} \\
& X_{1 a}=\left(V_{f}^{2}-V_{n}^{2}\right) / 25.92 a \\
& X_{1 d}^{\prime}=\left(V_{f}^{2}-V_{n+1}^{2}\right) / 25.92 d
\end{aligned}
$$


where

$\mathrm{X}_{\mathrm{la}}=$ length of road for acceleration from curve $\mathrm{n}$ speed to desired speed,

$X_{1 d}=$ length of road for deceleration from desired speed to curve $n+1$ speed,

$\mathrm{V}_{\mathrm{f}}=$ desired speed, and

$V_{n}$ and $V_{n+1}=85^{\text {th }}$ percentile speeds for curve $n$ and $n+1$ (using equations in Table 1)

If $\mathrm{TL}_{\mathrm{c}}$ is less than $100 \mathrm{~m}$, then it is a long tangent. The operating speed model has been improved by considering the effect of sight line obstruction (Easa 2003).

Table 1 Equations for Estimating Operating Speed on Varies Types of Speed-Limiting Curves (Fitzpatrick 1999)

\begin{tabular}{|c|l|c|}
\hline Type & \multicolumn{1}{|c|}{ Alignment Condition } & \multicolumn{1}{c|}{ Equation (a) } \\
\hline 1 & Horizontal curve on grade: $-9 \% \leq \mathrm{G}<-4 \%$ & $\mathrm{~V}_{85}=102.10-3077.13 / \mathrm{R}$ \\
\hline 2 & Horizontal curve on grade: $-4 \% \leq \mathrm{G}<0 \%$ & $\mathrm{~V}_{85}=105.98-3709.90 / \mathrm{R}$ \\
\hline 3 & Horizontal curve on grade: $0 \% \leq \mathrm{G}<4 \%$ & $\mathrm{~V}_{85}=104.82-3574.51 / \mathrm{R}$ \\
\hline 4 & Horizontal curve on grade: $4 \% \leq \mathrm{G}<9 \%$ & $\mathrm{~V}_{85}=96.91-2752.19 / \mathrm{R}$ \\
\hline 5 & $\begin{array}{l}\text { Horizontal curve combined with sag vertical } \\
\text { curve }\end{array}$ & $\mathrm{V}_{85}=105.32-3438.19 / \mathrm{R}$ \\
\hline 6 & $\begin{array}{l}\text { Horizontal curve combined with non limited sight } \\
\text { distance crest vertical curve }\end{array}$ & (b) \\
\hline 7 & $\begin{array}{l}\text { Horizontal curve combined with limited sight } \\
\text { distance crest vertical curve (i.e., } \mathrm{K} \leq 43 \mathrm{~m} / \%)(\mathrm{c})\end{array}$ & $\mathrm{V}_{85}=103.24-3576.51 / \mathrm{R}$ \\
\hline 8 & $\begin{array}{l}\text { Vertical crest curve with non limited sight } \\
\text { distance }(\mathrm{K}>43 \mathrm{~m} / \%) \text { on horizontal tangent }\end{array}$ & $\mathrm{V}_{85}=105.08-149.69 / \mathrm{K}$ \\
\hline
\end{tabular}

(a) $\mathrm{V}_{85}=85^{\text {th }}$ percentile speed of passenger cars $(\mathrm{km} / \mathrm{hr}), \mathrm{K}=$ rate of vertical curvature $(\mathrm{m} / \%), \mathrm{R}=$ radius of curvature $(\mathrm{m})$, and $\mathrm{G}=\operatorname{grade}(\%)$.

(b) Use lowest speed of the speeds predicted from Type 1 or 2 (for downgrade) and Type 3 or 4 (for upgrade).

(c) In addition, check the speeds predicted from Type 1 or 2 (for downgrade) and Type 3 or 4 (for upgrade) and use the lowest speed. This will ensure that the speed predicted along the combined curve crest vertical curve results in a higher speed. 


\subsubsection{Alignment Geometry Consistency}

Geometric alignment features can also be used to evaluate design consistency. If the general character of alignment changes between road segments, collisions due to inconsistencies may occur. Pignataro (1975) found that the total collision rate per million vehicle miles on two-lane rural highways decreased as the pavement width increased. Based on this finding, some design consistency models with respect to geometric elements were developed. For example, the model by Polus et al. (1987) is as follows:

$$
\begin{aligned}
& \mathrm{L}_{\mathrm{c}}=\frac{\mathrm{l}_{\mathrm{c}}}{\mathrm{l}_{\mathrm{c}}+\mathrm{l}_{\mathrm{T}}} \\
& \mathrm{R}_{\mathrm{R}}=\frac{\mathrm{R}_{\min }}{\mathrm{R}_{\max }} \\
& \mathrm{R}_{\mathrm{D}}=\frac{\mathrm{R}_{\mathrm{avg}}}{\mathrm{R}_{\mathrm{vd}}}
\end{aligned}
$$

where

$\mathrm{L}_{\mathrm{c}}=$ ratio between the length of the curves to the total length of the same section,

$1_{c}=$ length of the curved,

$1_{t}=$ length of the straight sections,

$R_{R}=$ ratio of minimum $\left(R_{\min }\right)$ to maximum radius $\left(R_{\max }\right)$ of the existing or proposed curves, and

$R_{D}=$ ratio of average radius $\left(R_{\text {avg }}\right)$ to minimum radius required for design speed $\left(\mathrm{R}_{\mathrm{vD}}\right)$

In Germany and England, alignment indices have been used to quantify the general character of road alignment. There are three alignment indices: the average 
radius, the ratio of an individual curve radius to the average radius, and the average rate of vertical curvature. The details are as follows:

$$
\begin{aligned}
& \mathrm{AR}=\sum \mathrm{R}_{\mathrm{i}} / \mathrm{n} \\
& \mathrm{CRR}_{\mathrm{i}}=\mathrm{R}_{\mathrm{i}} / \mathrm{AR} \\
& \mathrm{AVC}=\left[\sum \mathrm{L}_{\mathrm{i}} /\left|\mathrm{A}_{\mathrm{i}}\right|\right] / \mathrm{m}
\end{aligned}
$$

where
$\mathrm{AR}=$ average radius $(\mathrm{m})$,
$\mathrm{R}_{\mathrm{i}} \quad=\quad$ radius of ith curve of the road section (m),
$\mathrm{n}=$ number of horizontal curves within section,
$C R R_{i}=$ ratio of radius of ith curve to the average radius for the road section, AVC = average rate of vertical curvature ( $\mathrm{m} / \%$ grade), $\mathrm{L}_{\mathrm{i}} \quad=\quad$ length of the ith vertical curve on the road section $(\mathrm{m})$, $\left|A_{i}\right|=$ absolute value of the algebraic difference in grade for the ith vertical curve on the road section, and
$\mathrm{m}=\quad$ number of vertical curves within section.

\subsubsection{Driver Workload Consistency}

Driver workload theory assumes that there is a relationship between the effort needed to perform a task and the roadway geometric consistency. Driver workload can be used to evaluate individual features and the interacting effects of combinations of geometric features along the road. The designer should design the road to allow drivers to experience a consistent workload and to predict the correct path using little information. If the workload of a driver increases or decreases too quickly, problems may arise. 


\subsection{Driver Workload}

Workload has been defined as a measure of the 'effort' expended by a human operator while performing a task, independent of the performance of the task itself (Senders et al. 1970). Workload is composed of physical and mental components. As a complex task, driving requires attention to be directed towards longitudinal control (velocity and headway), lateral control (lane position and curve negotiation), navigation, monitoring and operating the vehicle, predicting, recognizing, and reacting to hazards, and often, but less importantly, attending to communications with passengers, mobile phones, and the radio (Schlegel 1993). The driver workload also includes the mental workload of the stress involved in information collection, information processing, and decision-making. Driving can be regarded as a typical information processing and decision making task (Rockwell 1972). As statistics show that about $90 \%$ of road collisions are caused by driver error, the creation of a manageable mental workload is a major objective of driver workload consistency measurement.

Driver workload can be divided into two types: direct workload and indirect workload (Hicks et al. 1979). Information related to the driving task, such as navigation and vehicle control, fall under direct workload. Information that is irrelevant to the driving task fall under indirect workload. Human beings have limits on their information processing capacity. A direct workload level higher than the upper limit results in a driving dangerous situation. Messer (1980) found a strong relationship between crashes, roadway-based geometric inconsistency, and driver workload. Then Krammes and Glascock (1992) pointed out the same relationship between road safety, geometric inconsistency and driver workload. Researchers want to know "How much attention is 
required?" and "How well will the operator be able to perform additional tasks (Knowles 1963)?" The research to date recognizes five broad categories of workload measurement techniques: (1) primary task measurement, (2) secondary task measurement, (3) physiological measurements, (4) subjective techniques, and (5) visual occlusion.

Primary Task Measurement: This technique of workload measurement is the most obvious. It measures performance of specific aspects of the primary driving task.. Aspects include the number of steering wheel reversals, the variation of the angle of the steering wheel, lateral variation and so on (McLean and Hoffmann 1975). Although there are several advantages to using primary task measures, such as its non-intrusive nature and the use of multivariate measures, "primary task performance still presents difficulties that unique measures must be developed for each experimental situation examined. The difficulty in generalizing to different tasks must be considered when choosing a method to evaluate mental workload (Hicks 1979)."

Secondary Task Measurement: Secondary tasking is a commonly used workload measurement tool, which requires a subject who is assigned a primary task to use any spare mental capacity to attend to a secondary task (Wickens and Hollands 2000). Secondary task performance while performing the primary task is compared with secondary task performance alone. According to this theory, if a driver can successfully handle a secondary task, his or her primary task is producing little workload. In contrast, if the driver's primary task increases, his or her secondary task performance will degrade. Some secondary tasks that are not similar to the driving task (such as conversation) can, however, be insensitive to workload changes. In a simulated driving experiment conducted by Wierwill, W.W. and Gutmann, J.C. (1978), the primary task scores were 
not significantly degraded by the secondary task when the primary task workload was moderate (Wierwille and Gutmann 1978).

Physiological Measurements: When the primary task increases in difficulty, certain changes occur in a driver's physiology. These changes, which include heart rate, heart rate variability, brain activity and eye activity, can be used as an index of workload. Various physiological measures of mental workload have been introduced to record physiological processes and to measure mental workload. Unfortunately, very few are reliable enough to be employed for solely measuring driving workload because they are intrusive and often discourage subject participation.

Subjective Techniques: This method uses rating scales to collect subjective operator opinion and to derive driving workload (Cooper 1969). Excellent subjective rating techniques include the Cooper-Harper Scale, the NASA Task Load Index (TLX), and the Subjective Workload Assessment Technique (SWAT). All these scales are employed to measure multidimensional mental workload. There are, however, some obvious problems with the subjective approach. A primary problem is that the operator may confuse mental and physical workload, so that the operator may overestimate or underestimate the various outputs when performing a task. Another problem is that subjective opinion ratings may be influenced by experience, emotions or abilities. Subjects need training in the experiment's methods, but the training may affect the scores, which means that adaptivity may produce scale rates too high or too low (Hick 1979).

Visual Occlusion: This method measures how long a driver is prepared to continue driving without being able to see where he or she is driving. A pair of visual occlusion 
helmet spectacles has been designed for this method (Senders 1967). This spectacles block the driver's vision unless he or she presses a switch or pedal: the less frequently the driver presses the switch or pedal, the lower the driver's need for vision information. Since visual tasks such as tracking the lane, selecting the path or preventing conflicts are some of the most important elements contributing to driver workload, and since the visual occlusion method can accurately determine visual demand by a time-sharing technique, visual occlusion was the primary means of workload measurement (Tsimhoni and Green 1999). The visual occlusion method has its limitations. It may intrude on the driver's primary task performance and it may make the driving task more difficult. These limitations can be resolved by eliminating certain primary driving tasks such as speed and/or brake control. The next section discusses the visual occlusion method in detail.

\subsection{Visual Occlusion Method}

\subsubsection{Background}

The visual occlusion method was first documented as a measure of workload by Senders, Kristofferson, Levison, Dietrich and Ward (1967). Later, a dozen studies were conducted using the method (summarized in Table 2). In Senders' research, a Vision Interruption Apparatus (VIA) was designed to determine the visual demand of drivers

(Figure 2). In this experiment, it was found that drivers need additional glimpses when driving on a complex roadway. Through using this equipment, the relationship between the number of interruptions of vision and the complexity of the driving task was identified. A mathematical model was calibrated to represent the moment-to-moment uncertainty of driving, but the model did not establish a direct relationship between road 
curvature and visual demand value.

That VIA was evaluated by Farber and Gallagher (1972). In this experiment, six drivers were invited to drive a vehicle on a slalom course. The speed was automatically controlled at 30 or $45 \mathrm{mph}$. A face shield like that used in the Vision Interruption Apparatus was used to block the driver's normal vision. The driver could have a 0.5 second "look" when he or she pressed a foot switch (pedal). It was found that visual occlusion provides a convenient measure of visual demand and did not affect other measures of performance.

Hicks and Wierwille (1979) started to use a driving simulator with a visual occlusion device to determine the differences among five workload measurement techniques. This study showed that driver subjects need time to become familiar with the visual occlusion device or the normal driver workload will be increased by the extra workload of learning to use that device.

The mechanical vision interruption apparatus was replaced by special spectacles that make use of the characteristics of liquid crystals (Milgram and Horst 1984). The normal state of the spectacles is non-transparent, but when the driver needs to track the roadway and environment and presses a switch to generate an electronic pulse, the pulse causes the glass in the spectacles to become transparent (Figure 3). The introduction of the liquid crystals visual occlusion spectacles significantly improved the visual occlusion technique.

Blaauw (1985) applied the new method to measure driver visual demand and the workload of car driving in normal circumstances and on wet roads at night. The visual occlusion analysis in this research established the importance of using delineation devices 

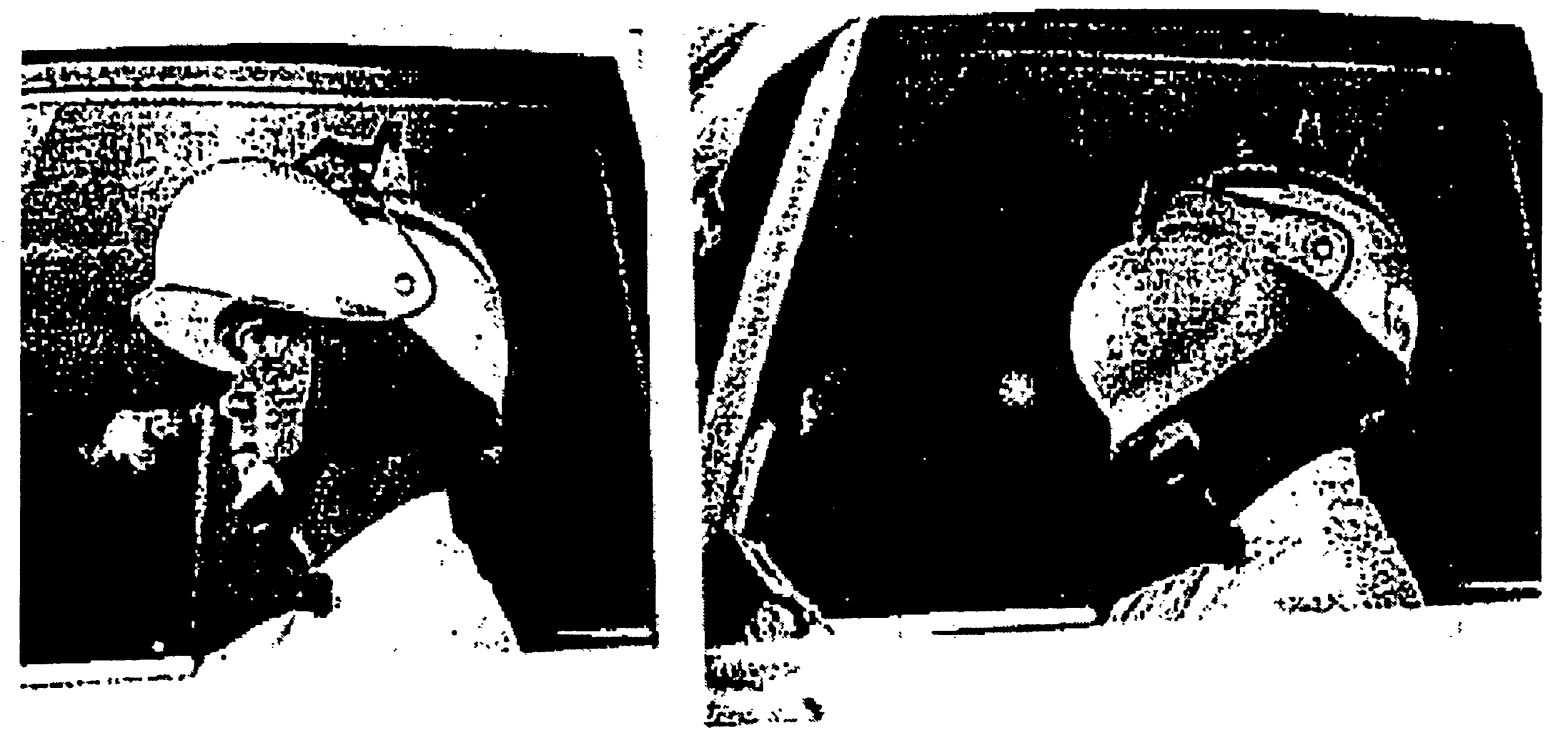

Figure 2 Device for controlling Driver Vision (Senders et al. 1967)

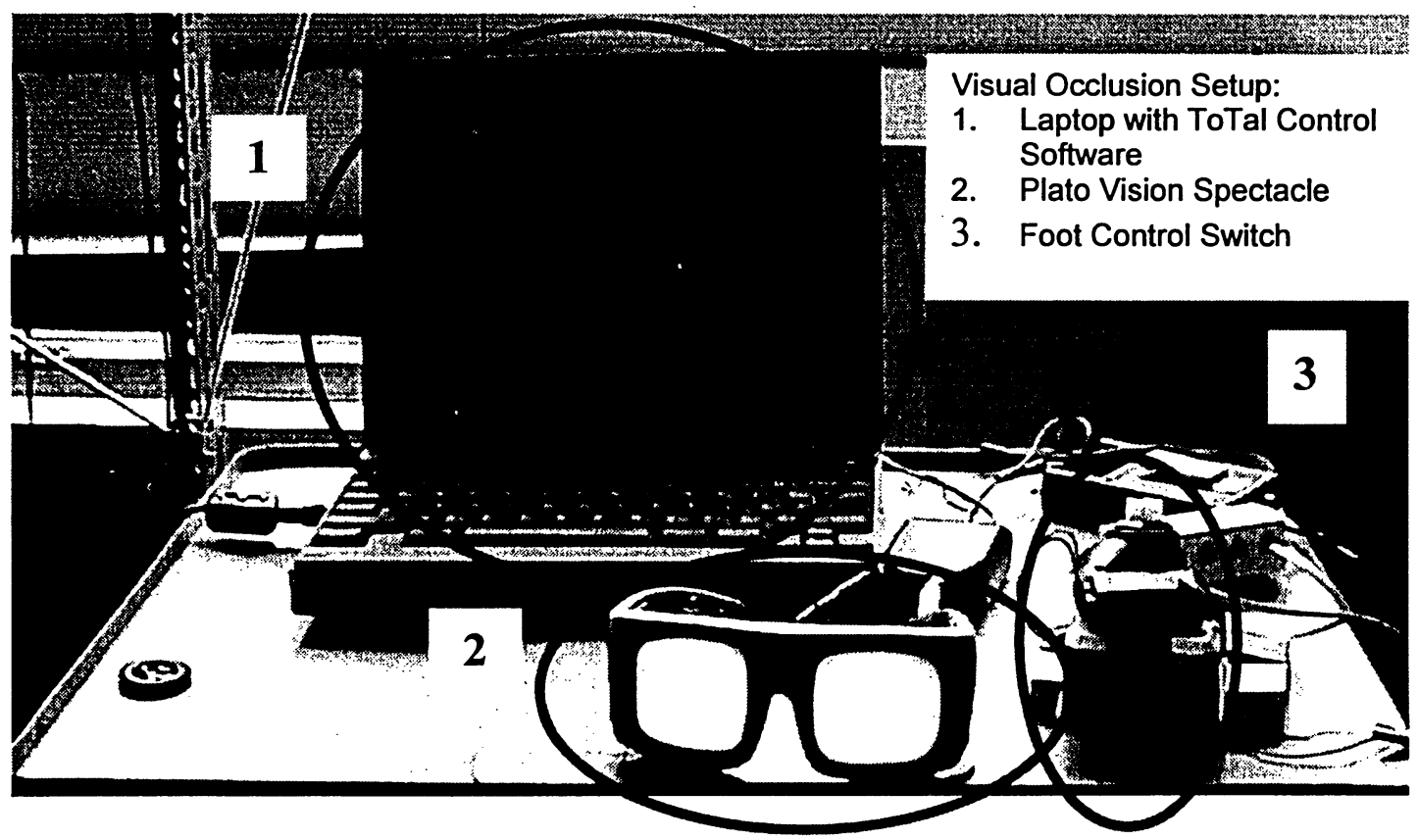

Figure 3 Driving Simulator at Ryerson University (Easa and Ganguly 2004)

on both sides of the traffic lane on straight and curved roads. Godthelp et al. (1984) used the method to develop vehicle control models. Godthelp (1988) used the same visual demand measurement to study vehicle handling characteristics. Shafer et al. (1995) at the Texas Transportation Institute (TTI) conducted visual demand experiments to reveal 
Table 2 Review of Objectives, Subjects and Results of Previous Research

\begin{tabular}{|c|c|}
\hline Experiment & Objectives, Subjects and Results \\
\hline $\begin{array}{l}\text { Senders } \\
\text { et al. } \\
(1967)\end{array}$ & $\begin{array}{l}\text { Objective: To realize the relationship between amount of visual } \\
\text { occlusion and driving speed, and various road parameters. } \\
\text { Subject: } 5 \text { young } \\
\text { Results: The relationship between driving speed and visual demand was } \\
\text { developed. A new method to measure driver workload was described. }\end{array}$ \\
\hline $\begin{array}{l}\text { Farber et al. } \\
\text { (1972) }\end{array}$ & $\begin{array}{l}\text { Objective: To evaluate the visual occlusion method, developed by } \\
\text { Senders. } \\
\text { Subject: } 6 \text { young men } \\
\text { Results: The method can be used for visual task difficulty to which } \\
\text { popular performance measures may be insensitive. }\end{array}$ \\
\hline $\begin{array}{l}\text { Blaauw and } \\
\text { Milgram } \\
\text { (1984) }\end{array}$ & $\begin{array}{l}\text { Objective: To measure the workload of car driving as a supervisory task } \\
\text { Subject: } 6 \text { experienced drivers } \\
\text { Results: Supervisory driver model was developed to evaluate road and } \\
\text { car design. }\end{array}$ \\
\hline $\begin{array}{l}\text { Godthelp } \\
\text { et al. (1984) }\end{array}$ & $\begin{array}{l}\text { Objective: To develop vehicle control models by studying supervisory } \\
\text { behavior in driving. } \\
\text { Subject: } 6 \text { young men } \\
\text { Results: New approaches to modeling vehicle control were described. }\end{array}$ \\
\hline $\begin{array}{l}\text { Shafer et al. } \\
\text { (1995) }\end{array}$ & $\begin{array}{l}\text { Objective: Try to reveal the relationship between collision rates and } \\
\text { highway geometric design consistency. } \\
\text { Subject: Experiment } 1: 7 \text { young, } 18 \text { middle, } 15 \text { old }(55+) \text {; Experiment 2: } \\
5 \text { young, } 5 \text { middle, } 5 \text { old }(55+) \text {. } \\
\text { Results: Calibrated driver workload model, showed that collisions } \\
\text { increase as the required speed reduction from an approach tangent to a } \\
\text { horizontal curve increases. }\end{array}$ \\
\hline $\begin{array}{l}\text { Mourant } \\
\text { and Ge } \\
\text { (1997) }\end{array}$ & $\begin{array}{l}\text { Objective: To establish baseline quantitative measures of attentional } \\
\text { demand respect to vehicle velocity, road curvature, and amount of on- } \\
\text { coming traffic by using driving simulator. } \\
\text { Subject: } 8 \text { young } \\
\text { Results: Several significant relationships between attentional demand } \\
\text { and vehicle velocity, road curvature and traffic demonstrated the } \\
\text { feasibility of using driving simulator to determine visual demand. }\end{array}$ \\
\hline $\begin{array}{l}\text { Fitzpatrick } \\
\text { et at. (1999) }\end{array}$ & $\begin{array}{l}\text { Objective: to measure visual demand of driving considering } 3 \text { age driver } \\
\text { groups and different types of curves } \\
\text { Subject: } 4 \text { men and } 4 \text { women in each of three age groups }(18-24,35-54 \text {, } \\
55+) \\
\text { Results: Visual demand appeared to be highly sensitive to the variation } \\
\text { in road geometry and driver's age. }\end{array}$ \\
\hline $\begin{array}{l}\text { Easa and } \\
\text { Ganguly } \\
(2004)\end{array}$ & $\begin{array}{l}\text { Object: To determine the effect of complex curves (simple, compound, } \\
\text { and reverse curves) on visual demand. } \\
\text { Subject: Young and middle } \\
\text { Result: The effect of compound, and reverse curves on visual demand } \\
\text { was significant. }\end{array}$ \\
\hline
\end{tabular}


the relationship between collision rates and highway geometric design consistency. In this study, the transparency of the visual occlusion goggles (spectacles) was controlled by an onboard microcomputer, which was triggered by a foot switch that produced a $0.5 \mathrm{~s}$ opening status and. The equation for calculating a workload observation, or visual demand, was introduced as follows:

$$
\mathrm{WLi}=\frac{0.5}{\mathrm{t}_{2}-\mathrm{t}_{1}}
$$

where

$\mathrm{WLi}=$ workload over time interval i from $\mathrm{t}_{1}$ to $\mathrm{t}$,

$\mathrm{t}_{2}=$ clock reading at current information request (s),

$\mathrm{t}_{1}=$ clock reading at previous information request $(\mathrm{s})$, and

$0.5=$ time increment during which subject has vision (s).

A driver workload model was developed and given as follows:

$$
\mathrm{WL}=0.193+0.016 * \mathrm{D}
$$

where

$\mathrm{WL}=$ average workload over the first half of curve, and

$\mathrm{D}=$ degree of curvature.

The model of Equation 10 shows that the degree of curvature is a significant factor on workload or visual demand, and that driver workload or visual demand increased linearly as the degree of curvature increased.

Three decades ago, researchers started using driving simulators to measure driver visual demand (Hicks and Wierwille 1979). Early driving simulators were video-based. 
They were later replaced by virtual environment-driving simulators (Mourant and Ge 1997). Without the safety concerns of the real roadway environment, researchers could test quantitative visual demand and establish the relationship between visual demand and vehicle velocity and road curvature. They could also test many additional factors existing on the real roadway, such as opposing traffic.

Using a driving simulator in the University of Michigan Transportation Research Institute (UMTRI), Tsimhoni and Green systemically examined the effects of roadway curvature and the effects of age-related differences in performance (Tsimhoni 1999). They also studied other aspects of a driver's vision behavior, such as "when the driver's vision is intermittently occluded," and "where does the driver look when the scene is visible?" The study confirmed that visual demand was higher on sharper curves and lower on smoother curves, and revealed the linear relationship between the visual demand for a curve and the inverse radius of curvature. By a stepwise regression process, the model considering the effect of roadway curvature is:

$$
\mathrm{VD}=0.388+\frac{33.2}{\mathrm{R}}
$$

where

$\mathrm{R}=$ radius of the curve in meters, and

$\mathrm{VD}=$ visual demand

It was also shown that older subjects had a higher visual demand, but the effect of age was not significant $(p<0.1)$. The regression model considering the effects of roadway curvature and age is:

$$
\mathrm{VD}=0.257+\frac{33.2}{\mathrm{R}}+0.003 * \text { age }
$$


where

VD = visual demand, and

age $\quad=$ the subject's age in years.

The researchers found that drivers preferred to watch the end of the road near the horizon and sometimes looked to the left or right side of the road to note changes on the curvature of the road (Tsimhoni and Green 1999). The study revealed detailed information about vision behavior when driving on a horizontal curve, from observing the beginning of the curve, through entering the curve, to negotiating the curvature.

Tsimhoni and Green (2001) applied the visual occlusion technique to determine invehicle tasks. In a simulator driving environment, 16 subjects were required to read electronic maps displayed in the vehicle and to reach a destination marked on the maps. Driving performance declined as visual demand increased. Like most other studies, however, this study was limited to 2D simple curves.

Easa and Ganguly (2004) explicitly examined the effects of complex curves on the driver's visual demand. Unlike simple curves, complex curves are defined as combinations of simple, compound, and reverse curves in a series. Eighteen hypothetical alignments for two-lane rural highways were developed and nine subjects drove in the simulator. The nominal variables were turning directions, characteristics of preceding elements, and combinations of curve to curve, tangent to curve, or curve to tangent. The authors found that the first arc of compound, reverse curves, deflection angle, and inverse of radius significantly affected visual demand. Especially, visual demand varied with the preceding elements. Visual demand models for curve and tangent were developed. The following is an example of the curve model: 
$\log (\mathrm{VDF})=-0.7885+63.6379$ RINVPE*CC +67.0418 RINVPE*RC +49.1648

$$
\text { RINV }-0.0901 \mathrm{LW}
$$

(Curve)

where

$\mathrm{VDF}=$ visual demand obtained on the whole length of the individual curve,

RINVPE $=$ inverse of radius of curvature of the preceding curve $\left(\mathrm{m}^{-1}\right)$,

RINV $=$ inverse of radius of current curve $\left(\mathrm{m}^{-1}\right)$, and

LW = lane width of current curve (m).

The variable RINVPE was defined as a nominal character variable in the analysis. When the preceding curve forms a compound curve (CC) or a reverse curve (RC) with the current curve, the value of $\mathrm{CC}$ or $\mathrm{RC}$ becomes 1 , respectively; otherwise the value remains 0 . When the preceding element is a tangent, both $\mathrm{CC}$ and $\mathrm{RC}$ become 0 . Another example of the tangent model is:

$\log (\mathrm{VDF})=-1.00-0.0002$ DELPE*LW +46.5084 RINVPE*TDPEL +36.5381 RINVPE*TDPER (Tangent)

where

$\mathrm{VDF}=$ visual demand obtained on the whole length of the individual tangent,

DELPE $=$ deflection angle of the preceding curve (degrees),

TDPEL $=$ the preceding curve is turning to left before the current tangent,

TDPER $=$ the preceding curve is turning to right before the current tangent,

$\mathrm{LW} \quad=$ lane width of the tangent $(\mathrm{m})$.

The variable RINVPE was defined as a nominal character variable. When the preceding element is a curve and turning to the left before the current tangent (TDPEL) or the 
preceding element is a curve and turning to the right before the current tangent (TDPER), the value of TDPEL or TDPER becomes 1 .

The driving simulator has become a popular tool for obtaining broad, accurate and repeatable information based on a safe and stable driving environment, but an important question remains: does the visual demand result from a simulator reflect the visual demand of real roads?

To answer this question, Wooldridge et al. (2000) compared the results from experiments conducted in three environments, a driving simulator, a test track and a public road. The results indicated that although there were differences in the baseline demand level in these three environments, the effects of curve radius on visual demand were almost the same. This suggests that the driving simulator and test track results are suitable for determining changes in visual demand on real roads. The paper by Wooldridge et al is discussed in detail in Section 2.3.3. However, all visual demand studies to date have addressed only 2D alignments involving horizontal curves.

\subsubsection{Development of Visual Occlusion Apparatus}

The first visual occlusion apparatus was designed in the experiment by Senders, et al. (1967). It was a mechanic's helmet with a translucent screen. When the translucent screen moved down over the driver's eyes, no roadway or other details outside of the screen could be seen. The movement of the translucent screen was remotely triggered by a pneumatic cylinder and linkage fixed on the protective helmet. The trigger was controlled by the driver's left foot to permit the driver "to look".

In an experiment conducted by Safford (1971), drivers used self-chosen eye closure instead of the visual occlusion apparatus. Visual demand was measured by recording the 
closing and opening of the driver's eyes. Another visual occlusion method involves integrating this function with the driving simulator. In an experiment conducted by Hicks and Wierwille (1979), the video signal on the simulator screen was blank until subjects requested vision information. This method is very similar to the visual occlusion device.

Making use of the characteristics of liquid crystals, Milgram and Horst (1984) invented a type of visual occlusion spectacles to take the place of the mechanical visual occlusion helmet, because unlike many other physical devices, the spectacles need no time to change the state from non-transparent to transparent. In the normal state, the spectacles are non-transparent so the driver cannot see anything. When the driver needs visual information to drive, he or she must press a switch to control the state of the spectacle lenses.

Later, Milgram and his associates developed software, called ToTaLcontrol, to program the state of the spectacle lenses according to the user's particular needs. Both periodic and non-periodic series of control pulses can be generated by the software to control the spectacle lenses so that they open and shut, as shown in Figure 4. The Internal mode in this software provides the user with a way to automatically control the spectacles with the periodic pulses based on the pre-designed parameter. The External mode provides the user with a way to trigger the spectacles to open for a fixed duration of time. This type of visual occlusion spectacles has become the most popular tool for determining driver's workload in visual demand studies.

\subsubsection{Comparison and Validation of Driving Environments}

It is important to establish whether the experimental environment reflects the visual demand of drivers on the real roadway. There are three popular driving environments in 


\section{Periodic Triggering}

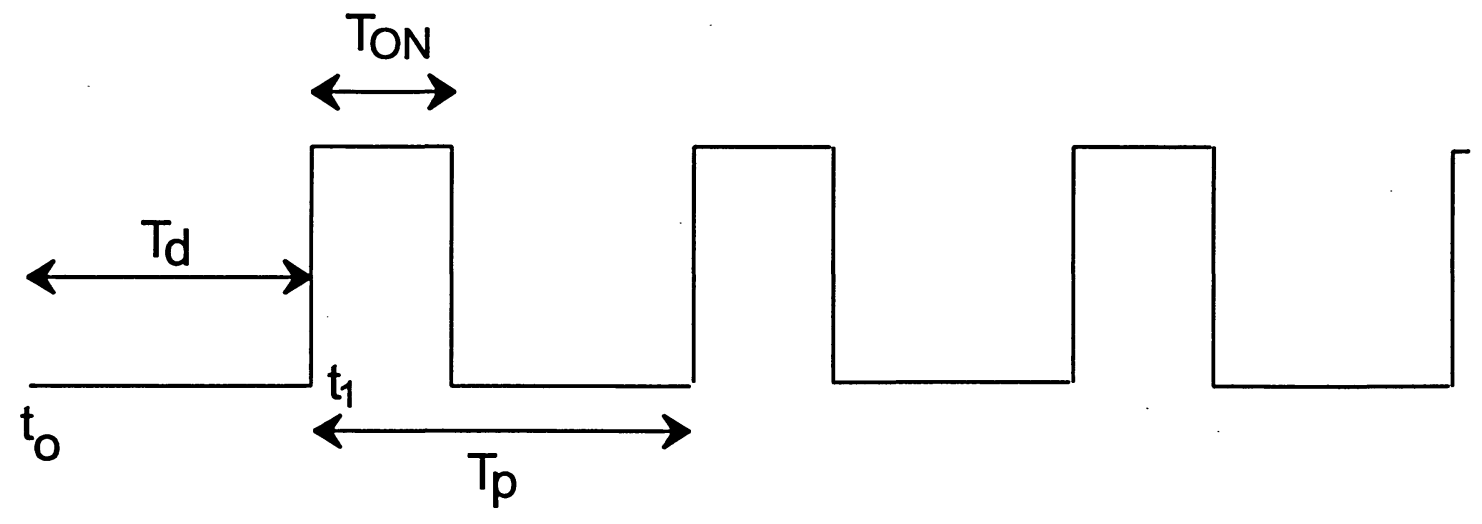

Figure 4 Definitions of Pulse Timing Parameters (Milgram et al. 1984)

visual demand experiments: on-road, test track and driving simulator.

On-road visual demand studies look like the best way to test driver visual demand accurately and have been conducted by several researchers, including Senders et al. (1967), Safford et al. (1971), Farber et al. (1972), Blaauw and Milgram (1984), and Godthelp et al. (1984, 1988). The use of real roads imposes limitations. Researchers do not have complete choice in the curves available for testing and in the different radii and deflection angles encountered. In addition, due to safety and traffic considerations, only easy roads or unopened roads can be used and the number of driver subjects was always very small ( 5 or 6 drivers). Some issues cannot be considered and studied at all. These include opposing traffic, pedestrians and lane changes. Hence, on-road study can be used to evaluate the visual demand data obtained in the simulator study or test track study.

Test track is another choice for visual demand studies. An abandoned airport was selected by Shafer et al. (1995) and Fitzpatrick et al. (1999) to be a test track in their studies. In this driving environment, it is possible to select certain curves, an improvement over testing on real roads. Unfortunately, it appears that test tracks differ 
considerably from the real driving environment on roadway. For example, some elements of the real roadway have to be ignored such as traffic, pedestrians and intersections.

Hicks and Wierwille (1979) were the first to use driving simulator and visual occlusion method to examine driver visual demand. Mourant and Ge (1997) used a virtual environment-driving simulator in their visual demand experiment. Without the safety concerns of traffic, numerous causal factors on visual demand could be considered in driving simulator experiments. These factors include pedestrians, opposing traffic, signals, signs, wild animals, and so on (Mourant et al. 1997, Tsimoni et al. 2001, and Easa and Ganguly 2004).

Wooldridge et al. (2000) compared experimental results from a driving simulator in University of Michigan Transportation Research Institute (UMTRI), from a test track and from a public road (Figure 5). Although there were certain differences in the absolute values obtained from the three environments, there were no difference in the slopes of the three regression lines, and the curve radius showed the same effect on visual demand. The results were considered reliable and repeatable. Following the study by Wooldridge et al., the results from simulators before 2000 have been used to evaluate changes in visual demand of real roadways.

\subsection{Three-Dimensional Highway Alignment Research}

Transportation analysis was conducted in one or two dimensions condition for a long time because the methods were simple and feasible. Although the 3D nature of highway alignment design had been recognized since the 1960's, unfortunately, due to the limitation of techniques and methods, little work focused on 3D highway 


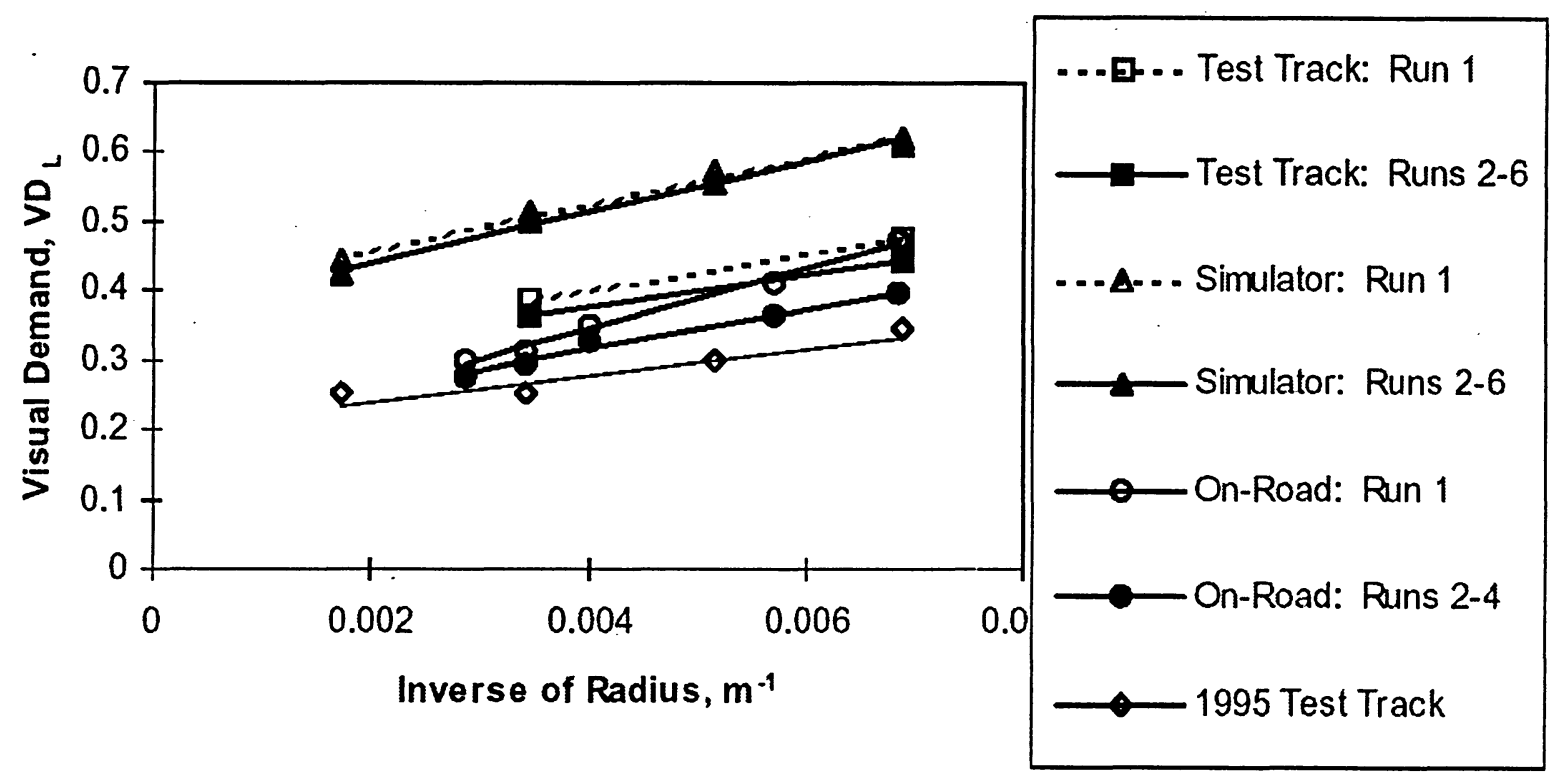

Figure 5 Comparison of Visual Demand Regression Equations

geometric issues, and 3D analysis was not considered feasible until the 1990s.

Easa (1991) developed models to determine the available sight distance for compound vertical curves. Easa (1994) then pointed out the need for considering the 3D sight distance in alignment design. At the same time, Smith and Lamm (1994) addressed the 3D nature of highway alignment in designing highways. Mori et al. (1995) indicated that alignment coordination may cause drivers to have an erroneous perception of horizontal curvature which may be observed flatter or sharper than it actually is. Hassan and Easa (2003) tested this perception hypothesis in a computer animation experiment.

Hassan and Easa (1997) found that 2D analysis of sight distance can underestimate or overestimate the available sight distance. Easa and Hassan (1998) described "red zones", another aspect of 3D coordination between horizontal and vertical alignments, by determining the locations where a horizontal curve and a sag curve should not overlap. 3D visualization is another important area. Easa et al. (2002) described 3D visualization 
models and analytical models for 3D transportation analysis. Janikula and Garrick (2002) developed a realistic and dynamic visual model consisting of short video clips of the highway as a $3 \mathrm{D}$ visualization tool for the purpose of teaching highway design.

Easa and other researchers have pointed out that 3D issues are important and that they include cross slope, sight distance, perception of radius, etc. Ignoring the 3D nature of the highway alignment may adversely affect the safety and efficiency of highways. 3D transportation models are expected to offer a more accurate representation of real highway systems. 3D analyses have been conducted to solve 3D issues, including the driver's perception of 3D combined alignments, sight distance, planning and design, visualization and vehicle stability (Easa et al. 2002).

\subsection{Challenge and Hypothesis}

Since Senders (1967) started to use visual occlusion technique to measure driver visual demand, there have been more than a dozen studies using this method to study all kinds of issues, including the driver's observation strategy, in-vehicle tasks, vehicle control and handling, speed effects, age effects and highway geometric effects. Senders (1967), Godthelp (1984), Shafer (1995), Mourant (1997), Tsimhoni (1999), and Easa and Ganguly (2004) explicitly examined driver visual demand on curves. The significant effect of inverse of radius and the considerable effect of age were noted in their studies. The studies only focused, however, on 2D horizontal alignments.

When studying driver behavior, Tsimhoni and Green (1999) found that drivers prefer to watch the end of the road near the horizon most of the time, and that drivers watch the edges of curves when negotiating curvatures. Because vertical curves may reshape the horizon and the edge lines of curves and the crest slopes may even block the 
driver's vision, it is clear that visual demand on 3D combined horizontal and vertical alignments might be different from that on 2D horizontal alignments. This research study will examine the hypothesis that vertical alignment and driver age have a significant effect on driver visual demand. 


\section{Chapter 3 SIMULATION PILOT STUDY}

\subsection{Method}

Three driver subjects representing young, middle-aged and older drivers respectively were invited to participate in the pilot study. The methodology for the pilot study is described below:

- Design the geometry of the hypothetical 2D and 3D curves for the test

- Develop ten hypothetical scenarios including all testing 2D and 3D curves in the simulator.

- Design the parameter in the software controlling visual occlusion spectacles.

- Run the simulator and collect visual demand data, running time, lateral position of vehicle, and running distance.

- Analyze the visual demand data and compare with past on-road test results for data validation.

- Calibrate models relating to visual demand and compare with models developed by other researchers.

Detailed aspects of the pilot study, including hardware integration, the occlusion spectacles software set up, and the simulator language programming are introduced in Chapter 4.

\subsubsection{Road Design Variables}

Because of the large number of road models required for a full factorial experiment design, a reduced experiment had to be designed. The road design parameters studied in this pilot study included a type of overlapping vertical curve (crest and sag), a horizontal 
curve radius (R), a total change in vertical grades (A), and the ratio of the curve's length to the absolute value of the change in vertical grades $(\mathrm{K}=\mathrm{L} / \mathrm{A})$.

\subsubsection{Test Alignments in Simulation Scenarios}

Ten test alignments were designed in ten simulation scenarios. Each test alignment included four 3D curves or 2D curves. Each test alignments curve had a unique ID as shown in Table 3. For example, s11 means refers to a sag curve with $\mathrm{R}$ equal to $600 \mathrm{~m}$ and $\mathrm{K}$ equal to 80 . In each combination, the curves were linked to each other by a $200 \mathrm{~m}$ tangent. The curve combinations and sequences are shown in Table 4.

\subsubsection{Process}

Each of the three subjects was required to drive the ten alignments (each alignment comprising four curves and three tangents). The visual occlusion spectacles and the foot switch (pedal) were provided to the subjects. Depression of the foot switch allowed the road scene to be viewed for $0.5 \mathrm{~s}$. The visual occlusion spectacles were synchronized with the simulator by recording the occlusion signal into the simulator via its horn cable. In this way, the simulator automatically recorded the state of visual occlusion spectacles into the data collection file.

Before formally running the ten hypothetical scenarios, the subjects were trained for about 30 to 45 minutes in practice scenarios so that they could become familiar with the equipment and gain confidence in driving the simulator and using the visual occlusion spectacles. When the subjects felt confident, the main experiment was started.

\subsection{Data Extraction}

During the simulation trial, the open and close states of the subject's visual 
Table 3 Geometry of Horizontal and Vertical Curves Used in Pilot Study and Simulation Experiment

\begin{tabular}{|c|c|c|c|}
\hline \multirow{2}{*}{$\mathrm{K}(\mathrm{m} \%)$} & \multicolumn{3}{|c|}{ Radius of Horizontal Curves (m) } \\
\cline { 2 - 4 } & (a) Horizontal Overlapping Sag Curves (3D Curves) \\
\hline \multicolumn{4}{|c|}{ (a) } \\
\hline 60 & $\mathrm{~s} 11$ & $\mathrm{~s} 12$ & $\mathrm{~s}$ \\
\hline 40 & $\mathrm{~s} 21$ & $\mathrm{~s} 22$ & $\mathrm{~s} 13$ \\
\hline \multicolumn{4}{|c|}{ (b) Horizontal Overlapping Crest Curves (3D Curves) } \\
\hline-80 & $\mathrm{c} 11$ & $\mathrm{c} 12$ & $\mathrm{~s} 33$ \\
\hline-60 & $\mathrm{c} 21$ & $\mathrm{c} 22$ & $\mathrm{c} 23$ \\
\hline-40 & $\mathrm{c} 31$ & $\mathrm{c32}$ & $\mathrm{c} 33$ \\
\hline \multicolumn{4}{|c|}{ (c) Flat Horizontal Curves (2D Curves) } \\
\hline NA & h1 & h2 & $\mathrm{h} 3$ \\
\hline
\end{tabular}

Other parameters: Operation speed: $80 \mathrm{~km} / \mathrm{hr}$, Deflection angle: 60 degree, Lane width: $3.6 \mathrm{~m}$, Tangent length: $200 \mathrm{~m}$

Table 4 Test Alignments for the Simulation

\begin{tabular}{|c|c|c|c|c|c|c|c|}
\hline Alignments & Curve-1 & Tangent & Curve-2 & Tangent & Curve-3 & Tangent & Curve-4 \\
\hline 1 & Vertical-1 & - & Vertical-2 & - & Vertical-3 & - & Vertical-4 \\
\hline 2 & $\mathrm{~h} 1$ & $200 \mathrm{~m}$ & $\mathrm{~h} 2$ & $200 \mathrm{~m}$ & $\mathrm{~h} 3$ & $200 \mathrm{~m}$ & $\mathrm{~h} 4$ \\
\hline 3 & $\mathrm{c} 13$ & $200 \mathrm{~m}$ & $\mathrm{~s} 12$ & $200 \mathrm{~m}$ & $\mathrm{c} 21$ & $200 \mathrm{~m}$ & $\mathrm{~s} 33$ \\
\hline 4 & $\mathrm{~s} 13$ & $200 \mathrm{~m}$ & $\mathrm{c} 11$ & $200 \mathrm{~m}$ & $\mathrm{~s} 22$ & $200 \mathrm{~m}$ & $\mathrm{c} 33$ \\
\hline 5 & $\mathrm{c} 33$ & $200 \mathrm{~m}$ & $\mathrm{~s} 12$ & $200 \mathrm{~m}$ & $\mathrm{c} 12$ & $200 \mathrm{~m}$ & $\mathrm{~s} 21$ \\
\hline 6 & $\mathrm{c} 12$ & $200 \mathrm{~m}$ & $\mathrm{~s} 13$ & $200 \mathrm{~m}$ & $\mathrm{c} 33$ & $200 \mathrm{~m}$ & $\mathrm{~s} 21$ \\
\hline 7 & $\mathrm{~s} 13$ & $200 \mathrm{~m}$ & $\mathrm{c} 33$ & $200 \mathrm{~m}$ & $\mathrm{~s} 32$ & $200 \mathrm{~m}$ & $\mathrm{c} 21$ \\
\hline 8 & $\mathrm{~s} 11$ & $200 \mathrm{~m}$ & $\mathrm{c} 23$ & $200 \mathrm{~m}$ & $\mathrm{~s} 33$ & $200 \mathrm{~m}$ & $\mathrm{c} 32$ \\
\hline 9 & $\mathrm{~s} 23$ & $200 \mathrm{~m}$ & $\mathrm{c} 22$ & $200 \mathrm{~m}$ & $\mathrm{~s} 21$ & $200 \mathrm{~m}$ & $\mathrm{c} 22$ \\
\hline 10 & $\mathrm{c31}$ & $200 \mathrm{~m}$ & $\mathrm{~s} 31$ & $200 \mathrm{~m}$ & $\mathrm{c} 32$ & $200 \mathrm{~m}$ & $\mathrm{~s} 23$ \\
\hline
\end{tabular}

occlusion spectacles were recorded in the simulator. The "0" means the open state and the " 1 " means the close state. The recorded data were saved in a *.dat file format for each alignment and each subject. Data can be extracted with Microsoft Excel spreadsheet.

After opening this file in Excel spreadsheet, a filter function was used to segregate the "0" data in the visual demand column (i.e. the horn information column). Because the 
data was recorded per 0.1 second and the duration time of the spectacles was 0.5 seconds, the visual demand data shows up in a group of fives ("00000"). The visual demand was then calculated by the equation:

$$
\mathrm{VD}=\frac{0.5}{\mathrm{t}_{\text {request }}-\mathrm{t}_{\text {last_request }}}
$$

where

$$
\begin{aligned}
& \mathrm{VD} \quad=\text { visual demand, } \\
& \mathrm{t}_{\text {request }} \quad=\text { clock reading at current information request (s), } \\
& \mathrm{t}_{\text {last_request }}=\text { clock reading at previous information request (s), and } \\
& 0.5 \quad=\text { time increment during which subject had vision (s). }
\end{aligned}
$$

This calculation provides a measure of the percentage of time a driver is observing the roadway at any point along the roadway.

\subsection{Data Analysis and Validation}

Visual demand values were re-calculated as the average value of all the observations within the curve. The visual demand data were saved in another Excel file for analysis, as shown in Table 5. To validate the visual demand data obtained from this pilot study, the value on $2 \mathrm{D}$ horizontal curves $(\mathrm{h} 1, \mathrm{~h} 2, \mathrm{~h} 3)$ was compared with the result of TTI's field tests (Shafer et al.1995, Fitzpatrick et al. 1999), shown in Table 6.

Comparing these results with those of the 2D horizontal alignment shown in Table 5, showed that the visual demand estimates in this pilot study are quite close to the TTI test results. As the results reflect to different operating speeds $(80 \mathrm{~km} / \mathrm{h}$ in this pilot study and $72.5 \mathrm{~km} / \mathrm{h}$ in both field studies) and different deflection angles, it is reasonable to believe that the results from this pilot study would be acceptable. 
Table 5 Average Visual Demand for Single Curves

\begin{tabular}{|c|c|c|c|c|c|c|}
\hline Curve Type & Curve ID & $\mathrm{K}$ & $\mathrm{R}$ & $1 / \mathrm{K}$ & $1 / \mathrm{R}$ & $\mathrm{VD}$ \\
\hline \multirow{4}{*}{$2 \mathrm{D}$} & $\mathrm{h} 1$ & & 600 & 0 & 0.002 & 0.337 \\
\cline { 2 - 7 } & $\mathrm{h} 2$ & & 400 & 0 & 0.003 & 0.361 \\
\cline { 2 - 7 } & $\mathrm{h} 3$ & & 300 & 0 & 0.003 & 0.390 \\
\hline \multirow{4}{*}{$\begin{array}{c}\text { 3D alignments } \\
\text { involving sag }\end{array}$} & $\mathrm{s} 11$ & 80 & 600 & 0.013 & 0.002 & 0.341 \\
\cline { 2 - 7 } & $\mathrm{s} 12$ & 80 & 400 & 0.013 & 0.003 & 0.370 \\
\cline { 2 - 7 } & $\mathrm{s} 13$ & 80 & 300 & 0.013 & 0.003 & 0.400 \\
\cline { 2 - 7 } & $\mathrm{s} 21$ & 60 & 600 & 0.017 & 0.002 & 0.356 \\
\cline { 2 - 7 } & $\mathrm{s} 22$ & 60 & 400 & 0.017 & 0.003 & 0.373 \\
\cline { 2 - 7 } & $\mathrm{s} 23$ & 60 & 300 & 0.017 & 0.003 & 0.391 \\
\cline { 2 - 7 } & $\mathrm{s} 31$ & 40 & 600 & 0.025 & 0.002 & 0.359 \\
\cline { 2 - 7 } & $\mathrm{s} 32$ & 40 & 400 & 0.025 & 0.003 & 0.362 \\
\cline { 2 - 7 } & $\mathrm{s} 33$ & 40 & 300 & 0.025 & 0.003 & 0.420 \\
\hline \multirow{4}{*}{$\begin{array}{c}\text { 3D alignment curvelving crest } \\
\text { vertical curves }\end{array}$} & $\mathrm{c} 11$ & 80 & 600 & 0.013 & 0.002 & 0.357 \\
\cline { 2 - 7 } & $\mathrm{c} 12$ & 80 & 400 & 0.013 & 0.003 & 0.384 \\
\cline { 2 - 7 } & $\mathrm{c} 13$ & 80 & 300 & 0.013 & 0.003 & 0.425 \\
\cline { 2 - 7 } & $\mathrm{c} 21$ & 60 & 600 & 0.017 & 0.002 & 0.369 \\
\cline { 2 - 7 } & $\mathrm{c} 22$ & 60 & 400 & 0.017 & 0.003 & 0.392 \\
\cline { 2 - 7 } & $\mathrm{c} 23$ & 60 & 300 & 0.017 & 0.003 & 0.421 \\
\cline { 2 - 7 } & $\mathrm{c} 31$ & 40 & 600 & 0.025 & 0.002 & 0.373 \\
\cline { 2 - 7 } & $\mathrm{c} 32$ & 40 & 400 & 0.025 & 0.003 & 0.411 \\
\hline
\end{tabular}

* Operating speed $=80 \mathrm{~km} / \mathrm{hour}$

$*$ Deflection angle $=60$ degrees

Table 6 Average Visual Demand from the TTI Occlusion Field Study (Shafer 1995)

\begin{tabular}{|c|c|c|c|c|}
\hline Degree of & Radius of & \multicolumn{3}{|c|}{ Deflection Angle (deg) } \\
\cline { 3 - 5 } Curvature (deg) & Curvature (m) & 20 & 45 & 90 \\
\hline 3 & 582 & 0.241 & 0.270 & --- \\
\hline 6 & 291 & 0.273 & 0.279 & 0.241 \\
\hline 9 & 194 & 0.322 & 0.340 & 0.285 \\
\hline 12 & 146 & -- & 0.412 & 0.332 \\
\hline
\end{tabular}

* Operating speed $=72.5 \mathrm{~km} /$ hour

Table 7 Average Visual Demand from the TTI Occlusion Field Study (Fitzpatrick et al. 1999)

\begin{tabular}{|c|c|c|c|c|c|c|c|}
\hline Degree of & Radius of & \multicolumn{6}{|c|}{ Deflection Angle (deg) } \\
\cline { 3 - 8 } Curvature (deg) & Curvature (m) & \multicolumn{2}{|c|}{20} & \multicolumn{2}{|c|}{45} & \multicolumn{2}{c|}{90} \\
\cline { 3 - 8 } & & Run1 & Run2 & Run1 & Run2 & Run1 & Run2 \\
\hline 6 & 290 & 0.367 & 0.368 & 0.377 & .0 .370 & 0.354 & 0.353 \\
\hline 9 & 145 & 0.431 & 0.424 & 0.455 & 0.449 & 0.461 & 0.461 \\
\hline
\end{tabular}

* Operating speed $=72.5 \mathrm{~km} /$ hour 


\subsection{Statistical Analysis and Comparison}

Microsoft's Excel Data Analysis Package was used to process the visual demand data obtained from the pilot study and to develop statistical relationships. All the statistical analyses were conducted at the 0.05 significance level $(\alpha)$. The method used assumes that the visual demand data are normally distributed, which has been verified by Shafer (1995).

The P-value is the probability of erroneously rejecting the null hypothesis based on the sample data. To reject this null hypothesis, the P-value must be less than 0.05 . The principle methods used to analyze visual demand on curves was regression and analysis of variance. In most visual demand studies, the basic form of the regression equation for driver visual demand was as follows:

$$
\mathrm{VD}=\mathrm{a}+\mathrm{b} \times 1+\mathrm{c} \times 2+\ldots
$$

where

$\mathrm{VD}=$ average visual demand on the curve,

$\mathrm{X} 1=$ variable 1 , and

$\mathrm{X} 2=$ variable 2 .

Two factors (inverse of radius $-1 / \mathrm{R}$ and $1 / \mathrm{K}$ value) were included in the analysis of variance for driver visual demand on 2D horizontal curves, 3D sag overlapping with horizontal curves, and 3D crest overlapping with horizontal curves. In this pilot study, radius of curvature had three levels $(300 \mathrm{~m}, 400 \mathrm{~m}$, and $600 \mathrm{~m})$ and the $\mathrm{K}$ value also had three levels $(40,60$, and 80$)$.

The first step was the model for the visual demand for 2D horizontal alignment. This model was based on the average visual demand of the three subjects, as follows: 


$$
\mathrm{VD}=0.283+31.8 / \mathrm{R} \quad . \quad\left(\mathrm{r}^{2}=0.99\right)
$$

where

$R=$ radius of Curve, $F=337>F$ Significance, and $P$-value for $1 / R=0.0346$

This equation, although based upon a limited number of observations, represents the expected visual demand on 2D horizontal curves and can be compared with similar models developed in other studies. The analysis-of-variance showed that there were significant differences among the visual demand values for $R=300,400$, and $600 \mathrm{~m}$ with a P-value less than 0.05 .

The intercept parameter of this equation is comparable with the model from the field study by Fitzpatrick (1999), which is given by VD $=0.285+23.1 / \mathrm{R}$ (Run 1 ). The coefficient of the inverse of $1 / R$ variable in this model is comparable with the model developed by Tsimhoni and Green (1999), which is give by $\mathrm{VD}=0.388+33.2 / \mathrm{R}$

In the second step, the average visual demand values for 3D horizontal alignment involving sag vertical curves and 2D horizontal alignments were analyzed, but considering only $1 / \mathrm{R}$ as the variable:

$$
\mathrm{VD}=0.294+31.15 / \mathrm{R} \quad\left(\mathrm{r}^{2}=0.81\right)
$$

where

F $>$ F Significance, and $P$-value for $1 / R<0.0001$

The data range and slope of Equation 18 is similar to that of Equation 17, but its $\mathrm{r}^{2}$ is lower than that for Equation 17. As there could have been other factors affecting visual demand, $1 / \mathrm{K}$ was considered as another variable in the regression analysis. The equation for the average visual demand for $3 \mathrm{D}$ alignments, involving sag vertical curves and $2 \mathrm{D}$ horizontal alignments is as follows: 


$$
\mathrm{VD}=0.292+0.704 / \mathrm{K}+27.75 / \mathrm{R} \quad\left(\mathrm{r}^{2}=0.86\right)
$$

where

P-value for $1 / \mathrm{R}<0.0001$, and $\mathrm{P}$-value for $1 / \mathrm{K}=0.04$

The visual demand estimation in Equation 18 was improved slightly by including the $1 / \mathrm{K}$ variable in Equation 19. This suggests that vertical curvature could be a significant factor in visual demand on $3 \mathrm{D}$ alignments involving sag vertical curves. The 2D horizontal alignment can be considered as a special case of the 3D curve, where $1 / \mathrm{K}$ equals zero. The average visual demand values on 3D alignments involving crest vertical curves and $2 \mathrm{D}$ horizontal alignments were also analyzed, considering only $1 / \mathrm{R}$ as the independent variable for the first step:

$$
\mathrm{VD}=0.302+33.8 / \mathrm{R} \quad\left(\mathrm{r}^{2}=0.68\right)
$$

where

P-value for $1 / \mathrm{R}<0.001$

Since the $r^{2}$ dropped down around $20 \%, 1 / \mathrm{K}$ was also included in the next step which was a regression analysis for $3 \mathrm{D}$ alignments involving crest vertical curves and $2 \mathrm{D}$ horizontal alignments.

$$
\mathrm{VD}=0.280+1.660 / \mathrm{K}+33.8 / \mathrm{R} \quad\left(\mathrm{r}^{2}=0.97\right)
$$

where

P-value for $1 / R<0.0001$, and $P$-value for $1 / \mathrm{K}<0.0001$

All the models developed in the pilot study are summarized in Table 8. The models that consider $1 / \mathrm{K}$ and $1 / \mathrm{R}$ are clearly much better than the models that include only $1 / \mathrm{R}$. The $\mathrm{r}^{2}$ of both Equations 19 and 21 are higher than that of Equations 18 and 20, especially for the 3D horizontal alignment overlapping with crest vertical curves. The 
Table 8 Models Developed in the Pilot Study

\begin{tabular}{|c|l|c|c|}
\hline Feature & Model & $\mathrm{r}^{2}$ & P-value \\
\hline 2D horizontal alignments & $\mathrm{VD}=0.283+31.8 / \mathrm{R}$ & 0.99 & $=0.0346(1 / \mathrm{R})$ \\
\hline 3D alignments involving & $\mathrm{VD}=0.294+31.15 / \mathrm{R}$ & 0.81 & $<0.0001(1 / \mathrm{R})$ \\
\cline { 2 - 4 } sag vertical curves & $\mathrm{VD}=0.292+0.704 / \mathrm{K}+27.75 / \mathrm{R}$ & 0.86 & $\begin{array}{c}=0.04(1 / \mathrm{K}) \\
<0.0001(1 / \mathrm{R})\end{array}$ \\
\hline $\begin{array}{c}\text { 3D alignments involving } \\
\text { crest vertical curves }\end{array}$ & $\mathrm{VD}=0.302+33.8 / \mathrm{R}$ & 0.68 & $<0.001(1 / \mathrm{R})$ \\
\cline { 2 - 5 } & $\mathrm{VD}=0.280+1.660 / \mathrm{K}+33.8 / \mathrm{R}$ & 0.97 & $\begin{array}{c}<0.0001(1 / \mathrm{K}) \\
<0.0001(1 / \mathrm{R})\end{array}$ \\
\hline
\end{tabular}

P-values for $1 / \mathrm{K}$ in Equations 19 and 21 are less than 0.04 and 0.0001 respectively. Thus the $\mathrm{K}$ or $1 / \mathrm{K}$ parameter has a significant effect on visual demand of $3 \mathrm{D}$ alignments involving crest vertical curves and a considerable effect on 3D alignments involving sag vertical curves.

\subsection{Summary}

The results of this pilot study show that the visual occlusion measurements integrated with the environment of STISIM driving simulator are a reasonable method for obtaining visual demand data accurately. The visual demand results were supported by the field occlusion study. The model developed for the 2D alignments is comparable with models from past visual demand studies conducted in similar 2D conditions. The results also show that $\mathrm{K}$ or $1 / \mathrm{K}$ has a significant contribution in determining visual demand for 3D alignments involving crest or sag vertical curves. In conclusion, the results of this pilot study proved to be encouraging. 


\section{Chapter 4 SIMULATION EXPERIMENT}

\subsection{Apparatus}

\subsubsection{Driving Simulator}

The driving simulator system using in this research is the product of over three decades of research by Systems Technology, Inc. (STI) into creating laboratory tasks relevant to the psychomotor and cognitive demands of real world driving. The STISIM Model 300 in the Human Factors Lab in the Department of Civil Engineering, Ryerson University is an advanced version of simulators developed by STI. Operating under the Windows operating system, it can develop and simulate any hypothetical or real highway geometric alignments, including horizontal and vertical curves, and 3D horizontal curves overlapping with vertical curves. The highway design parameters include turning direction, radius of horizontal curve, vertical curvature parameter, tangent, shoulder, and lane width, and so on.

Extensive research on vehicle dynamics, driver control behavior, driver decision making, divided attention behavior and response to traffic control devices has been applied to the creation of control tasks and cognitive scenarios typical of real world driving. Driving tasks and scenarios are easily specified with simple commands listed in an event file. A simple scenario definition language (SDL) has been developed to minimize the effort required to specify experimental alignment designs. The SDL The also simplifies the specification of scenario attributes that relate to driver psychomotor, divided attention and cognitive behavior, and permit the definition of road curvature. The simulator uses software and commercially available PC compatible hardware components 


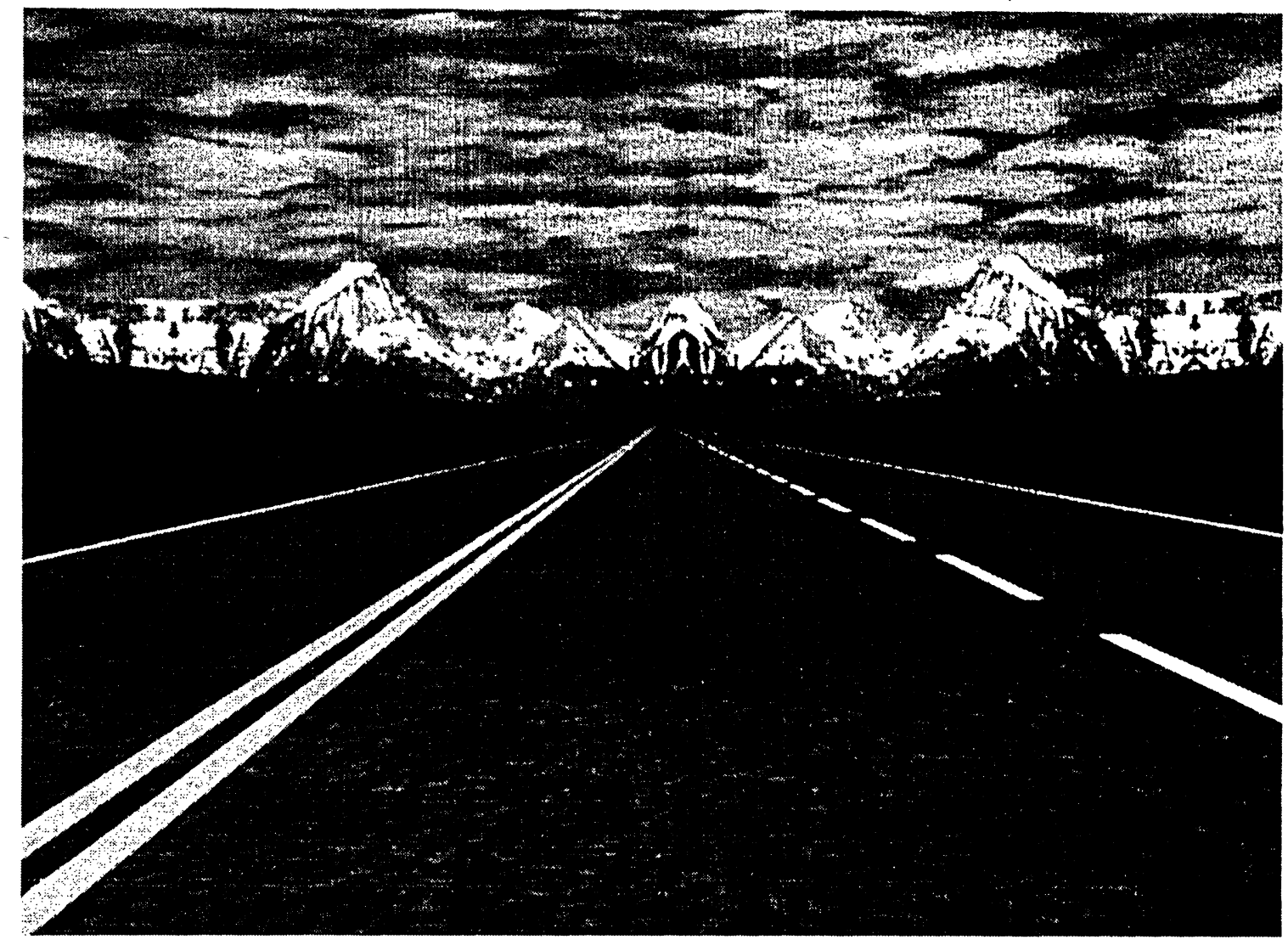

Figure 6 Roadway Scene of STISIM Simulator

to produce visual scenes and auditory displays relevant to driving. An open module option allows the user to create his/her own custom events and to integrate them directly with the STISIM program through the SDL.

\subsubsection{Data Definition of 3D Highway Alignments}

In the STISIM driving simulator, a simulation scenario is designed using SDL, which provides a simple tool for scenario programming. Horizontal curvature, vertical curvature, road cross-section, traffic, and pedestrians are called "events" in SDL. Each event is defined in a simple syntax:

Distance, event, parameter 1 , parameter $2, \ldots$, parameter $\mathrm{n}$

All events occur as a function of distance from the start of the simulation and 
different number of parameters are used to distinguish different events. It is possible to activate any number of events at the same time in order to create complex events. This property was recently employed in the $3 \mathrm{D}$ driver visual demand measurement for designing the 3D horizontal alignment overlapping with vertical alignment. The key method of designing a 3D alignment is to define overlapping horizontal and vertical curves that have the same location and length.

In SDL, "VC" is used to define a vertical curve event and the elevation of the roadway centerline as a function of roadway distance. There are two types of vertical alignments specified by SDL, a constant grade and a vertical curve. The vertical curve event can generate the geometry of both the constant grade and the vertical curve (Figure 7). Grade is in the percent grade $(\mathrm{m} / \mathrm{m}$ or $\mathrm{ft} / \mathrm{ft})$, and a negative value means a downgrade road and a positive value means an upgrade road. To specify a vertical curve, two parameters need to be used: the length of the vertical curve, and the rate of change of grade in percent grade per meter or per foot $(1 / \mathrm{K}$ or DelVC). This parameter causes the grade to change linearly along the roadway. A constant grade will be obtained at the end of a vertical curve and will continue until the next vertical curve event is reached.

In the simulator, the grade always starts from zero at the beginning of the scenario alignment. Therefore, for the first step, an initial vertical curve event must be designed to generate a constant grade for the first hypothetical vertical curve, and to represent its start grade: In addition, the position of the start point of each hypothetical vertical curve must be decided by the user. Then the length of the vertical curve is computed based on the length of the horizontal curve on the $3 \mathrm{D}$ alignment according to its design radius and deflection angle. Finally, the rate of change of grade with the distance along the vertical 


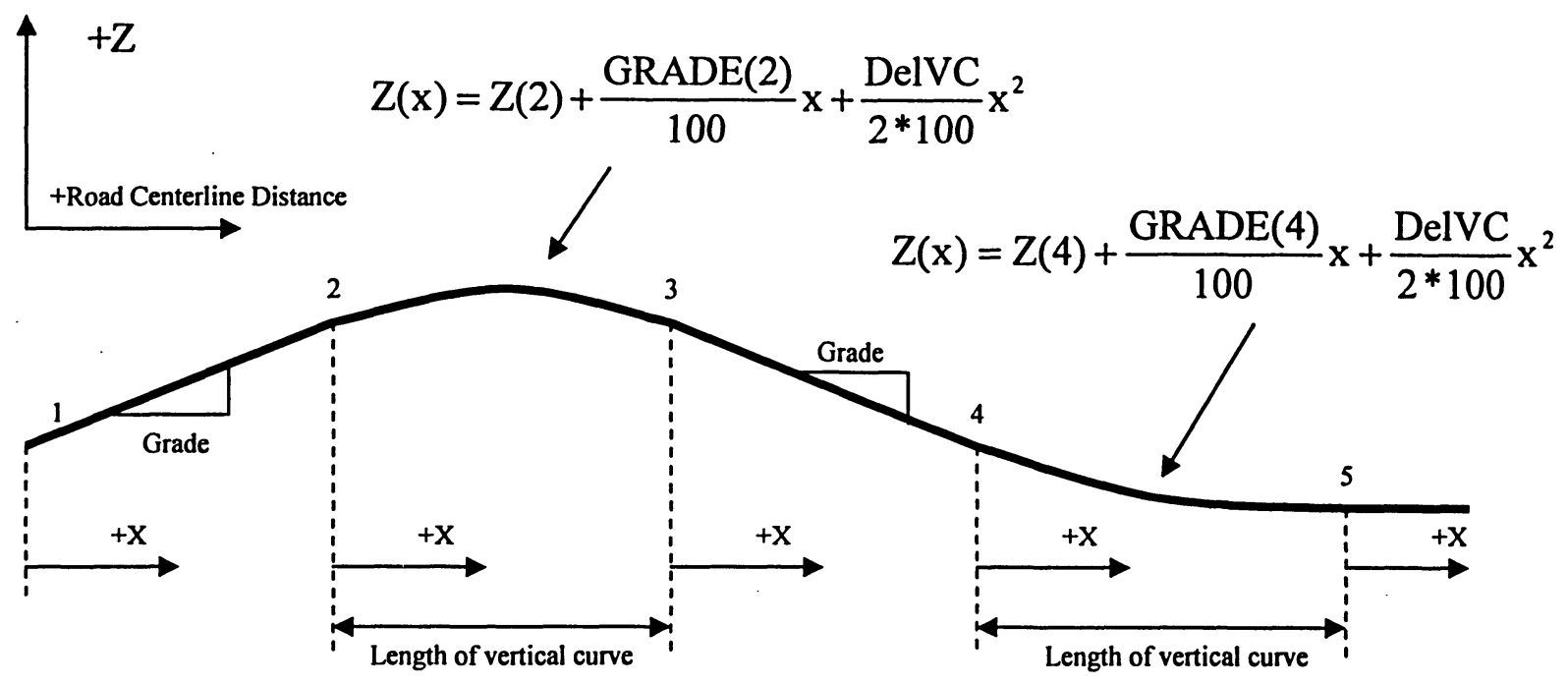

Figure 7 The Geometry of Constant Grade and Vertical Curve

curve $(1 / \mathrm{K}$ or DelVC) needs to be input to the simulator. For example, " $1500, \mathrm{VC}, 600$, .01 " means that a vertical curve will start at the roadway distance of $1500 \mathrm{~m}$; this vertical curve will be $600 \mathrm{~m}$ long, and its $\mathrm{K}$ value equals $1 / 0.01=100$.

In SDL, "C" is used to define a horizontal curve with a constant radius in the roadway display. A positive value of curvature will display the horizontal curve turning to the right and a negative value will display the horizontal curve turning to the left. For designing a successful horizontal curve, the users must follow two important rules:

- The user must ensure that the previous curvature has been completely finished before beginning to design a new curve. Otherwise, depending on the way the simulator generates the roadway display, the simulator will act unpredictably or fail to run.

- The user must not use curves that change the direction of the road by more than 90 degrees. Trying to display turns that are greater than 90 degrees will cause the road to turn back on itself and the results will be unpredictable. 
Three important parameters are needed to define a horizontal curve: longitudinal distance, longitudinal length, and constant roadway curvature. Longitudinal distance is used to define the start of the curve. The roadway will be straight until the beginning of the curve and then a constant radius will be followed. The longitudinal length is the length of the curved section of roadway. In this study, the length of the horizontal curve is identical to that of the vertical curve because both curves completely overlapped.

To design a 3D horizontal alignment overlapping with vertical curve, the user needs to design a horizontal curve and a vertical curve, which have the same curve length and distances of start points and end points (Figure 8). For a horizontal curve, the beginning and end of the curve are defined by the point of curvature (PC) and the point of tangency (PT). For a vertical curve, the corresponding points are defined by the point of vertical curvature (PVC) and the point of vertical tangency (PVT). The details of the calculation method are presented in Section 4.4.1.

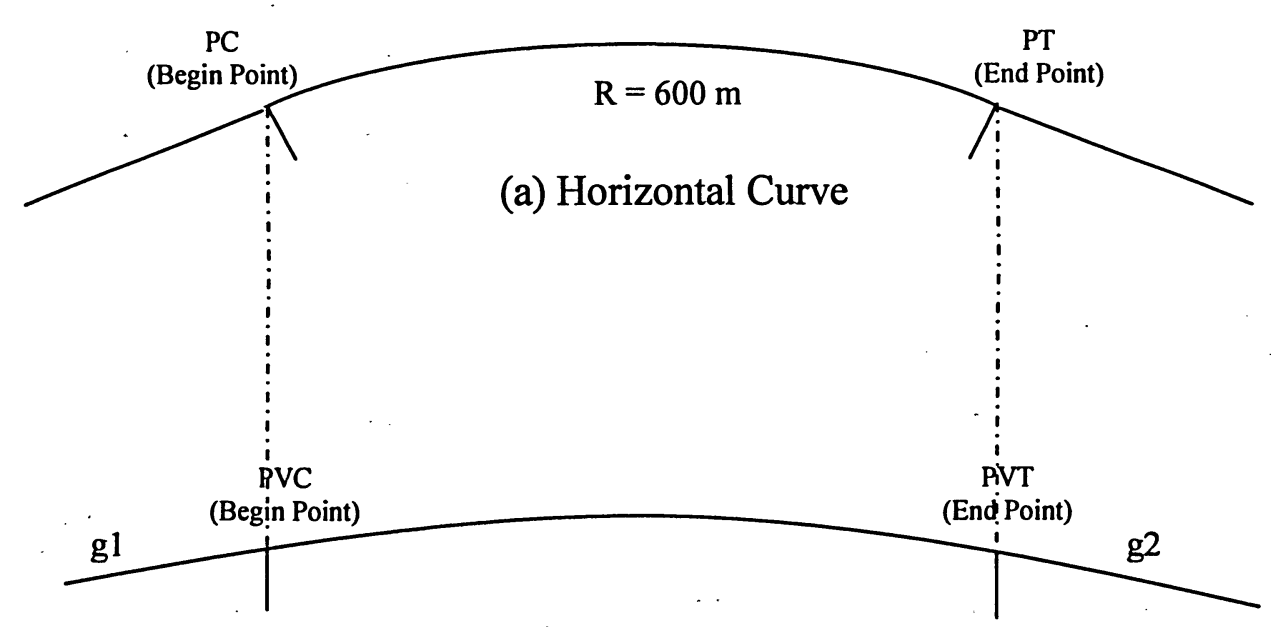

(b) Vertical Curve

Figure 8 An Example of 3D Combined Alignment 
"V" is used to define a vehicle in the subject's lane. The speed of the subject vehicle can be specified as any given constant speed, or controlled by the subject using the throttle and the brake pedal. In this study, the speed of the subject vehicle was set at $80 \mathrm{~km} /$ hour for measuring the visual demand at one specified speed.

\subsubsection{STISIM Data Input Files}

STISIM needs three input files to describe the configuration of the simulator and the various elements of the events in a simulation run: GAINS, STISIM.COL and EVENTS FILE. The GAINS file is the primary configuration file in STISIM, which allows numerous program options and configurations to be specified. A highly important step in this experiment is to adjust the units of the original configuration file from English to Metric.

At the beginning of a simulation run, the GAINS file is found first and read into the memory. If the GAINS file cannot be found in STISIM or if a parameter is not matched with the event file (for example, there are Metric units in the event file and English units in the GAINS file), it will issue an error and stop the run. Trying to use a Metric event file with an English configuration file will produce the wrong dimensions of lane, shoulder, and vehicle.

STISIM.COL is the file that specifies the color of each element of the driving display, and gives the user complete control over the display appearance. In the STISIM simulator, the graphics card used for the simulation is a Texas Instruments Graphic Architecture (TIGA) board. The EVENTS FILE, called the project file, contains all the information that tells STISIM how and when to act. SDL is used to create the custom files. The user can create and name many event files. Wordpad, Notepad or any other 
ASCII text editor can be used to create an event file. This is clearly the main file for developing the hypothetical alignment scenario.

Other program files for the STISIM program include *.OVL files, *.BAT files, *.VOC files, *.EXE files, *.HLP files, *.FNT files, and *.PDE files. The *.OVL file simulates and displays such elements as lateral objects, text, and signs. In the STISIM program. *.BAT files are general DOS batch files and help to execute the program. *.VOC files produce sound effects during the simulation run. *.EXE files help run the program, and so on. These files are designed for the various common functions required for any simulation.

\subsubsection{STISIM Data Output Files}

When a run is finished, the program creates a data file containing data acquired during the simulation run. Eight general sections may appear in the file, including General information, BSAV/ESAV Block data, RMSB/RMSE Data blocks, Divided attention data, DI/DO Digital I/O data, Time till collision, subject mistakes and PI Data blocks. Each STISIM Data file will vary slightly depending on the individual scenario that was run. The general information in this file includes the subject's identification number, the time of day when the simulation run started, the date when the simulation was run, and the name of the events or call project file that was used.

BSAV/ESAV Block data contains all of the data collected when using the BSAV/ESAV event options. The data are saved in the file in the order that the events were called. Users can assign each block of data a unique name by a user defined block name. Some additional information will automatically be included at the bottom of the block before it begins to save a new block of data. For example, the number of off road 
accidents occurring when the subject steers the vehicle too far of the road is included in those data.

RMSB/RMSE Data blocks contain the data collected during the RMS segments of the simulation. The data include number of off road accidents, number of collisions, correct responses, incorrect responses, average time of response, average lane position, average steering wheel rating, average road heading error, average curvature error, average curvature error, average throttle input, average throttle input, average longitudinal acceleration and average longitudinal speed. The time till collision data refers to how close the vehicle of the subject gets to other vehicles in the subject path. STISIM saves the data when the time till collision flag is set. STISIM only gathers the data for vehicles specified with the $\mathrm{V}$ event.

The subject mistakes block contains a listing of the mistakes the subject has produced when he or she driving. There are two parts in this section. The first one contains a cumulative total of all of the subject's mistakes and responses. The second section is comprised of a list of numbers of each individual mistakes, which include off road accidents, collisions, pedestrians hit, exceeding the speed limit, speeding tickets, traffic light tickets, stops at traffic lights, correct DA responses and incorrect DA responses and finally the total run length.

\subsubsection{Visual Occlusion Device}

A pair of visual occlusion spectacles and the spectacles control box developed by Translucent Technologies Inc. in Toronto, Ontario were used in this experiment. The control box with a $9 \mathrm{~V}$ battery has two switches to control the opening of the right and left lens. The control box was connected by a laptop computer on which the ToTal Control 
software package was installed to control the visual occlusion spectacles.

The ToTalcontrol file has an extension *.gl. The *.gl file can be programmed to control the opening time of the spectacles and the total period of each pulse. The signal input to the ToTal Control software can be given in two forms, Internal Sync and External Sync. When the Internal Sync mode is set with looping, the signal keeps generating in an internal loop and the spectacles keep opening as per the given time. This mode was not suitable for this experiment.

The External Sync mode was used in this experiment because it offers the user a manual way to trigger the spectacles to open for a fixed duration time. In the normal state, both lenses of the spectacles remain opaque to prevent the subject from watching through the lens. When the laptop computer received a trigger pulse generated by the subject, it generates a $0.5 \mathrm{~s}$ duration signal to open both lenses of the spectacles for 0.5 seconds. This process was saved in a ${ }^{*}$.gl file. In the input table of this file, the glimpse time was set at 500 milliseconds $(0.5 \mathrm{~s})$ and the pulse width was 600 milliseconds. The gap between two corresponding vision requests was at least 100 milliseconds. Hence in any situation, the visual demand value is still less than 1 .

To use the External Sync mode, an external pulse generator was needed to register the signal by the software. It was connected to the laptop computer through the input cable and acted as an input source to the ToTal Control software. Therefore, after an external pulse from the pulse generator is triggered, it stimulated the *.gl file designed by the ToTal Control software to generate a specific pulse with the 500 milliseconds $(0.5 \mathrm{~s})$ duration and the 600 milliseconds width, so that both lenses were opened simultaneously for a period of 500 milliseconds and both were closed within another 100 milliseconds. 


\subsubsection{Linking of Devices}

In total, seven devices were used in this experiment: a driving simulator, visual occlusion spectacles, the spectacles' control box and control computer, a pulse generator, a switch pedal and a splitter (Easa and Ganguly 2004). The switch pedal was fixed upon the "shot" trigger button on the pulse generator. The pulse generator was linked with the spectacles and the computer. The cable from the $\mathrm{I} / \mathrm{O}$ interface of the spectacles laptop computer was plugged into the splitter. One output cable from the splitter was connected into the control box for the spectacles, and the other was linked with the signal cable of the horn (Figure 9).

The entire circuit was developed in such a way that, whenever the pedal was pressed by the right foot of the subject, the "one shot" switch on the pulse generator was triggered. A short electronic pulse was then generated by the pulse generator. This short pulse stimulated the ToTal Control software in the laptop control to output a stable and clean pulse with 500 milliseconds duration to open the visual occlusion spectacles and then close them automatically. At the same time, the controlling pulse output from ToTal Control software was recorded by the simulator via the cable of the horn of the simulator. On receiving the pulse generated by the ToTal Control software, the visual occlusion spectacles provided a glimpse to the subject. The glimpse time was fixed at 500 milliseconds $(0.5 \mathrm{~s})$ and the whole width of this pulse was 600 milliseconds.

\subsection{Methodology}

A sample of 15 licensed drivers served as subjects. They were recruited through advertisements and contacts in the local community. Most of the younger drivers were recruited from the campus of Ryerson University. Most of the middle aged and older 


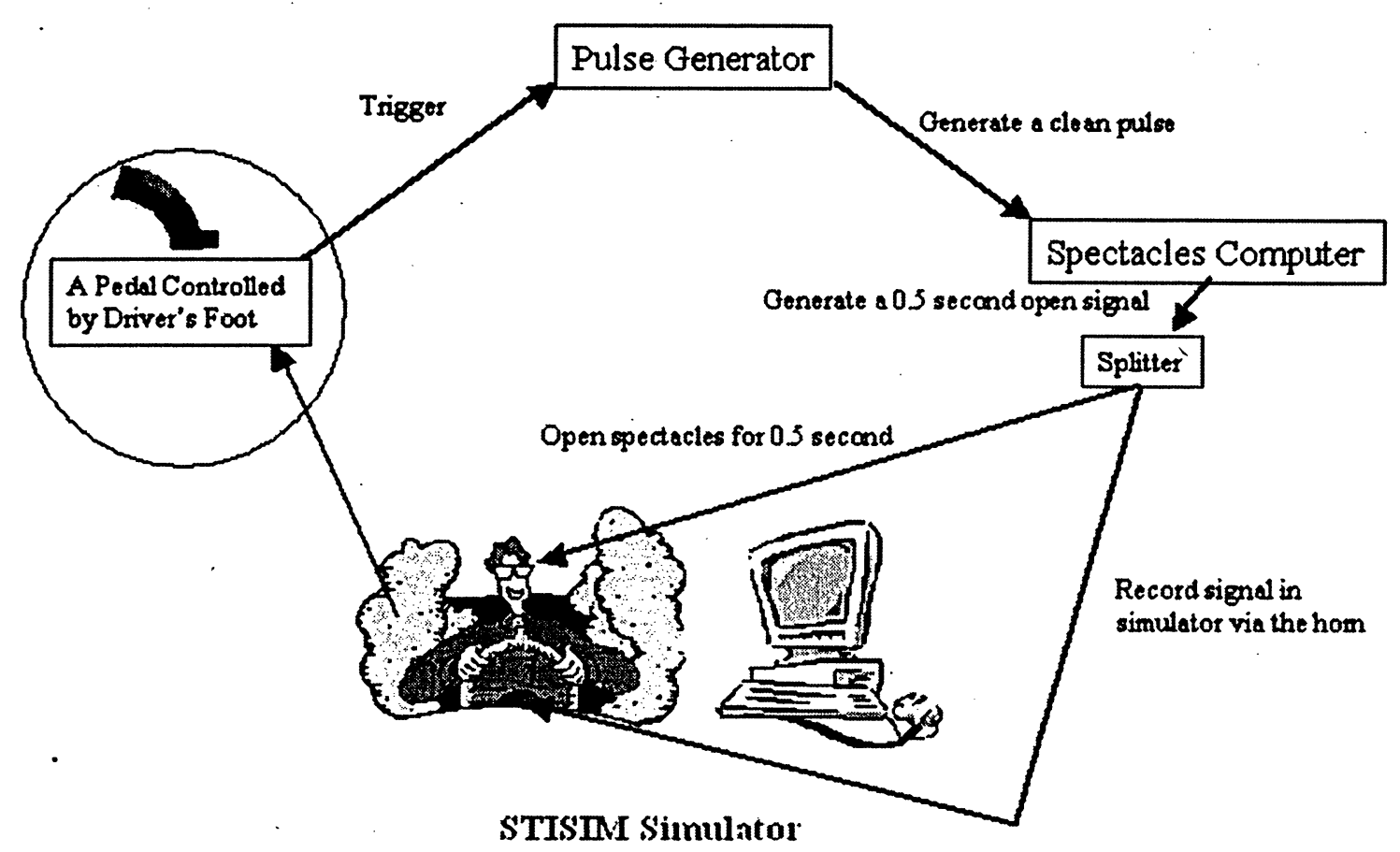

Figure 9 Linkage of Devices for Visual Demand Experiment

drivers came from the community. The drivers' ages ranged from 20 to 70 . The subjects included 6 young drivers ( $<30$ years old), 4 middle-aged drivers (30-50), and 5 older drivers ( $>50$ years old).

As noted in Chapter 2, there is a significant linkage between collisions, roadwaybased geometric inconsistency and driver workload. There is a clear correlation between workload and either driving performance or crashes. Since driving is primarily a visual task and one cannot drive more than a few seconds without visual cues, it is likely that vision occlusion measures should be highly correlated with workload.

The literature review of past visual demand studies showed that visual demand (VD) is related to the radius of the horizontal curve, but no studies (from Senders (1967), Godthelp (1984), Shafer (1995), and Mourant (1997), to Tsimhoni (1999), and Easa and Ganguly (2004)). considered how the vertical alignment parameter would affect visual 
demand. To test the effect of vertical alignment parameters and other related parameters, a series of scenarios was developed using the following approach:

- Ten hypothetical alignment scenarios were developed for the daytime environment in the simulator. The scenarios included 2D alignments and 3D alignments. These alignments represented two-lane rural highways that satisfy the AASHTO and TAC guidelines.

- The 2D alignment was constituted of four horizontal curves with preceding and following tangents. These alignments reflect the visual demand in the 2D environment.

- Each 3D alignment was constituted of four different 3D curves combining the horizontal curves with the vertical curves, and with the preceding and following tangents. These alignments reflect the visual demand on 3D alignments.

- The vertical curve including either a crest curve or a sag curve was completely overlapped with the horizontal curve (i.e the start point of vertical curve was the same as that of horizontal curve and the end point of vertical curve was the same as that of horizontal curve).

- The visual demand data on 2D and 3D curves were used to develop models for 2D alignment and 3D alignment.

\subsection{Experimental Design}

The experimental design followed the methodology outlined in Section 4.2. The steps followed were similar to those in the experiments carried out by TTI and FHWA. A flow chart showing the experiment design is shown in Figure 10.

The following points regarding the experimental design should be noted: 
- All the alignments were designed for two-lane rural highways and there were, no intersections, pedestrians, other traffic, or other elements that add complexity to the visual demand.

- The vehicle operation speed was designed to keep a constant value (80 km/hour). During the experiment, the subject needed to use his or her right foot to press and release the pedal for changing the visual occlusion spectacles. The constant operating speed made it easier for the subject to control the vehicle and to manipulate the visual occlusion device.

- The parameters of the $2 \mathrm{D}$ and $3 \mathrm{D}$ alignments in the experiment satisfy TAC and AASHTO standards for the speed of $80 \mathrm{~km} / \mathrm{h}$. For example, the values of $\mathrm{K}$ for all curves were kept greater than 36; the radii of curves were kept greater than $230 \mathrm{~m}$; the grades of curves were kept lower than $8 \%$.

- In addition to the ten alignments tested in the experiment, several similar alignments were designed for subjects to drive when becoming familiar with running the simulator and manipulating the visual occlusion device.

- Each subject started by running the driving simulator without the visual occlusion device. After driving 20 to 30 minutes, depending on each individual's driving experience and adaptability, the subject could run the simulator well and the visual occlusion spectacles and its switch pedal were introduced. As the switch is controlled by the subject's right foot, the subject could drive using both hands and could concentrate entirely on guiding the vehicle. Details of the equipment's integration and circuit development are discussed in Section 4.1.6.

- In general, subjects needed 20 to 35 minutes of practice. When the subject was able 


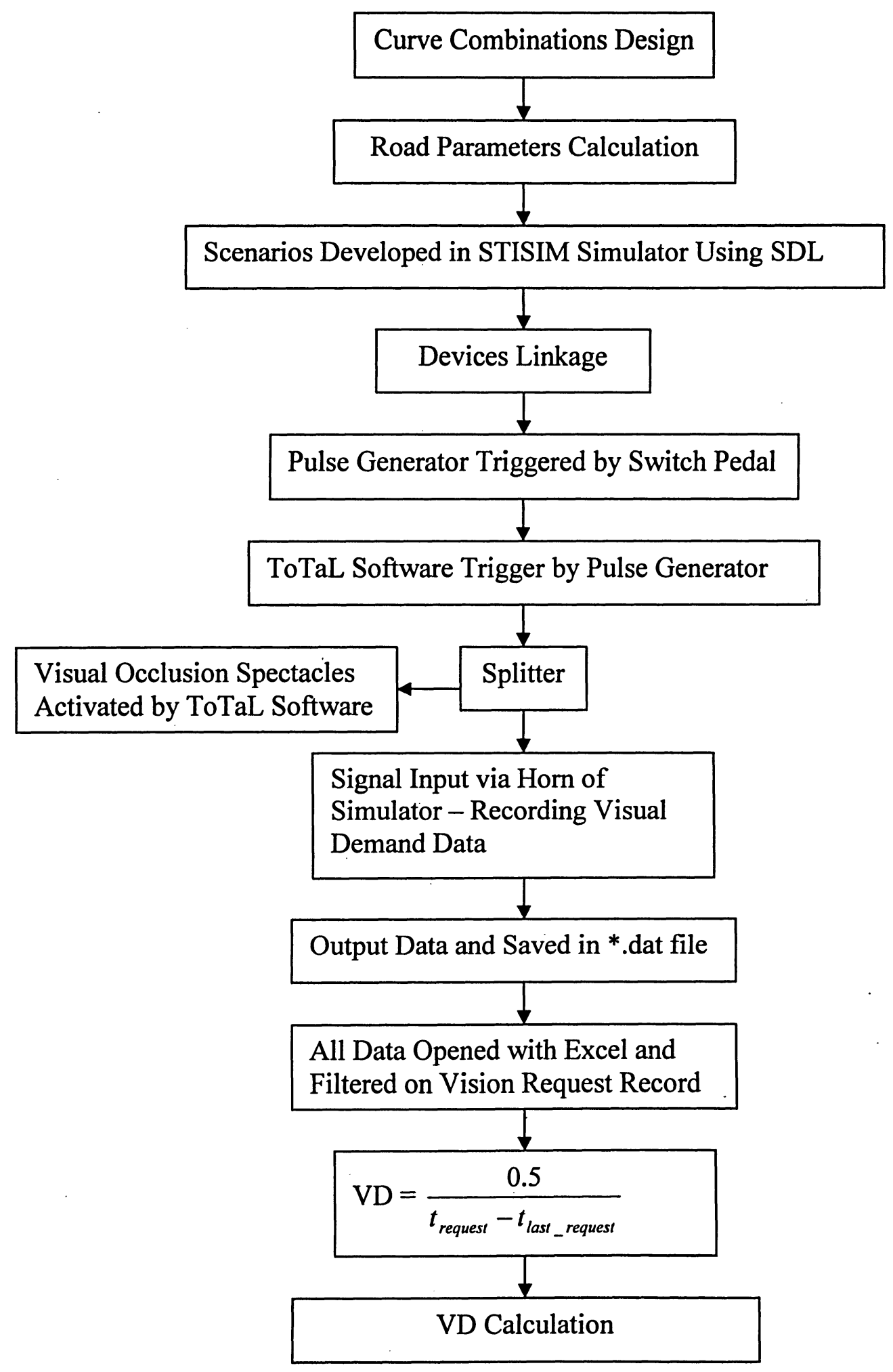

Figure 10 Flow Chart Showing Various Steps of the Experimentation and Visual Demand Analysis 
to control both the driving and the visual occlusion spectacles comfortably, the formal test began.

- If the subject was ran off-road or ran into the opposite traffic lane in the formal test, the scenario must was stopped and re-tested later.

- After completing the experiment, the visual demand on each curve was evaluated using the principles detailed in the methodology section. The visual demand models of the effects of the horizontal alignment and the vertical alignment were then developed and analyzed.

\subsubsection{Road Variables Calculation}

The ten scenarios used in the experiment were the same as those in the pilot study, (the curve combinations, sequences and parameters were described in Chapter 3). There were several steps in calculating the parameters for the geometry data of the 3D horizontal curve overlapping with vertical curve:

Step 1: calculate the length of individual 3D curve (the horizontal curve length $=$ the vertical curve length):

$$
\begin{aligned}
& \text { Length }=\frac{3.1416}{180} * \mathrm{R} * \text { deflection angle } \\
& =\frac{3.1416}{180} * \mathrm{R} * 60(\mathrm{def}=60 \text { in this study })
\end{aligned}
$$

Step 2: calculate A value for each 3D curve: $\quad A=\frac{L}{K}$

Step 3: calculate Start grade and End grade of each 3D curve, based on A value.

Step 4: calculate Start distance and End distance of each 3D curve.

Step 5: check whether every grade is $>-8 \%$ and $<8 \%$ ( the TAC and the AASHTO 
standard for $80 \mathrm{~km} / \mathrm{h}$ ).

Step 6: Input parameters into the simulator.

Steps 1 to 4 can be performed using an Excel table, as shown in Table 8

In this table, the VLOOKUP function was used to search for the curve ID, to find the $R$ value and $K$ value according to the curve ID, and then to return those values in the same row from a column in the table. Then the road parameters, such as start distance, end distance, length, start grade and end grade could be calculated automatically based on equations in the Excel table.

\subsubsection{Developing Hypothetical Scenarios in STISIM}

The STISIM simulator can create laboratory tasks relevant to the psychomotor and cognitive demands of real world driving. A combination of vehicle dynamics characteristics and compensation for CGI (Computer Generated Imagery) transport delays have been employed to create an appropriate stimulus-response relationship between steering inputs and visual display motions.

In general, there are four basic components that make up the STISIM Drive simulator: the graphics environment, the driver controls, the SDL that controls the scenarios, and the STISIM Drive software that ties it all together. The work environment includes the graphics card that generates the images, the display system that displays the Table 9 Spreadsheet for Calculating Road Parameters

\begin{tabular}{|c|c|c|c|c|c|c|c|c|c|c|}
\hline $\begin{array}{c}\text { Curve } \\
\text { id }\end{array}$ & $\mathrm{R}$ & $\mathrm{K}$ & $\mathrm{A}$ & $\begin{array}{c}\text { Def } \\
\text { angle }\end{array}$ & $\begin{array}{c}\text { Tangent } \\
\text { length }\end{array}$ & $\begin{array}{c}\text { Start } \\
\text { Dist }\end{array}$ & $\begin{array}{c}\text { End } \\
\text { Dist }\end{array}$ & $\begin{array}{c}\text { Start } \\
\text { grade }\end{array}$ & $\begin{array}{c}\text { End } \\
\text { grade }\end{array}$ & $\begin{array}{c}\text { Curve } \\
\text { length }\end{array}$ \\
\hline s13 & 300 & 80 & 3.9 & 60 & 200 & 279 & 593 & -1.96 & 1.96 & 314 \\
\hline c11 & 600 & -80 & -7.9 & 60 & 200 & 793 & 1421 & 1.96 & -5.89 & 628 \\
\hline s22 & 400 & 60 & 7.0 & 60 & 200 & 1621 & 2040 & -5.89 & 1.09 & 419 \\
\hline c33 & 300 & -40 & -7.9 & 60 & 200 & 2240 & 2554 & 1.09 & -6.76 & 314 \\
\hline
\end{tabular}


images, and the models that are used so that images can be displayed. A separate graphics package such as 3D Studio or NuGraph is required to build the models that are displayed using the simulator. The STISIM simulator comes with a number of models that can be used directly by the SDL.

To carry out a driving simulator experiment using the STISIM simulator, the experimenter needs to input several files. The main one is the Event file, which contains driving scenarios specified with simple commands listed in the Events file. A scenario definition language (SDL) was developed to minimize the effort required to specify experimental designs. The SDL permits the definition of road curvature, elevation, intersections, signal timing, interactive traffic, etc, and also simplifies the specification of scenario attributes that relate to driver psychomotor, divided attention and cognitive behavior.

All of the events occur as a function of the distance from the start of the simulation run and the different number of parameters associated with them. The most important function available to researchers studying $3 \mathrm{D}$ highway geometric issues is the function that allows users to create more than two events at the same location. This means that it is possible to create a horizontal curve and a vertical curve in the same place. In this way, a 3D horizontal overlapping with vertical curve can be generated using SDL. (The details of defining an event were introduced in Section 4.1.2)

When the simulator was running, the SDL gathered simulation data in STISIM Data files. The most useful form of data collection, evoked using BSAV/ESAV events, allows the user to save data with a number of events parameters, including (Table 10):

A. Elapsed time since the beginning of the run (s). 

B. Vehicle's longitudinal acceleration $\left(\mathrm{m} / \mathrm{s}^{2}\right.$ or $\left.\mathrm{ft} / \mathrm{s}^{2}\right)$.
C. Driver's longitudinal velocity $(\mathrm{m} / \mathrm{s}$ or $\mathrm{ft} / \mathrm{s})$.
D. Driver's lateral velocity $(\mathrm{m} / \mathrm{s}$ or $\mathrm{ft} / \mathrm{s})$.
E. Total longitudinal distance that the driver has traveled since the beginning of the run ( $\mathrm{m}$ or $\mathrm{ft})$.

F. Driver's lateral lane position with respect to the roadway dividing line, positive to the right $(\mathrm{m}$ or $\mathrm{ft})$.

G. Vehicle curvature that is determined based on the driver's steering and speed) $(1 / \mathrm{m}$ or $1 / \mathrm{ft})$.

H. Horn indicator, 0 if horn button is pressed. This indicator has been adjusted to record the visual demand information (VDI): it is 0 if the visual occlusion spectacles are opened and 1 if the visual occlusion spectacles are closed.

I. Other parameters based on the need of users

Those data were stored in a *.DAT file. A sample of a *.DAT file was given shown in Table 10. The primary information saved in the file was the time when the foot pedal was pressed. For example, in Table 10, the first ' 0 ' occurred in the sixth row, in which A $=0.6$, which means that at $0.6 \mathrm{~s}$, the foot pedal was pressed by the subject to trigger an open state for the visual occlusion spectacles with $0.5 \mathrm{~s}$ time duration. As the simulator recorded data every $0.1 \mathrm{~s}$, there are five ' 0 's shown on the $\mathrm{H}$ column.

Another form of data collection, evoked using the RMSB/RMSE events, computes the standard deviation of a range of variable in the steering and speed control tasks over a specified distance. Using road parameters calculated by the method introduced in Section 4.3.1, ten hypothetical scenarios were designed by the SDL. 
Table 10 Sample of *.DAT File for Visual Demand Data Collection

\begin{tabular}{|c|c|c|c|c|c|c|c|}
\hline$\cdot \mathrm{A}$ & $\mathrm{B}$ & $\mathrm{C}$ & $\mathrm{D}$ & $\mathrm{E}$ & $\mathrm{F}$ & $\mathrm{G}$ & $\mathrm{H}$ \\
\hline 0.1 & 0 & 22.22 & 0 & 1.85 & 1.83 & 0 & 1 \\
\hline 0.2 & 0 & 22.22 & 0 & 4.07 & 1.83 & 0 & 1 \\
\hline 0.3 & 0 & 22.22 & 0 & 6.3 & 1.83 & 0 & 1 \\
\hline 0.4 & 0 & 22.22 & 0 & 8.52 & 1.83 & 0 & 1 \\
\hline 0.5 & 0 & 22.22 & 0 & 10.74 & 1.83 & 0 & 1 \\
\hline 0.6 & 0 & 22.22 & 0 & 12.96 & 1.83 & 0 & 0 \\
\hline 0.7 & 0 & 22.22 & 0 & 15.18 & 1.83 & 0 & 0 \\
\hline 0.8 & 0 & 22.22 & 0 & 17.41 & 1.83 & 0 & 0 \\
\hline 0.9 & 0 & 22.22 & 0 & 19.63 & 1.83 & 0 & 0 \\
\hline 1 & 0 & 22.22 & 0 & 21.85 & 1.83 & 0 & 0 \\
\hline 1.1 & 0 & 22.22 & 0 & 24.07 & 1.83 & 0 & 1 \\
\hline 1.2 & 0 & 22.22 & 0 & 26.29 & 1.83 & 0 & 1 \\
\hline
\end{tabular}

\subsection{Experimental Process}

The experiment was carried out once all of the prerequisites discussed were met. All ten alignments were developed using the method discussed above. Details of these alignments are given in Appendix A. Using the Scenario Development Language (SDL), all the event files were developed in the simulator. The road scenario comprised $2 \mathrm{D}$ or 3D curves of given radius, the start point (PC or PVC), length, $\mathrm{K}$ value, and point of tangency (PT or PVT). The rural two-lane highways for all the scenarios were developed with varying lane widths. No intersections, pedestrians, other traffic or lateral obstructions were included in any scenario. The operating speed of the vehicle was kept as $80 \mathrm{~km} / \mathrm{h}$ or $22.22 \mathrm{~m} / \mathrm{s}$ for all the scenarios.

Twelve subjects participated in this experiment and drove the ten $2 \mathrm{D}$ or $3 \mathrm{D}$ alignments. Another three subjects attended the pilot study with the same scenarios. Each participant went through the simulation individually. Firstly, the subject was asked to 
drive on several practice 2D and 3D hypothetical alignments to get familiar with driving in a driving simulator. The subject was asked to run those practice scenarios with the random sequence again and again until the subject had gained enough confidence driving in a simulator.

When the subject was found to have enough confidence and driving performance, the visual occlusion device was introduced and the subject was asked to drive the same practice scenarios wearing and controlling the visual occlusion spectacles. Before starting this practice, each subject was told how the visual occlusion spectacles worked. Each subject was taught how to press the switch pedal to control opening the glasses when the subject needed to watch the screen. The subject was asked to take as few glimpses as necessary to remain in the driving lane. Once the subject was trained and felt comfortable and confident enough to proceed, the formal experiment started.

Regarding data collection, all of the data were collected for each scenario of each subject through the STISIM database. The ten alignments were named (from curve combination 1 (comb1) to curve combination 10 (comb 10)). The data were recorded in the individual data file through the BSAV and ESAV code. All of the data were stored by individual run and by individual subject.

The visual demand information in the visual occlusion spectacles was recorded by the STISIM simulator through the cable of the horn, and saved on the last column of the data record file. If the visual occlusion spectacles were closed (most of the time), 1 was recorded and if they were opened, 0 was recorded in the data record file; As mentioned previously, the opening of the spectacles controlled by ToTal Control Software was kept as $0.5 \mathrm{~s}$, so that when the foot pedal was pressed, five consecutive zeros would be shown 
in the data file. The record data files were copied in separate folders with a name representing each subject and each scenario. 


\section{Chapter 5 ANALYSIS RESULTS}

\subsection{Analysis Procedures}

After performing all the scenarios, the output data for each subject driving each alignment was recorded in individual *.dat files in the STISIM simulator. The data extraction procedure was briefly described in the Pilot Study chapter. The detailed steps are as follows:

- Used Notepad to open the *.dat file and deleted the additional description in the beginning of the file.

- Used Microsoft Excel to open the *.dat file. In Microsoft Excel, selected the delimited option with separating tab and space.

- In the last data column, the visual demand information was saved in a binary format, ' 0 ' or ' 1 '.

- In Microsoft Excel, the whole column of visual demand information (VDI) was selected and then the filter function was used to collect all records with ' 0 ' in the visual demand information column.

- Opened another worksheet in this Excel file, and pasted the filtered VDI data to it. Since the opening time for the visual occlusion spectacles was kept as $0.5 \mathrm{~s}$ and the data was collected at every $0.1 \mathrm{~s}$, there were five consecutive ' 0 's for each opening activity for visual occlusion spectacles.

- The rows with visual demand values were filtered and carried onto another Excel worksheet, which showed the time when the vision was needed, the traveling distance, and other relevant data such as lateral position and acceleration. 
- The rows with visual demand values were filtered and carried onto another Excel worksheet, which showed the time when the vision was needed, the traveling distance, and other relevant data such as lateral position and acceleration.

- Visual demand, in the form of VDF, was calculated by averaging the visual demand values obtained on the whole length of the individual element (curve or tangent).

- Visual demand, in the form of $\mathrm{VDH}$, was calculated by averaging the visual demand values obtained on the first half of the full length of each element (curve or tangent).

- Visual demand, in the form of VD30, was calculated by averaging the visual demand values on the first 30 meters of each element (curve or tangent) on the alignment.

- When this procedure was completed for all 150 data recording files, all of the visual demand data for each curve and tangent in all the scenarios and for each subject was copied to a new Excel file.

- Correlation matrices in SAS were used to calculate correction coefficients between all pairs of variables. Instead of average visual demand value, the individual visual demand value of each observation was analyzed to calibrate models to prevent data from disturbing the variance.

- Taking all the independent variables and the different probability distribution types into consideration, a modeling process was carried out to develop a variety of models.

- Different models were compared and one that produced the best result for all visual demand values was selected. 


\subsection{Calibrated Visual Demand Models}

\subsubsection{Curve Models}

The primary objective of this research is to evaluate a driver's visual demand. To oversee the effect of 3D curves on visual demand, the variation of VD was plotted and shown in Figure 11. It was observed that visual demand rises on the curves and tangents. The average visual demand value on each curve was calculated, as shown in Table 11. It was observed that the visual demand increases as the radius of the curve decreases, and the $\mathrm{K}$ values decreases. The effect of the radius of the horizontal curve was noted in previous studies. The effect of the $\mathrm{K}$ value on visual demand could be a potential causal factor influencing the variation of visual demand.

The method using average visual demand could, however, disturb the variance of individual subjects, and visual demand varies considerably for each individual. Hence, an in-depth study was carried out to establish the relationship between individual visual demand, the radius of the horizontal curve, the $\mathrm{K}$ value of the vertical curve, and other potential causal factors such as turning direction, the preceding grade (g1) and age. All curves were categorized depending on their $3 \mathrm{D}$ properties.

The 3D horizontal overlapping with vertical curves, were categorized by the type of the vertical curve as follows:

- The crest curvature of the 3D horizontal overlapping with vertical curve was taken as a nominal character variable $C_{-}$type $(\mathrm{C})$;

- The sag curvature of the 3D horizontal overlapping with vertical curve was taken as a nominal character variable C_type (S). 
fulwer

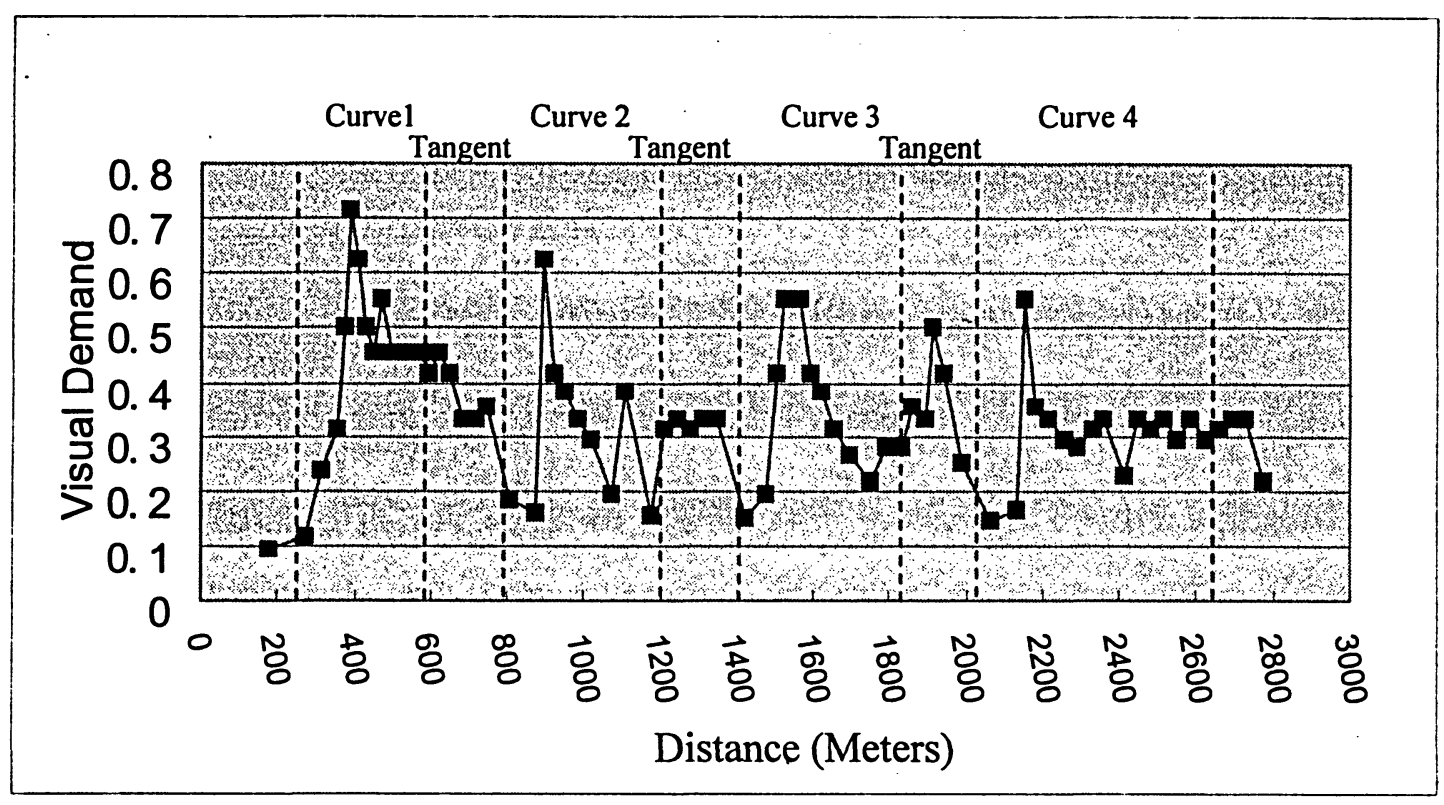

Figure 11 Variability of Visual Demand on a Test Alignment

Table 11 Average Visual Demand on 3D Alignments with different $\mathrm{R}$ and $\mathrm{K}$

\begin{tabular}{|c|c|c|c|}
\hline $\mathrm{K}$ & 600 & 400 & 300 \\
\hline 80 & 0.354 & 0.373 & 0.394 \\
\hline 60 & 0.35 & 0.371 & 0.399 \\
\hline 40 & 0.356 & 0.382 & 0.409 \\
\hline Flat & 0.327 & 0.358 & 0.387 \\
\hline-80 & 0.351 & 0.373 & 0.402 \\
\hline-60 & 0.357 & 0.376 & 0.408 \\
\hline-40 & 0.362 & 0.39 & 0.416 \\
\hline
\end{tabular}

The curve types of vertical curves shown in Figure 12 are: C_type (C) for crest vertical

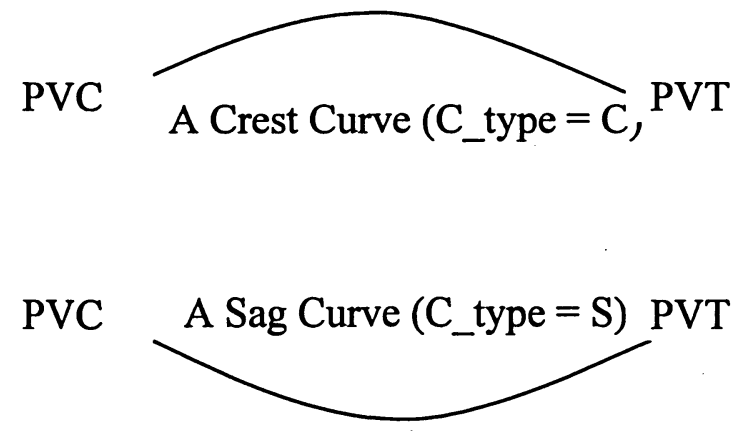

Figure 12 Sketches Showing Characteristics of Vertical Curve Types 
curve overlapping with horizontal curve, and C_type (S) for the sag vertical curve overlapping with horizontal curve. These curve types were considered in the SAS analysis as nominal character variables in SAS.

Depending on the horizontal alignment property, individual curves were also categorized by the turning direction of the horizontal curve:

- Direction (L) for a left-turning horizontal curve;

- $\quad$ Direction $(\mathrm{R})$ for a right-turning horizontal curve.

Several models were developed for VDF, VDH and VD30 for curves (see Appendix D). The best model is as follows:

$$
\begin{aligned}
\mathrm{VDF}= & 0.1668+28.6502 \mathrm{RINV}+1.2826 \mathrm{KINV}^{*} C_{-} \text {type }(\mathrm{C})+0.9592 \mathrm{KINV}^{*} \mathrm{C}_{-} \text {type}(\mathrm{S}) \\
& +0.0032 \mathrm{Age} \quad\left(\mathrm{r}^{2}=0.80\right) \\
\mathrm{VDH}= & 0.1685+37.2199 \mathrm{RINV}+1.0282 \mathrm{KINV}^{*}{ }^{2} \text { _type }(\mathrm{C})+0.6457 \mathrm{KINV}^{*} \mathrm{C}_{\text {type }}(\mathrm{S}) \\
& +0.0029 \mathrm{Age} \quad\left(\mathrm{r}^{2}=0.57\right)
\end{aligned}
$$

$\log ($ VD30 $)=-1.5148+85.3096 \mathrm{RINV}+0.0084$ Age $\quad($ Pearson Chisq/DF $=0.01)(26)$ where

$\mathrm{VDF}, \mathrm{VDH}, \mathrm{VD} 30=$ the visual demand for full, half and first 30 meters on curves, RINV = inverse of radius of curvature, and $\mathrm{KINV}=$ inverse of $\mathrm{K}$ (the absolute value is used for $\mathrm{K}$ on crest and sag vertical curves). C_type (C) and C_type (S) = Nominal character variables, as described above. C_type (C) takes a value of 1 , and C_type (S) takes a value of 0 when this 3D curve includes a crest vertical curve; C_type (C) takes a value of 0 , and C_type (S) takes a value of 1 when this 3D curve includes a sag vertical curve; C_type (C) takes a value of 0 , and C_type (S) takes a value of 0 when this is a $2 \mathrm{D}$ horizontal curve. 
All independent variables were tested with the null hypothesis Ho. The RINV, $\mathrm{KINV} * \mathrm{C}_{\text {_type, }}$ and Age were observed as the statistically significant variables for visual demand in all the models developed. The models for 2D and 3D curves show that visual demand is directly proportional to the product of the inverse of curve radius and the inverse of the $\mathrm{K}$ value of the current element, and the age of subject. The variable RINV (Inverse of radius) continues to play a significant role and has the greatest influence on visual demand.

The inverse of $\mathrm{K}$ and Age, however, are also important. The VDF and VDH for 3D curves were based on a normal distribution that produced the best fit for all models. The VD30 for 3D curves was based on a log normal distribution, which is the best method to calibrate VD30 models. The goodness of fit of the models of Equations 24 and 25 were $0.80\left(\mathrm{r}^{2}\right)$ and $0.57\left(\mathrm{r}^{2}\right)$ respectively, indicating good fit. The goodness of fit of the model of Equation 21 was 5.5341 (Chi-Square), indicating considerable fit. Table 12 shows the statistical significance of the independent variables, all of which have reliability greater than $99.99 \%$ for curves.

Table 12 Parameter Estimates on VDF of Curves

\begin{tabular}{|c|c|c|c|c|c|}
\hline Variable & C_type & DF & Std Error & t Stat & $\operatorname{Pr}>|\mathrm{t}|$ \\
\hline Intercept & & 1 & 0.0071 & 23.33 & $<0.0001$ \\
\hline RINV & & 1 & 2.2900 & 12.51 & $<0.0001$ \\
\hline KINV*C_type & $\mathrm{C}$ & 1 & 0.2176 & 5.89 & $<0.0001$ \\
\hline & $\mathrm{H}$ & 0 & - & - & - \\
\hline Age & $\mathrm{S}$ & 1 & 0.2418 & 3.97 & $<0.0001$ \\
\hline & & 1 & $8.321 \mathrm{E}-05$ & 38.00 & $<0.0001$ \\
\hline
\end{tabular}




\subsubsection{Tangent Models}

VD models on tangents were also developed. The characteristics of the preceding curve, including the inverse of radii, turning directions, the inverse of the $\mathrm{K}$ values, and the curve types were considered when calibrating the model. The models developed for VDF, VDH, and VD30 of tangents are given in Appendix D. The best of the models are as follows:

$$
\begin{array}{ll}
\text { VDF }=0.2022+11.2527 \text { PINVR }+0.0028 \text { Age } & \left(\mathrm{r}^{2}=0.35\right) \\
\text { VDH }=0.1940+19.9492 \text { PINVR }+0.0029 \text { Age } & \left(\mathrm{r}^{2}=0.35\right) \\
\text { VD30 }=0.1837+19.8707 \text { PINVR }+0.0036 \text { Age } & \left(\mathrm{r}^{2}=0.35\right)
\end{array}
$$

where

VDF, VDH, and VD30 are the visual demand for full, half and first 30 meters on tangent, PINVR = Inverse of radius of curvature of the preceding curve, where radius is in meters.

In addition, the values of observed VDF, VDH and VD30 are $0.3403,0.3571$ and 0.3790. Tables 13 shows the statistical significance of the independent variables considered for evaluating VDF on tangents. As mentioned above, the age variable has a reliability greater than $99.99 \%$. PINVR is also a significant factor in visual demand on tangents. There were, however, a number of variances in the tangent models.

The tangent models clearly showed that PINVR (the inverse of radius of the preceding curve) significantly affect the visual demand of the current tangent. The age variable is another significant factor on visual demand. The $r^{2}$ values of the VDF tangent model, VDH tangent model and VD30 tangent model are $0.3465,0.3476$ and 0.3494 , respectively, indicating considerable fit. The influence of the characteristics of the preceding or following vertical curvature was not found established. 
Table 13 Parameter Estimates on VDF on Tangents

\begin{tabular}{|c|c|c|c|c|c|}
\hline Variable & DF & Estimate & Std Error & $\mathrm{t}$ Stat & $\operatorname{Pr}>|\mathrm{t}|$ \\
\hline Intercept & 1 & 0.2022 & 0.0161 & 12.52 & $<0.0001$ \\
\hline Age & 1 & 0.0028 & 0.0002 & 14.44 & $<0.0001$ \\
\hline PINVR & 1 & 11.2527 & 5.3048 & 2.12 & 0.0345 \\
\hline
\end{tabular}

\subsection{Discussion of Visual Demand on Curves}

The variability of visual demand on $3 \mathrm{D}$ curves and tangents was established using the model developed. Visual demand on 3D curves was found to be significantly related to the vertical alignment characteristics. There were no new findings in tangent modeling, and there were a large number of variances in the tangent models. As a result, the following discussion focuses mainly on the VDF model for 2D and 3D curves. For the curve models, the radius of curvature and the $K$ value of the $3 \mathrm{D}$ curve were varied to understand the impact of the horizontal alignment and the vertical alignment. Motorists aged from 18 to 71 were selected to test the effect of age on visual demand.

\subsubsection{Effect of 3D Curvature}

The primary objective of this research was accomplished with the development of the models. A number of independent variables were investigated in the course of the research. The vertical alignment characteristics, including the inverse of the $\mathrm{K}$ value of the crest curve and sag curve showed a statistically significant relationship with visual demand. The inverse of radius also showed a significant influence on the evaluation of visual demand. Figures 13-15 show the variation of VD with respect to Inverse of $\mathrm{K}$ (KINV) of 2D and 3D curves. Figure 13 shows the variance of VD with respect to the 


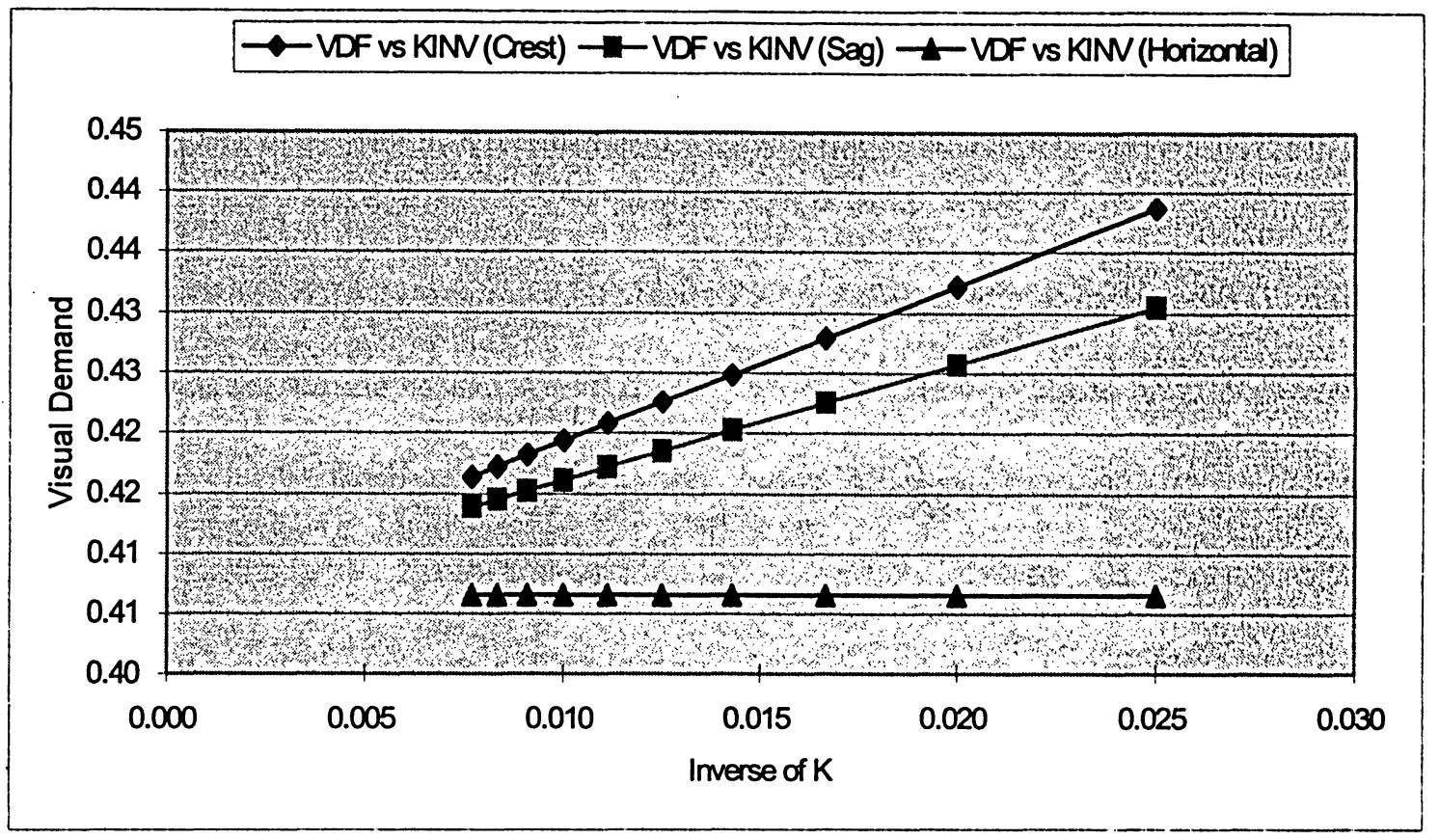

Figure 13 Sensitivity of VDF with varying Inverse of $\mathrm{K}$ of the Vertical Curve

$$
\text { (Radius }=600 \mathrm{~m} \text {, Subject age }=60 \text { ) }
$$

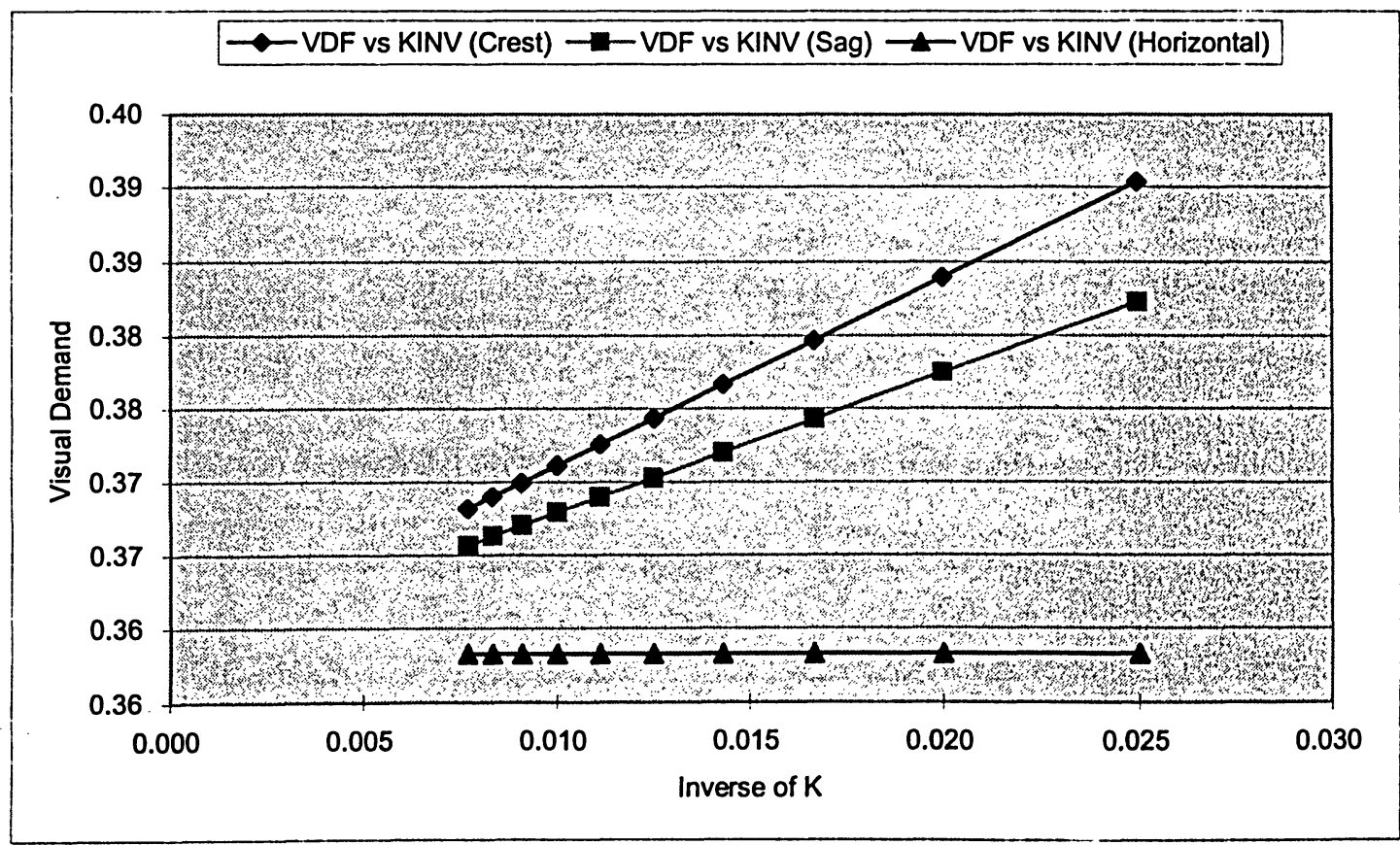

Figure 14 Sensitivity of VDF with varying Inverse of $\mathrm{K}$ of the Vertical Curve

$$
\text { (Radius }=300 \mathrm{~m} \text {, Subject age }=30 \text { ) }
$$


inverse of radius (RINV) of 2D and 3D curves. The visual demand values for either the horizontal alignment overlapping with crest vertical curve or the horizontal alignment overlapping with sag vertical curve show a higher visual demand than the visual demand for the 2D horizontal curve. The RINV variable, however, still shows the highest influence on evaluation of visual demand. The KINV variable shows the second highest influence on evaluation of visual demand. The type of the vertical curve including crest vertical curve, sag vertical curve or $2 \mathrm{D}$ horizontal curve was barely statistically significant, but when crossed with KINV, it was statistically significant.

The signs of RINV (or $1 / \mathrm{R}$ ) and KINV (or $1 / \mathrm{K}$ ) clearly show that visual demand is directly proportional to these variables, and the coefficients show that RINV always has the highest effect on all types of visual demand (Figure 16). KINV also has a significant influence in all types of visual demand. It becomes clear that visual demand on 3D curves is strongly influenced not only by the inverse of the radius, but also by the inverse of $\mathrm{K}$. Although the influence of the inverse of $\mathrm{R}$ has the most significant effect on visual demand, a new finding from this research is that the effect of the inverse of $\mathrm{K}$ always makes the visual demand on the horizontal alignment overlapping with the crest vertical curve (crest 3D curve) or the horizontal alignment overlapping with the sag vertical curve (sag 3D curve) higher than the visual demand on the flat horizontal curve. Moreover, the visual demand on the crest $3 \mathrm{D}$ curve is higher than that on the sag $3 \mathrm{D}$ curve with the same, geometry parameters ( $\mathrm{R}$ and absolute $\mathrm{K})$.

When driving on a roadway curve, drivers preferred to watch the end of the road near the horizon. They sometimes looked to the left or right side of the road to note changes in the curvature of the road (Tsimhoni and Green 1999). Vertical curvature, 


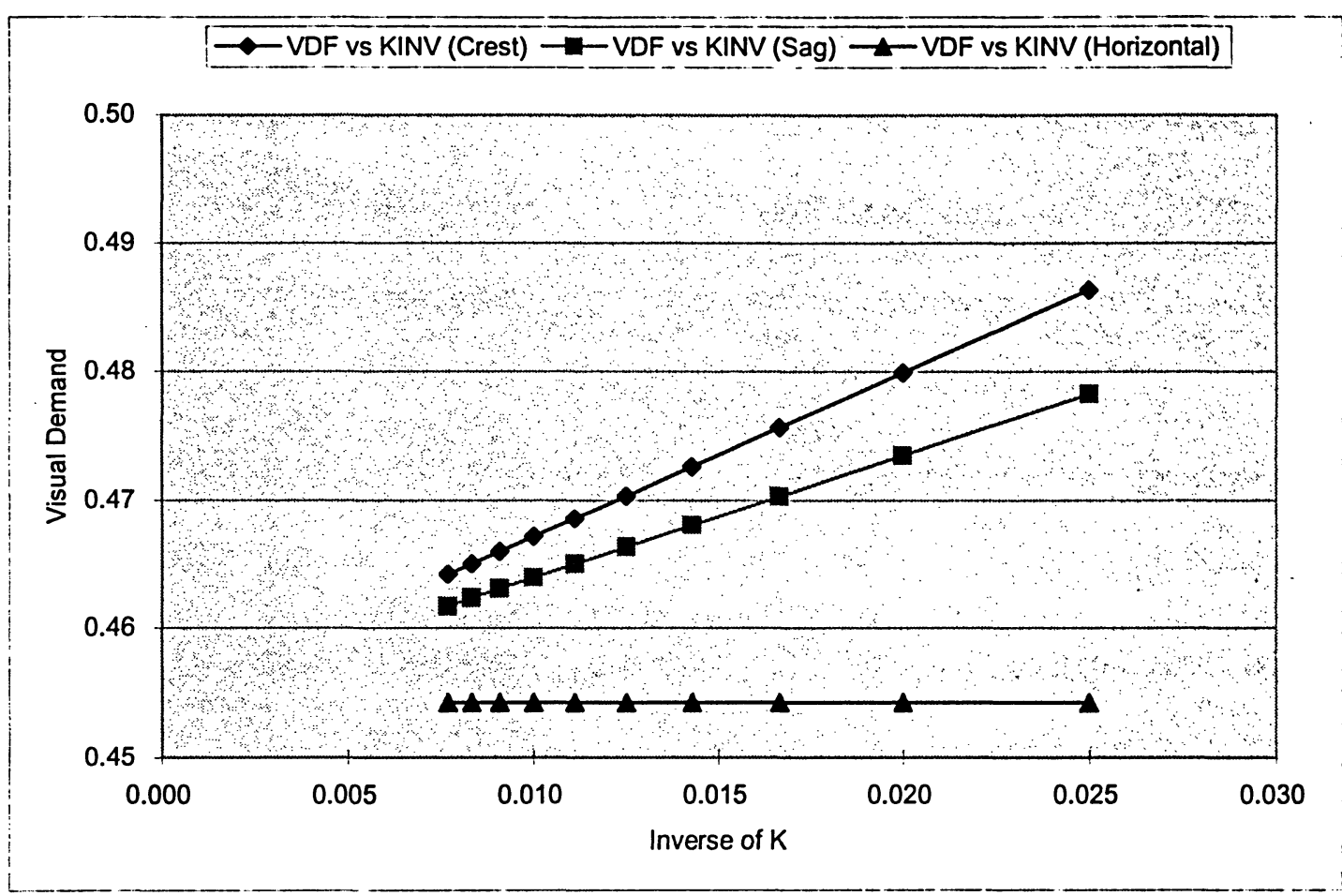

Figure 15 Sensitivity of VDF with varying Inverse of $\mathrm{K}$ of the Vertical Curve (Radius $=300 \mathrm{~m}$, Subject age $=60$ )

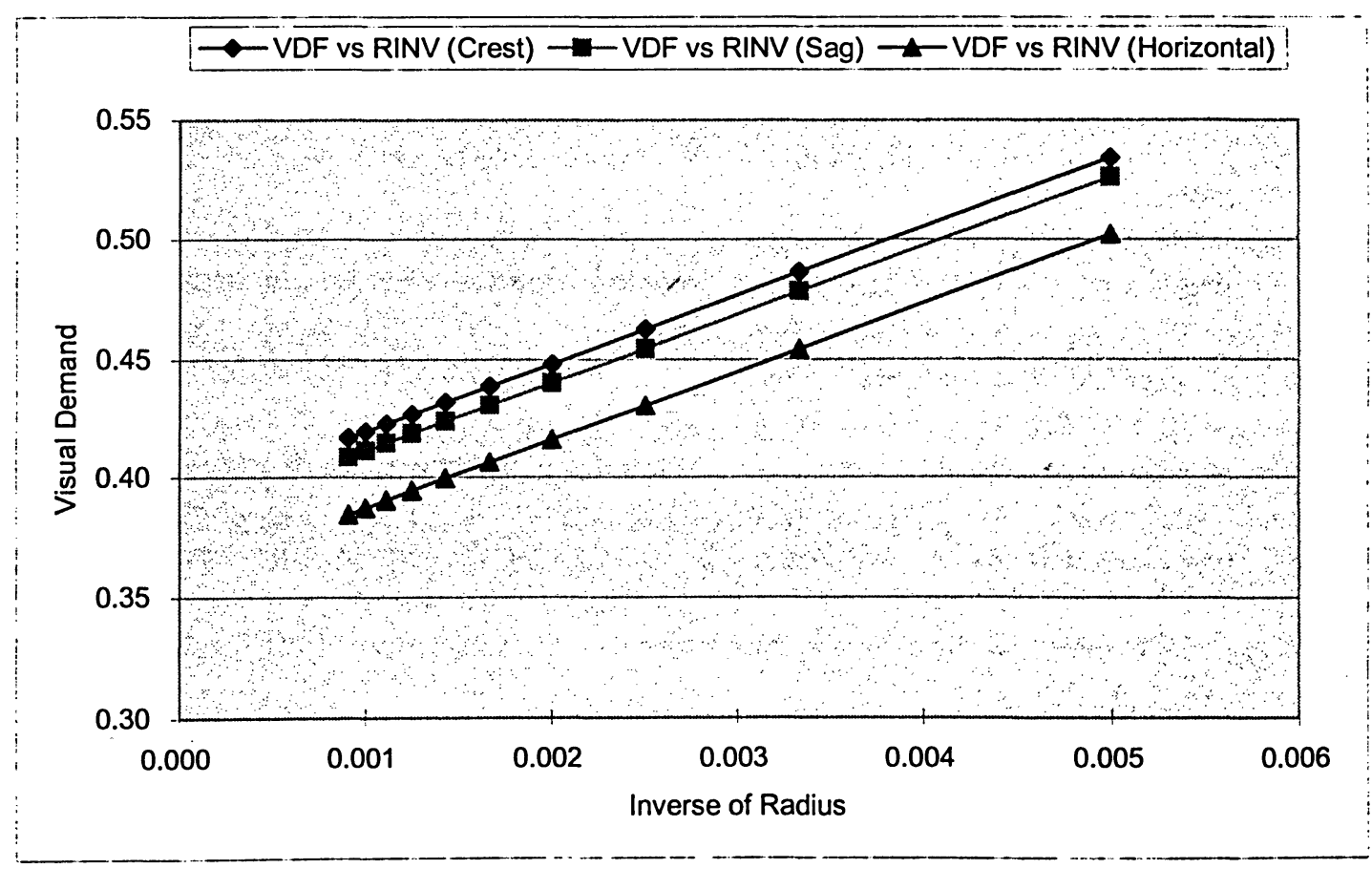

Figure 16 Sensitivity of VD with varying Inverse of Radius $(K=40$, Subject age $=60)$ 
either crest or sag, reshapes the 3D perception of the horizontal curvature, and makes it appear either sharper (when combined with a crest curve) or flatter (when combined with a sag curve) (Hassan and Easa 1998). These perceptions lead drivers to make slightly erroneous decisions in vehicle control compared with usual their experience on the regular 2D horizontal curves. As a result, drivers have to spend addition time and attention re-adjusting the position of the vehicle while they negotiate the $3 \mathrm{D}$ alignment. During this time, the driver's vision may be blocked by the crest curve. This is the reason that the visual demand on a crest $3 \mathrm{D}$ curve is higher than that on a sag $3 \mathrm{D}$ curve with the same geometric parameters.

\subsubsection{Effect of Age}

The effect of age was found that to be significant $(\mathrm{P}<0.0001)$, using SAS. Figure 17 shows how older subjects had higher visual demand than younger subjects on both 2D and 3D curves. Obviously, the mere presence of a curve was a strong loading factor for older subjects.

As people grow older, they suffer non-pathological changes in sensory efficiency that is both gradual and insidious. People may not be aware of the extent to which their eyesight is declining and the resulting failure to compensate may put them at risk as drivers or pedestrians. When talking with other older drivers in this experiment, it was found that the drivers in their 60 s to 80 s were not generally aware of the extent to which their visual acuity had declined, especially on complex and 3D alignments.

There could be two reasons for this. Firstly, the sensory losses of older drivers not only put them at risk of failing to promptly perceive curves, other road users or obstructions, but also greatly increase the time it takes them to decode information in the 


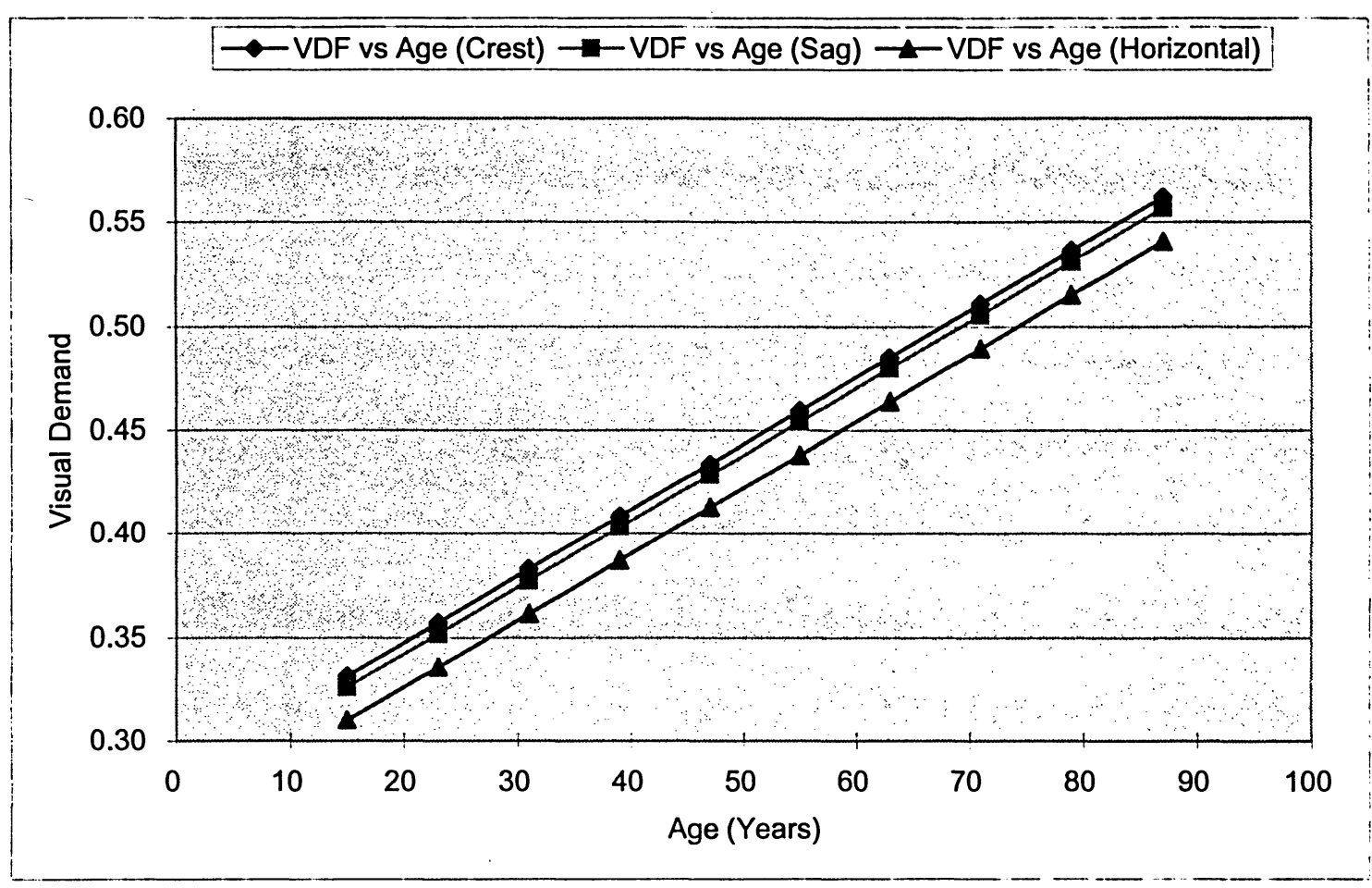

Figure 17 Sensitivity of VD with varying Age (Radius $=300 \mathrm{~m}, \mathrm{~K}=60$ )

visual field. Secondly, changes in visual function occur. There are two classes of change in the ageing eye: the first, transmissiveness and accommodative power, begins to take effect between the ages of 35 and 45. Distance vision, sensitivity to glare, binocular depth perception and color sensitivity may deteriorate. The second type of change, which begins between 55 and 65 years of age, concerns the retina and nervous system and may affect the metabolism of the retina. These changes may affect the size of the visual field, sensitivity to low light levels and sensitivity to flicker.

\subsubsection{Comparison with On-road Test}

In this research, the visual demand was evaluated under a driving simulator environment. To utilize driver visual demand as a reliable source of information about a roadway alignment, researchers and designers must know whether the information is 
roadway alignment, researchers and designers must know whether the information is consistent and reliable. One method is to compare the results of this experiment with the similar work conducted by TTI on local highways and test track (Fitzpatrick et al. 1999).

The TTI on-road study was undertaken to evaluate the workload measures obtained in a test track study, as shown in Table 14. A key difference between the on-road study and this driving simulator study is that in the TTI study, only six drivers (compared with 15) were tested. In addition, it was impossible to find real roadway curves that were exactly comparable to those tested in this driving simulator experiment. When using the model developed in this simulator experiment, subject age is equal to 30 years and curve type is the flat horizontal curve $(1 / \mathrm{K}=0)$, which is a special case of $3 \mathrm{D}$ horizontal overlapping with vertical curves. Figure 18 shows that the visual demand value (VD) obtained in this research was similar to the result in the Test Track Study (Run 2). The slope of the regression line of the simulator study data was similar to that of the TTI OnRoad Study (Run 2). VD reflects the absolute terms of visual demand of drivers, and the Table 14 Comparison of this Study and Previous Studies

\begin{tabular}{|c|c|c|c|}
\hline Study & $\begin{array}{c}\text { This Simulator } \\
\text { Experiment }\end{array}$ & $\begin{array}{c}\text { TTI } \\
\text { On-Road Test }\end{array}$ & $\begin{array}{c}\text { TTI } \\
\text { Test Track Study }\end{array}$ \\
\hline Characteristics & Rural highways & $\begin{array}{c}\text { Two local rural } \\
\text { highways }\end{array}$ & $\begin{array}{c}\text { Three closed } \\
\text { courses }\end{array}$ \\
\hline Location & Ryerson University & TTI & TTI \\
\hline Sample & 15 drivers & 6 drivers & 23 drivers \\
\hline $\begin{array}{c}\text { Independent } \\
\text { Variables }\end{array}$ & $\begin{array}{c}1 / \text { Radius, 1/K, Age, } \\
\text { and so on }\end{array}$ & $1 /$ Radius & $1 /$ Radius \\
\hline $\begin{array}{c}\text { Dependent } \\
\text { Variables }\end{array}$ & VDF & VDF & VDF \\
\hline Deflection Angle & 60 deg & 20,45 deg $*$ & $20,45,90$ deg $*$ \\
\hline Model & Chapter 5.3 & $\begin{array}{l}\text { VDF (run1) }= \\
0.173+43.013 R I N V\end{array}$ & $\begin{array}{l}\text { VDF (run1) }= \\
0.297+25.832 R I N V \\
\end{array}$ \\
& & $\begin{array}{l}\text { VD(run2) }= \\
0.297+25.832 R I N V\end{array}$ & $0.285+23.133$ RINV \\
\hline
\end{tabular}

* The previous research by TTI has found that deflection angle is not a significant factor. 


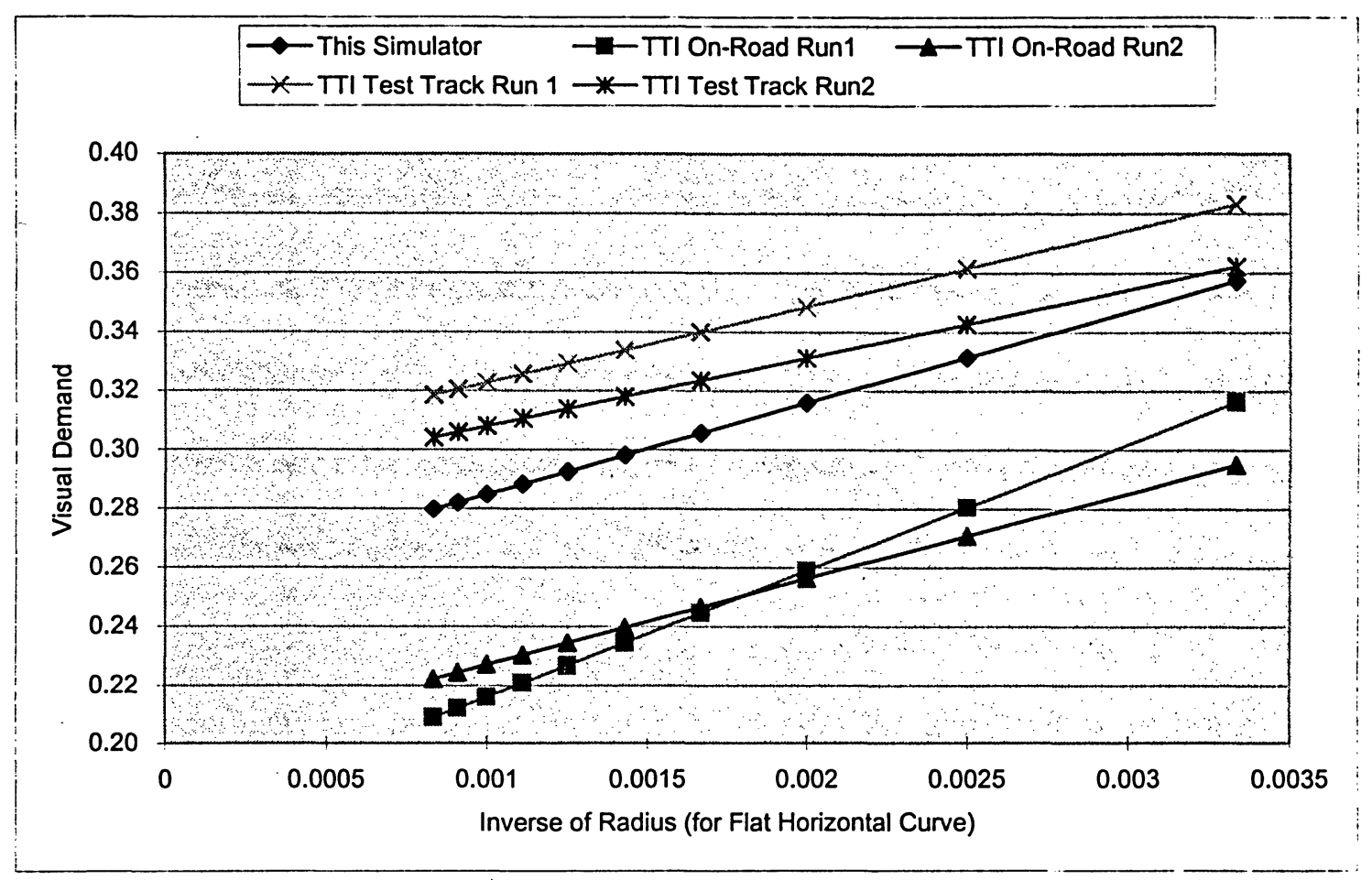

Figure 18 Comparison of Simulator Study and On-Road Study and Test Track

slope of regression line reflects the change trend of visual demand. This similarities found in this comparison should increase confidence in the findings of this driving simulator experiment.

\subsubsection{Model Verification and Comparison}

A comparative study was carried out to consider the goodness of fit of the models developed. The $13 \%$ observed visual demand data based on two subjects (a 30 year old driver and a 61 year old drivers) on all test alignments were selected to verify the newly developed VDF model (Equation 24) estimated based on 13 subjects, and to compare the model results with those predicted by the following FHWA VDF model (Fitzpatrick et al.1999): $\vee$

$$
\mathrm{VDF}=0.388+34.663 / \mathrm{R} \checkmark
$$


In total, seventy-two VDF data observations on all tested curves were used for verification and comparison, including thirty-two 3D horizontal curves overlapping with sag curves, thirty-two 3D horizontal curves overlapping with crest curves, and eight 2D horizontal curves. A series of visual demand values for the individual elements of all combinations was calculated using the model equation developed in this research. The model is called New Model VD. Another series of visual demand values for each element was calculated using the FHWA model of Equation 30. The objective of this comparison was to verify the effectiveness of applying the developed model in evaluating visual demand on any highway alignment.

Firstly, the three types of VDF data on 2D horizontal curves were compared. The comparison graph presented in Figure 19 illustrates the goodness of fit of the VD. The information about observation elements is given in Table 15. The comparative study for VDH and VD30 models shows similar results. In the graph of VDF on 2D horizontal curves, the visual demand estimated by the new developed model showed a trend similar to the observed visual demand. Its absolute values were much closer to the observed value at each observation element, compared with the FHWA model data in each location. From the verification study, it becomes evident that for the 2D horizontal curves, the VDF calculated from the new model in this research succeeds in representing the observed VDF data from the simulator experimentation. It also becomes evident that the new model reflects much more accurate VDF values than the existing popular model.

Secondly, the three types of VDF data on 3D curves for young and middle aged drivers (30-year age) were compared (Figure 20) to illustrate the goodness of fit of the visual demand on 3D curves. The information on observation elements was given in 
Table 16. The graph of VDF on 3D curves indicated that the new model VDF for young and middle aged drivers showed a trend similar to that of the observed VD. Compared with the FHWA model, its absolute values were also much closer to the observed value at all 32 observation elements. From these results, it is evident that for the 3D curves for young and middle aged drivers, the visual demand calculated from the new VDF model represents the observed VDF data well. In addition, the new model predicts visual demand more accurately than does the FHWA model.

The three types of VDF data on 3D curves for the older driver were compared and the comparison graph is shown in Figure 21 to illustrate the goodness of fit of the VD on 3D curves. The information on observation elements was given in Table 17. The graph of VDF on 3D curves for older driver indicated that the new model VDF also showed a

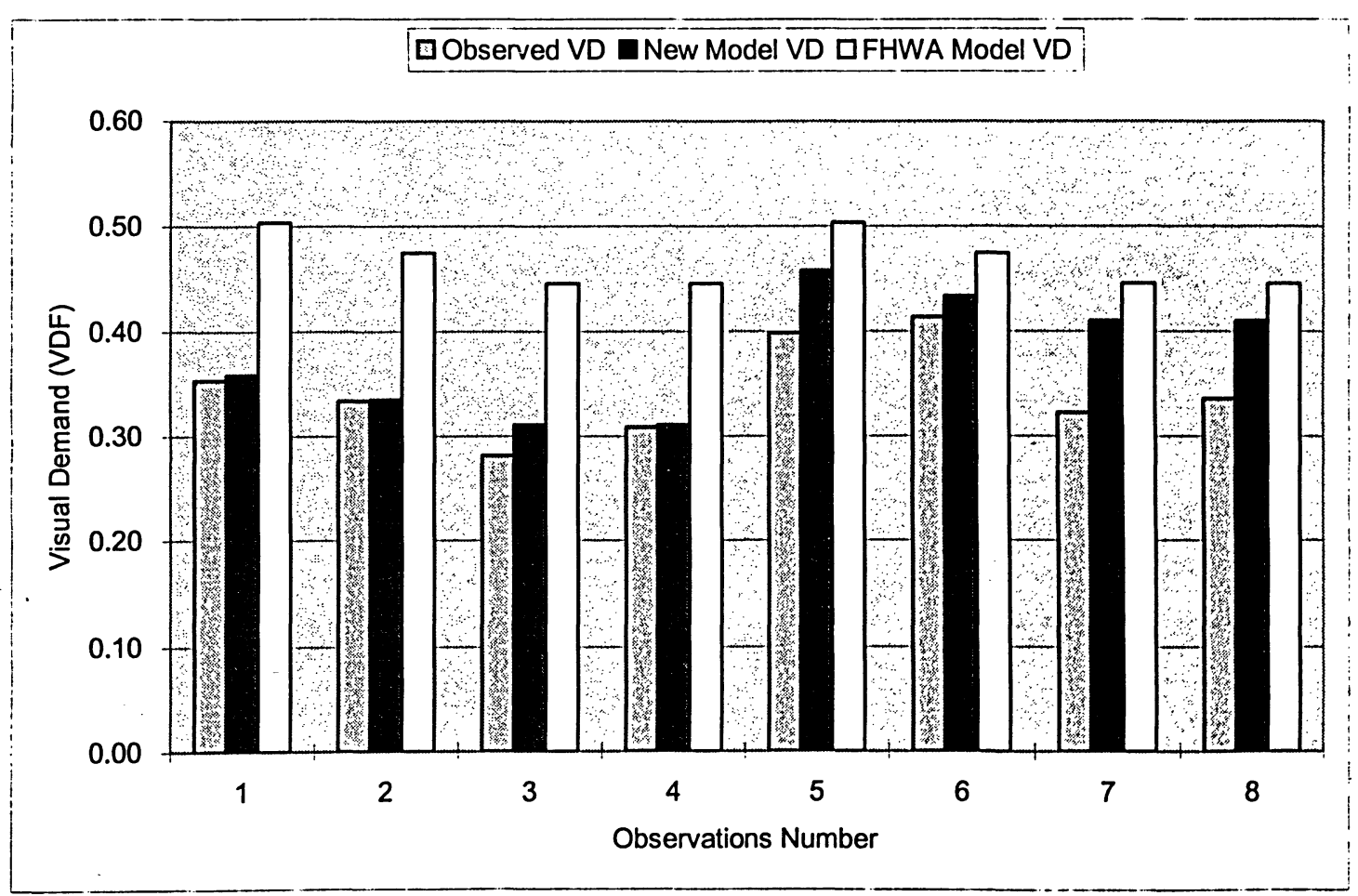

Figure 19 Comparative Study on Goodness of Fit (2D Horizontal Curves) 
Table 15 Information of Individual Observation Elements (Horizontal Curves)

\begin{tabular}{|c|c|c|c|c|c|c|}
\hline $\begin{array}{c}\text { Observation } \\
\text { Number }\end{array}$ & Comb ID & Curve ID & Curve type & $\mathrm{R}$ & $\mathrm{K}$ & Subject Age \\
\hline 1 & 2 & $\mathrm{~h} 3$ & 2D Horizontal & 300 & $\mathrm{NA}$ & 30 \\
\hline 2 & 2 & $\mathrm{~h} 2$ & 2D Horizontal & 400 & NA & 30 \\
\hline 3 & 2 & $\mathrm{~h} 1$ & 2D Horizontal & 600 & NA & 30 \\
\hline 4 & 2 & $\mathrm{~h} 1$ & 2D Horizontal & 600 & NA & 30 \\
\hline 5 & 2 & $\mathrm{~h} 3$ & 2D Horizontal & 300 & NA & 61 \\
\hline 6 & 2 & $\mathrm{~h} 2$ & 2D Horizontal & 400 & NA & 61 \\
\hline 7 & 2 & $\mathrm{~h} 1$ & 2D Horizontal & 600 & NA & 61 \\
\hline 8 & 2 & $\mathrm{~h} 1$ & 2D Horizontal & 600 & NA & 61 \\
\hline
\end{tabular}

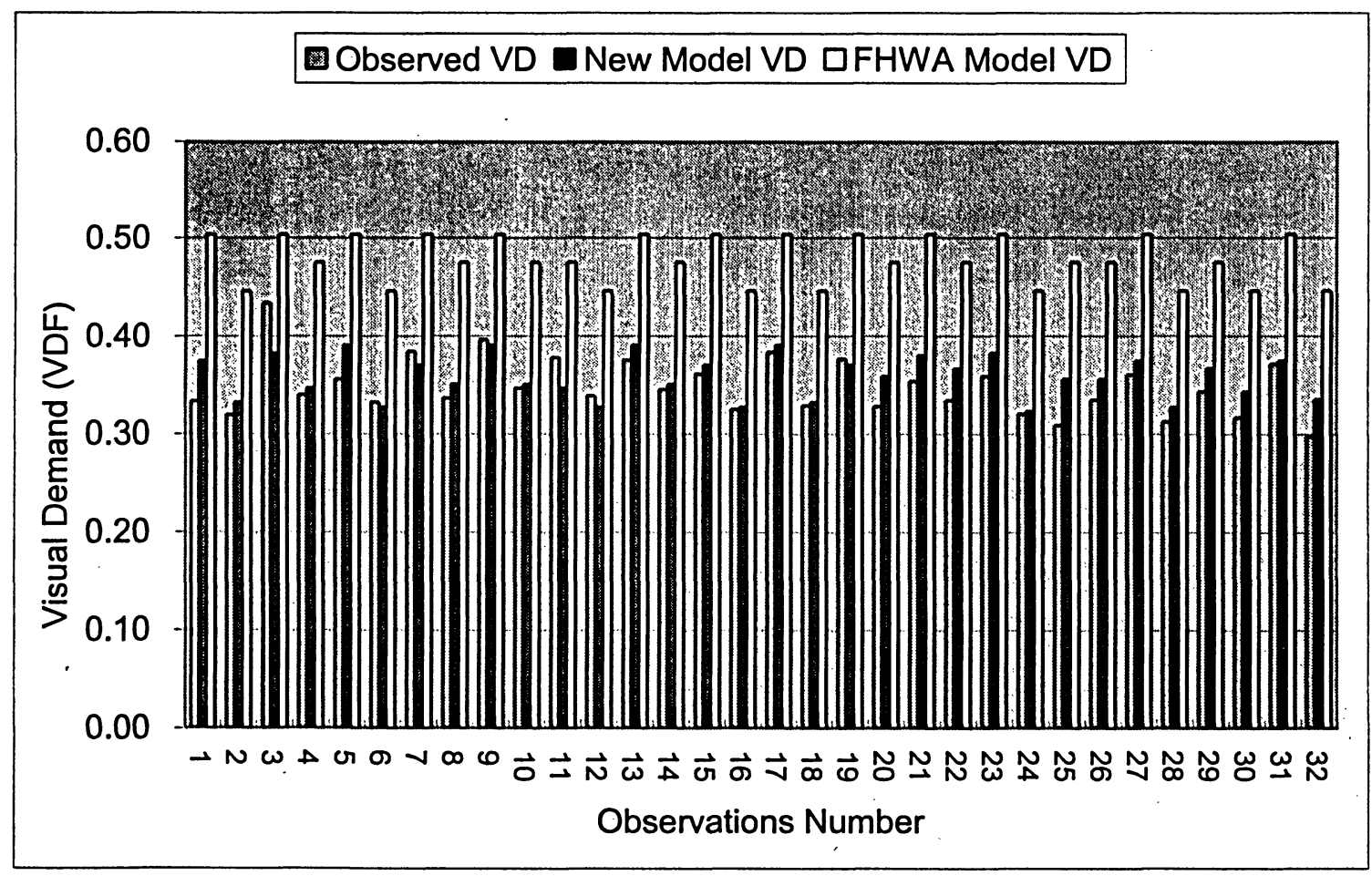

Figure 20 Comparative Study on Goodness of Fit (Sag and Crest Curves, Subject age $=30$ ) 
Table 16 Information of Individual Observation Elements (Subject Age = 30)

\begin{tabular}{|c|c|c|c|c|c|}
\hline Observation ID & Comb Num & Curves ID & Curve type & $\mathrm{R}$ & $\mathrm{K}$ \\
\hline 1 & 3 & $\mathrm{c} 13$ & Horizontal + Crest & 300 & 80 \\
\hline 2 & 3 & c21 & Horizontal + Crest & 600 & 60 \\
\hline 3 & 3 & s33 & Horizontal + Sag & 300 & 40 \\
\hline 4 & 3 & s12 & Horizontal + Sag & 400 & 80 \\
\hline 5 & 4 & c33 & Horizontal + Crest & 300 & 40 \\
\hline 6 & 4 & c11 & Horizontal + Crest & 600 & 80 \\
\hline 7 & 4 & s13 & Horizontal + Sag & 300 & 80 \\
\hline 8 & 4 & s22 & Horizontal + Sag & 400 & 60 \\
\hline 9 & 5 & c33 & Horizontal + Crest & 300 & 40 \\
\hline 10 & 5 & $\mathrm{c} 12$ & Horizontal + Crest & 400 & 80 \\
\hline 11 & 5 & s12 & Horizontal + Sag & 400 & 80 \\
\hline 12 & 5 & s21 & Horizontal + Sag & 600 & 60 \\
\hline 13 & 6 & c33 & Horizontal + Crest & 300 & 40 \\
\hline 14 & 6 & c12 & Horizontal + Crest & 400 & 80 \\
\hline 15 & 6 & s13 & Horizontal + Sag & 300 & 80 \\
\hline 16 & 6 & s21 & Horizontal + Sag & 600 & 60 \\
\hline 17 & 7 & c33 & Horizontal + Crest & 300 & 40 \\
\hline 18 & 7 & c21 & Horizontal + Crest & 600 & 60 \\
\hline 19 & 7 & s13 & Horizontal + Sag & 300 & 80 \\
\hline 20 & 7 & s32 & Horizontal + Sag & 400 & 40 \\
\hline 21 & 8 & c23 & Horizontal + Crest & 300 & 60 \\
\hline 22 & 8 & c32 & Horizontal + Crest & 400 & 40 \\
\hline 23 & 8 & s33 & Horizontal + Sag & 300 & 40 \\
\hline 24 & 8 & s11 & Horizontal + Sag & 600 & 80 \\
\hline 25 & 9 & c22 & Horizontal + Crest & 400 & 60 \\
\hline 26 & 9 & c22 & Horizontal + Crest & 400 & 60 \\
\hline 27 & 9 & s23 & Horizontal + Sag & 300 & 60 \\
\hline 28 & 9 & $s 21$ & Horizontal + Sag & 600 & 60 \\
\hline 29 & 10 & c32 & Horizontal + Crest & 400 & 40 \\
\hline 30 & 10 & c31 & Horizontal + Crest & 600 & 40 \\
\hline 31 & 10 & s23 & Horizontal + Sag & 300 & 60 \\
\hline 32 & 10 & s31 & Horizontal + Sag & 600 & 40 \\
\hline
\end{tabular}


trend similar to that of the observed VD. Its visual demand values were also closer to the observed value at 19 observation elements $(59.4 \%$ of all elements) than were the FHWA model results. Thus, for 3D curves, the visual demand calculated from the new model .represents the observed VD data from the simulator experimentation well, and this model is better than the FHWA model. The FHWA model developed using an old model simulator may overestimate visual demand values than the result from the on-road test. On the other hand, the effect of age takes a positive influence on visual demand. So in Figure 21, the result of FHWA model appears improved for the old driver.

A comparison for a specific curves combination (Alignment 7) was given in Figure 22 and the values on the $\mathrm{x}$-axis are the start distances of 3D curves along this alignment. This combination includes two 3D horizontal + sag curves (s13 and s32) and two 3D horizontal + crest curves (c33 and c21). Table 18 shows the design parameters of the

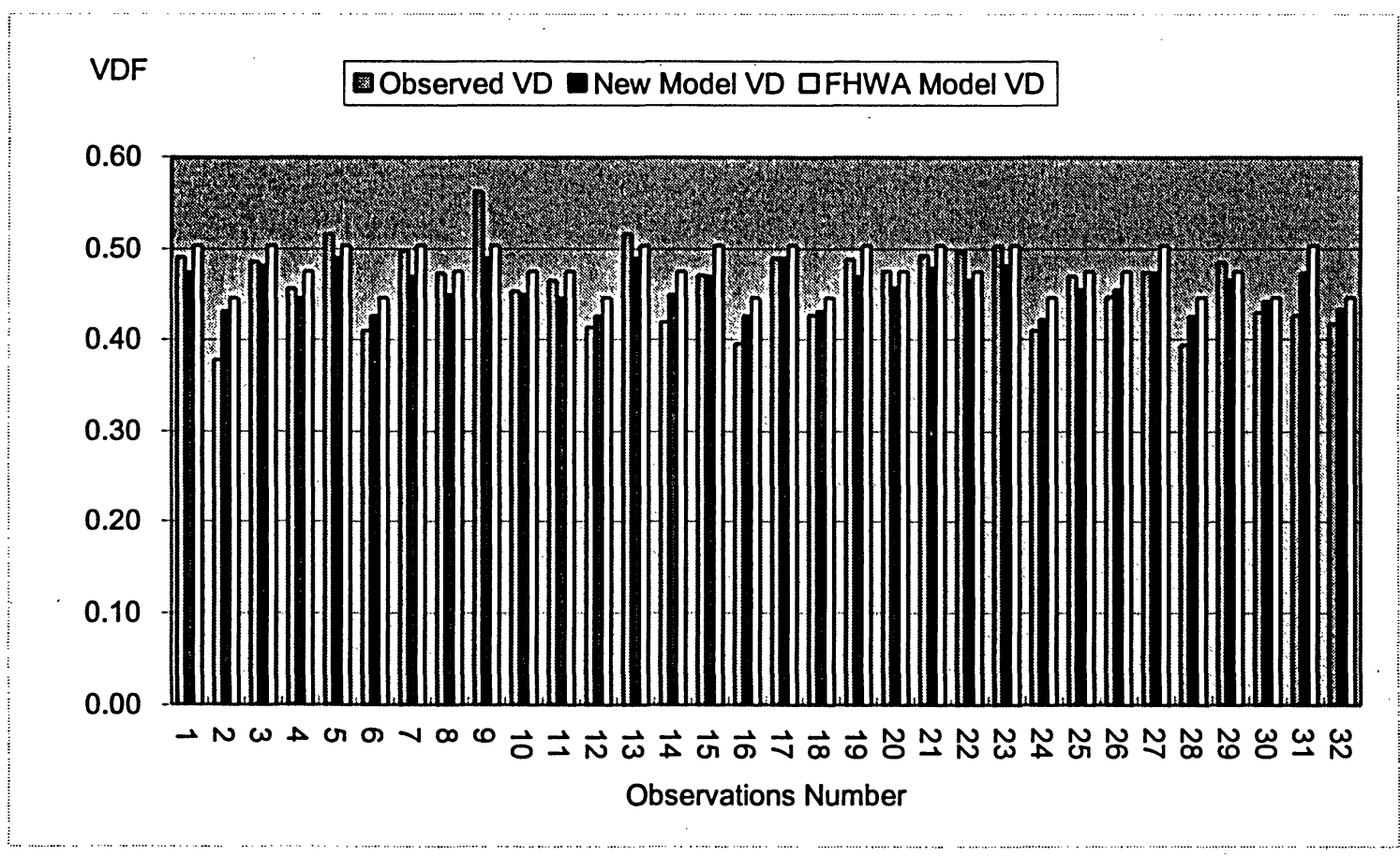

Figure 21 Comparative Study on Goodness of Fit (Sag and Crest Curves, Subject age $=61$ ) 
Table 17 Information of Individual Observation Elements (Subject Age $=61$ )

\begin{tabular}{|c|c|c|c|c|c|}
\hline Observation ID & Comb Num & Curves ID & Curve type & $\mathbf{R}$ & $\mathrm{K}$ \\
\hline 1 & 3 & $\mathrm{c13}$ & Horizontal + Crest & 300 & 80 \\
\hline 2 & 3 & $\mathrm{c} 21$ & Horizontal + Crest & 600 & 60 \\
\hline 3 & 3 & s33 & Horizontal + Sag & 300 & 40 \\
\hline 4 & 3 & s12 & Horizontal + Sag & 400 & 80 \\
\hline 5 & 4 & c33 & Horizontal + Crest & 300 & 40 \\
\hline 6 & 4 & c11 & Horizontal + Crest & 600 & 80 \\
\hline 7 & 4 & s13 & Horizontal + Sag & 300 & 80 \\
\hline 8 & 4 & s22 & Horizontal + Sag & 400 & 60 \\
\hline 9 & 5 & c33 & Horizontal + Crest & 300 & 40 \\
\hline 10 & 5 & c12 & Horizontal + Crest & 400 & 80 \\
\hline 11 & 5 & s12 & Horizontal + Sag & 400 & 80 \\
\hline 12 & 5 & s21 & Horizontal + Sag & 600 & 60 \\
\hline 13 & 6 & c33 & Horizontal + Crest & 300 & 40 \\
\hline 14 & 6 & c12 & Horizontal + Crest & 400 & 80 \\
\hline 15 & 6 & s13 & Horizontal + Sag & 300 & 80 \\
\hline 16 & 6 & s21 & Horizontal + Sag & 600 & 60 \\
\hline 17 & 7 & c33 & Horizontal + Crest & 300 & 40 \\
\hline 18 & 7 & c21 & Horizontal + Crest & 600 & 60 \\
\hline 19 & 7 & s13 & Horizontal + Sag & 300 & 80 \\
\hline 20 & 7 & s32 & Horizontal + Sag & 400 & 40 \\
\hline 21 & 8 & $\mathrm{c} 23$ & Horizontal + Crest & 300 & 60 \\
\hline 22 & 8 & c32 & Horizontal + Crest & 400 & 40 \\
\hline 23 & 8 & s33 & Horizontal + Sag & 300 & 40 \\
\hline 24 & 8 & s11 & Horizontal + Sag & 600 & 80 \\
\hline 25 & 9 & c22 & Horizontal + Crest & 400 & 60 \\
\hline 26 & 9 & c22 & Horizontal + Crest & 400 & 60 \\
\hline 27 & 9 & s23 & Horizontal + Sag & 300 & 60 \\
\hline 28 & 9 & s21 & Horizontal + Sag & 600 & 60 \\
\hline 29 & 10 & c32 & Horizontal + Crest & 400 & 40 \\
\hline 30 & 10 & c31 & Horizontal + Crest & 600 & 40 \\
\hline 31 & 10 & s23 & Horizontal + Sag & 300 & 60 \\
\hline 32 & 10 & s31 & Horizontal + Sag & 600 & 40 \\
\hline
\end{tabular}


curves on this alignment. The FHWA model clearly overestimated the visual demand value on each 3D curve. The FHWA model predicted the same visual demand value for s13 at 278.54 meters and c33 at 792.7 meters because both have the same radius, but the observed VD at c33 is actually higher than that at $\mathrm{s} 13$ because of different $\mathrm{K}$ values ( 80 and 40) and curve types (sag and crest). This trend was matched well by the newly developed model. The model developed in this simulation study appears to be much better than the FHWA simulation model.

According to the results of the comparative study, it becomes evident that vertical curvature including either sag curve or crest curve has a significant impact on evaluating visual demand on 3D curves. Age also has a significant impact on evaluating visual demand on either 2D horizontal curves or 3D curves. The primary and main objectives of this research work have been successfully accomplished. The model developed in this study for measuring visual demand appears to be an effective start in evaluating VD with respect to 3D highway geometric parameters. On the other hand, the studies of visual demand related to performance measures did not produce an acceptable result that could be applied to compute an upper and lower limit as thresholds of visual demand for VD evaluation. For this reason, more work is needed to continue driver visual demand evaluation in this area.

Table 18 Test Alignment 7

\begin{tabular}{|c|c|c|c|c|c|c|}
\hline Num & Curve id & $\mathrm{R}(\mathrm{m})$ & $\mathrm{K}$ & $\begin{array}{c}\text { Curve } \\
\text { Length }(\mathrm{m})\end{array}$ & $\begin{array}{c}\text { Start } \\
\text { Distance }(\mathrm{m})\end{array}$ & $\begin{array}{c}\text { End } \\
\text { Distance }(\mathrm{m})\end{array}$ \\
\hline 1 & $\mathrm{~s} 13$ & 300 & 80 & 314.16 & 278.54 & 592.7 \\
\hline 2 & $\mathrm{c} 33$ & 300 & 40 & 314.16 & 792.7 & 1106.86 \\
\hline 3 & $\mathrm{~s} 32$ & 400 & 40 & 418.88 & 1306.86 & 1725.74 \\
\hline 4 & $\mathrm{c} 21$ & 600 & 60 & 628.32 & 1925.74 & 2554.06 \\
\hline
\end{tabular}




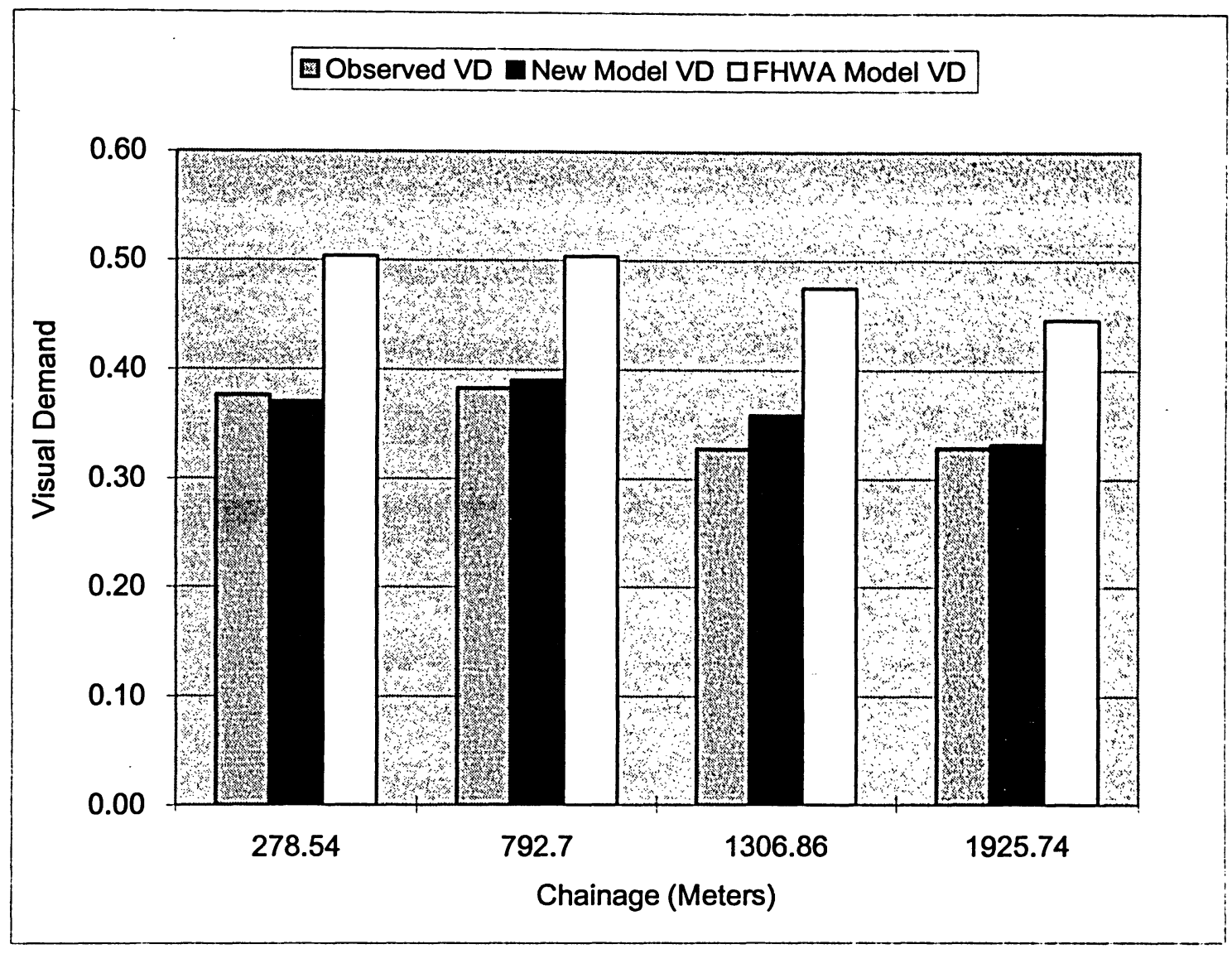

Figure 22 Comparative Study for a specific Curves Combination (Test Alignment 7)

\subsection{Discussion of Visual Demand on Tangents}

Due to the considerable variability existing among subjects, the regression models of VDF, VDH and VD30 on tangents explain only a limited part of the variability ( $\mathrm{r}^{2}=$ $0.3465,0.3476$, and 0.3494 , respectively). Nevertheless, the regression model describes the linear relationship between visual demand and two significant factors: preceding curvature and subject age (see Equations 27-29). This study did not find that grade had a significant impact on visual demand on tangents. One possible reason is that the subjects do not experience real world forces of gravity while driving on a tangent in the simulator. 


\subsubsection{Effect of 3D Curvature}

The impact of 3D curvature on the visual demand of tangents has become clear from the results of this research. The variability of visual demand on tangents was established using the model developed. Figure 23 shows the variation of visual demand with respect to PINVR (inverse of radius of preceding curve). It was observed that the PINVR variable individually causes a significant impact on the evaluation and that it has a high correlation with the observed visual demand values. The rate of change of visual demand due to the influence of PINVR is higher for VD30 and VDH, and lower for VDF. The rate of change of visual demand for VD30 is the same as that for VDH because the PINVR variable causes a similar impact on VD30 and VDH of tangent and causes a lower impact on VDF.

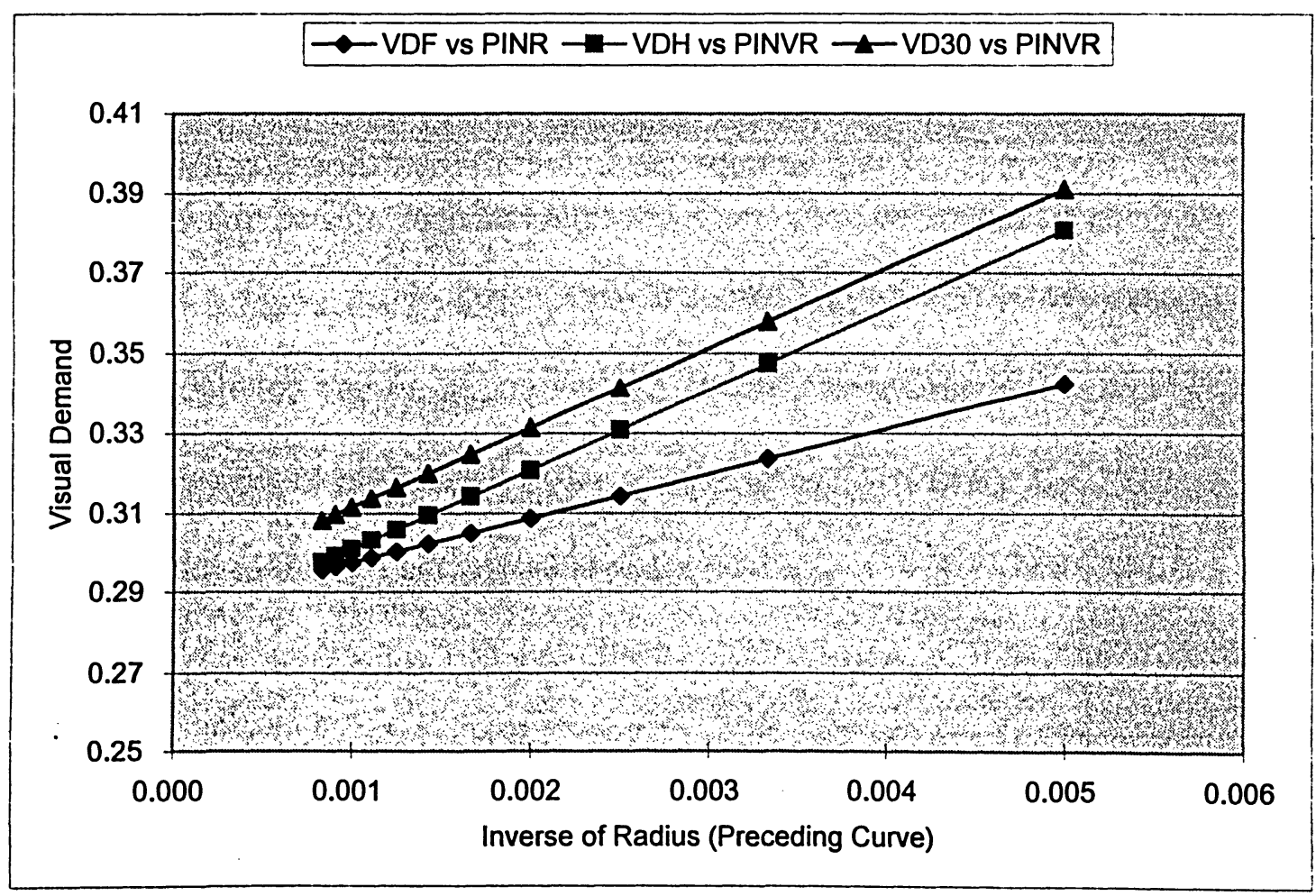

Figure 23 Sensitivity of VD on Tangents with varying Preceding Curve Radius (Subject age $=30 \mathrm{~s}$ ) 


\subsubsection{Effect of Age}

The Age variable had a great impact on the evaluation of visual demand on tangents. The models developed in this study also reflect the impact of the age variable and PINVR. Figure 24 shows the sensitivity of VDF, VDH and VD30 with varying subject age. It clearly indicates that the drivers older than 70 years of age have twice the visual demand on tangents of young drivers. The graph also indicates that VD 30 remains higher than other visual demand values (VDF and VDH). The slope of the VD30 line is much sharper than the others, which indicates that a little variation in the age of the subject has much more influence on VD30 than on VDF and VDH.

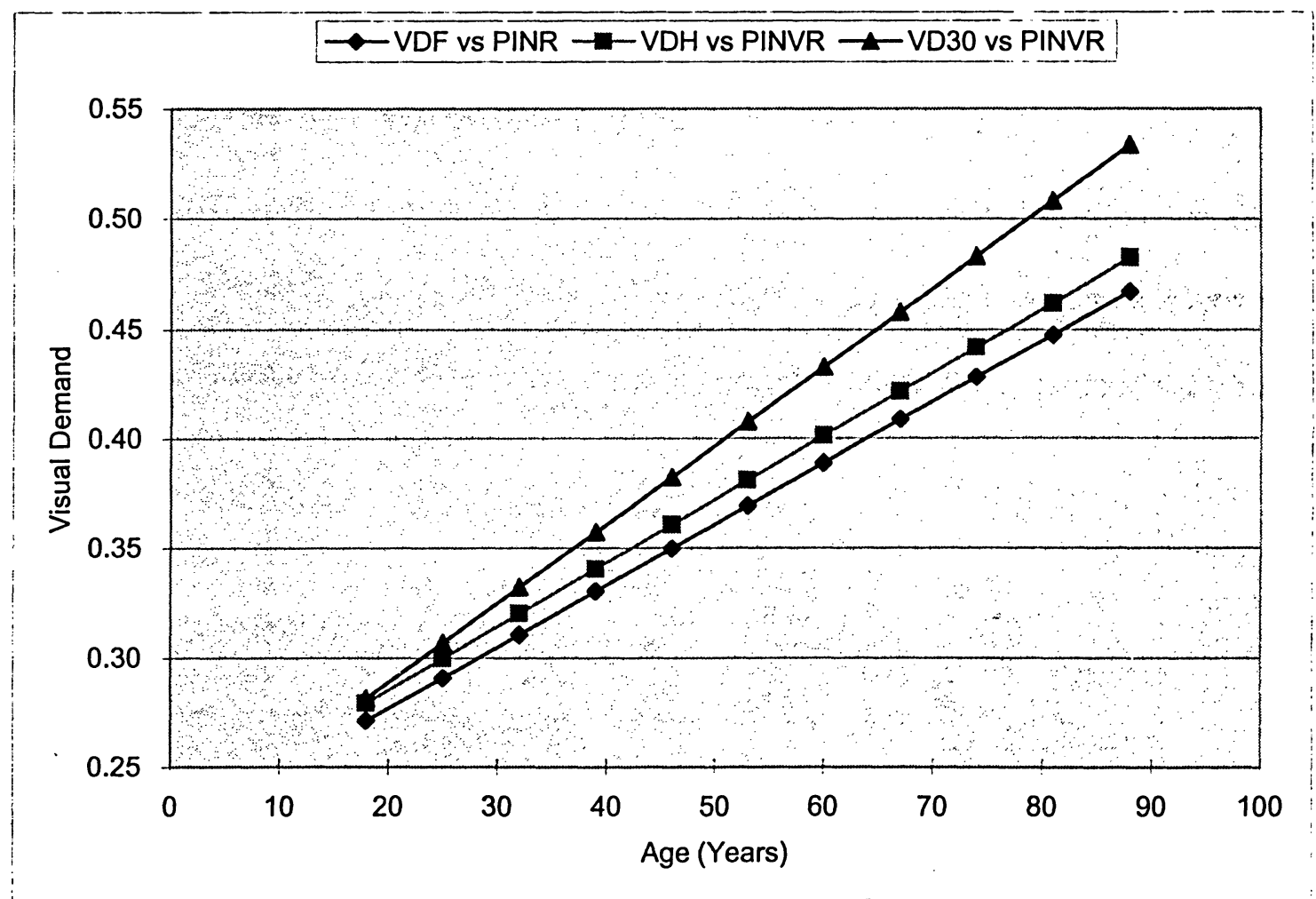

Figure 24 Sensitivity of VD with varying Subject Age (Radius $=600 \mathrm{~m}$ ) 


\section{Chapter 6 MODEL APPLICATION AND VISUALIZATION}

The driving simulation method and the model developed for visual demand on 3D curves all together offer great promise for evaluating visual demand on 3D alignments of real roadways. The applicability of the newly develop model was verified by applying the model to evaluate visual demand in different combinations of $2 \mathrm{D}$ and $3 \mathrm{D}$ elements. In addition, a method for presenting visual demand data using Geographic Information Systems (GIS) is presented.

\subsection{Description of Test Alignments}

Two hypothetical alignments were established: (1) an alignment with five 2D horizontal curves with different radii; and (2) an alignment with ten 3D curves with different radii and $\mathrm{K}$ values. The $2 \mathrm{D}$ horizontal alignment was composed of five horizontal curves with the radii of $300 \mathrm{~m}, 400 \mathrm{~m}$ and $600 \mathrm{~m}$. See Figure 25 for a the plan of this 2D horizontal alignment. The design parameters of this 2D alignment are shown in Table 19.

Table 19 Detailed Geometric Information for 2D Test Alignment

\begin{tabular}{|c|c|c|c|c|c|c|c|}
\hline $\begin{array}{c}\text { Element } \\
\text { No. }\end{array}$ & Feature & $\mathrm{R}(\mathrm{m})$ & $\mathrm{K}$ & $\begin{array}{c}\text { Def Angle } \\
(\text { degree })\end{array}$ & Length (m) & $\begin{array}{c}\text { Start } \\
\text { Distance }(\mathrm{m})\end{array}$ & $\begin{array}{c}\text { End } \\
\text { Distance (m) }\end{array}$ \\
\hline 1 & h3 & 300 & NA & 60 & 314.2 & 200 & 514.2 \\
\hline 2 & Tangent & & & & 200 & 514.2 & 714.2 \\
\hline 3 & h1 & 600 & NA & 60 & 628.3 & 714.2 & 1342.5 \\
\hline 4 & Tangent & & & & 200 & 1342.5 & 1542.5 \\
\hline 5 & h2 & 400 & NA & 60 & 418.9 & 1542.5 & 1961.4 \\
\hline 6 & Tangent & & & & 200 & 1961.4 & 2161.4 \\
\hline 7 & h3 & 300 & NA & 60 & 314.2 & 2161.4 & 2475.6 \\
\hline 8 & Tangent & & & & 200 & 2475.6 & 2675.6 \\
\hline 9 & h1 & 600 & NA & 60 & 628.3 & 2675.6 & 3303.9 \\
\hline
\end{tabular}


The 3D alignment consisted of ten 3D curves with different $R$-values and $\mathrm{K}$-values.

Table 20 shows the design parameters of the $3 \mathrm{D}$ alignment. The tangents between each curve are equal to 200 meters. Figure 26 shows the plan view of the 3D alignment. The operating speed is $80 \mathrm{~km} / \mathrm{h}$.

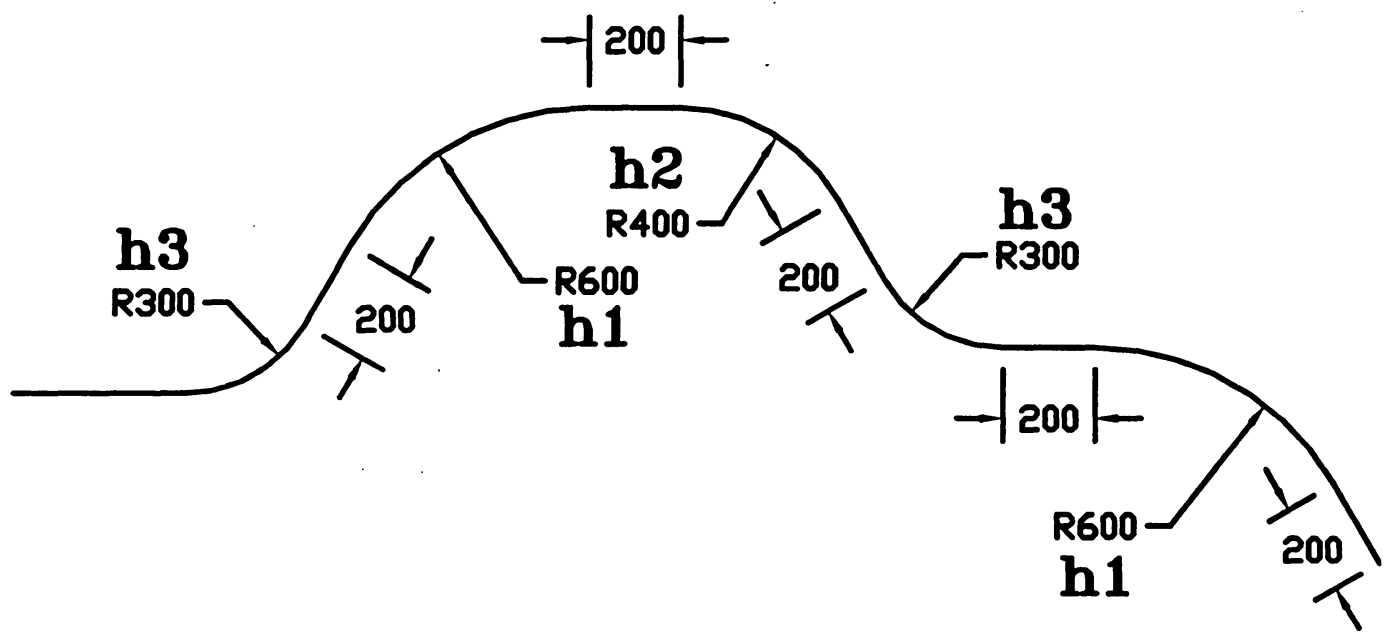

Figure 25 Sketches showing Plan View of 2D Test Alignment

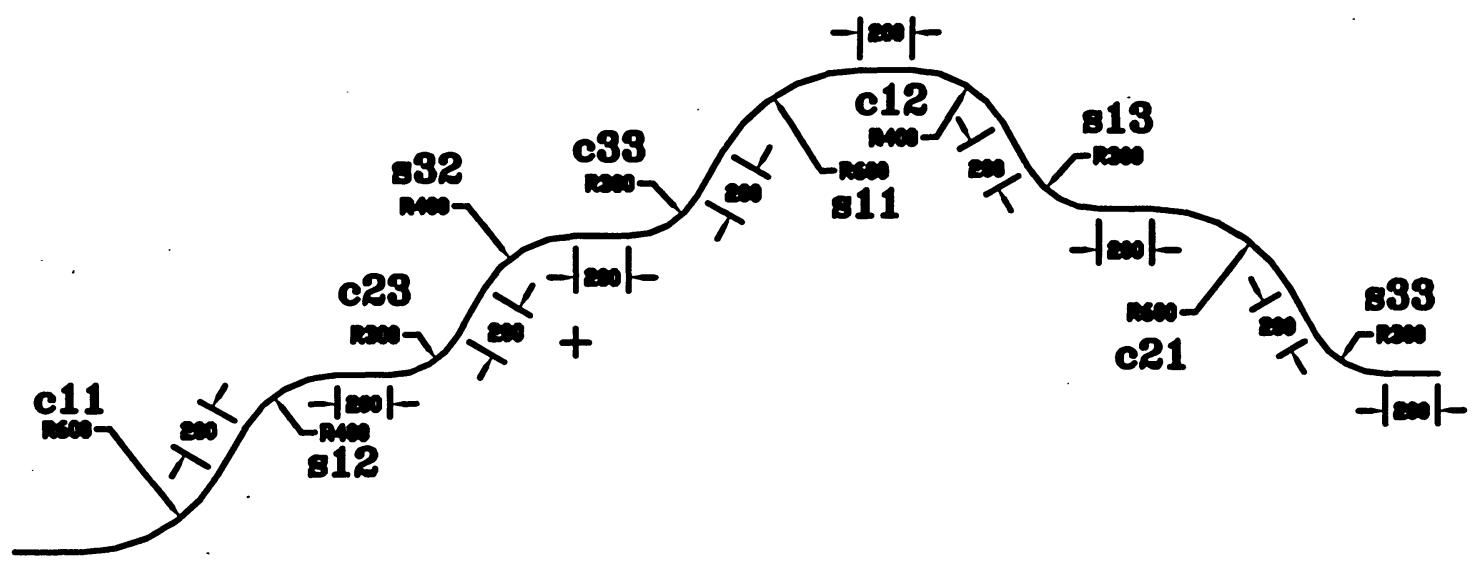

Figure 26 Sketches showing Plan View of 3D Test Alignment 
Table 20 Detailed Geometric Information for 3D Test Alignment

\begin{tabular}{|c|c|c|c|c|c|c|c|c|}
\hline $\begin{array}{c}\text { Element } \\
\text { No. }\end{array}$ & Feature & $\mathrm{R}$ & $\mathrm{K}$ & $\begin{array}{l}\text { Curve } \\
\text { Length } \\
\text { (m) }\end{array}$ & $\begin{array}{c}\text { Start } \\
\text { Distance } \\
\text { (m) }\end{array}$ & $\begin{array}{c}\text { End } \\
\text { Distance } \\
\text { (m) }\end{array}$ & $\begin{array}{c}\text { Start Grade } \\
(\%)\end{array}$ & $\begin{array}{c}\text { End Grade } \\
\qquad(\%)\end{array}$ \\
\hline 1 & c11 & 600 & $\begin{array}{c}80 \\
\text { (Crest) }\end{array}$ & 628.3 & 357.1 & 985.4 & 3.927 & -3.927 \\
\hline 2 & Tangent & & & 200 & 985.4 & 1185.4 & -3.927 & -3.927 \\
\hline 3 & s12 & 400 & $\begin{array}{c}80 \\
\text { (Sag) }\end{array}$ & 418.9 & 1185.4 & 1604.3 & -3.927 & 1.309 \\
\hline 4 & Tangent & & & 200 & 1604.3 & 1804.3 & 1.309 & 1.309 \\
\hline 5 & c23 & 300 & $\begin{array}{c}60 \\
\text { (Crest) }\end{array}$ & 314.2 & 1804.3 & 2118.4 & 1.309 & -3.927 \\
\hline 6 & Tangent & & & 200 & 2118.4 & 2318.4 & -3.927 & -3.927 \\
\hline 7 & s32 & 400 & $\begin{array}{c}40 \\
\text { (Sag) }\end{array}$ & 418.9 & 2318.4 & 2737.3 & -3.927 & 6.545 \\
\hline 8 & Tangent & & & 200 & 2737.3 & 2937.4 & 6.545 & 6.545 \\
\hline 9 & c33 & 300 & $\begin{array}{c}40 \\
\text { (Crest) }\end{array}$ & 314.2 & 2937.4 & 3251.5 & 6.545 & -1.309 \\
\hline 10 & Tangent & & & 200 & 3251.5 & 3451.5 & -1.309 & -1.309 \\
\hline 11 & s11 & 600 & $\begin{array}{c}80 \\
\text { (Sag) }\end{array}$ & 628.3 & 3451.5 & 4079.8 & -1.309 & 6.545 \\
\hline 12 & Tangent & & & 200 & 4079.8 & 4279.8 & 6.545 & 6.545 \\
\hline 13 & c12 & 400 & $\begin{array}{c}80 \\
\text { (Crest) }\end{array}$ & 418.9 & 4279.8 & 4698.7 & 6.545 & 1.309 \\
\hline 14 & Tangent & & & 200 & 4698.7 & 4898.7 & 1.309 & 1.309 \\
\hline 15 & s13 & 300 & $\begin{array}{c}80 \\
\text { (Sag) }\end{array}$ & 314.2 & 4898.7 & 5212.8 & 1.309 & 5.236 \\
\hline 16 & Tangent & & & 200 & 5212.8 & 5412.8 & 5.236 & 5.236 \\
\hline 17 & c21 & 600 & $\begin{array}{c}60 \\
\text { (Crest) }\end{array}$ & 628.3 & 5412.8 & 6041.2 & 5.236 & -5.236 \\
\hline 18 & Tangent & & & 200 & 6041.2 & 6241.2 & -5.236 & -5.236 \\
\hline 19 & s33 & 300 & $\begin{array}{c}40 \\
\text { (Sag) }\end{array}$ & 314.2 & 6241.2 & 6555.3 & -5.236 & 2.618 \\
\hline
\end{tabular}

* The absolute value was used for $\mathrm{K}$ in the visual demand calculation. 


\subsection{Results}

The consistency evaluation results based on the visual demand estimated by the models developed for 3D alignments were compared with the results obtained from the operating speed consistency method presented in Chapter 2. The purpose of the comparison was to determine whether the two methods produce comparable trends in design consistency.

\subsubsection{Results for 2D Horizontal Alignment}

The operating speeds on individual horizontal curves of this 2D test alignment were estimated using the $85^{\text {th }}$ percentile speed equations in Section 2.1.2. The desired speed on tangents is equal to $100 \mathrm{~km} / \mathrm{h}$ according to the recommendation by TAC. After checking $\mathrm{TL}_{\mathrm{c}}$ by using Equations 2-4 in Section 2.1.2, all were found to be long tangents, so the operating speed is $100 \mathrm{~km} / \mathrm{h}$. The operating speed on horizontal curves was calculated using the Type 3 equation in Table 1 (Section 2.1.2).

The visual demand (VDF) for the 2D horizontal test alignment was estimated using the model developed in this study, assuming a middle-aged driver ( 30 years old) driving on a two-lane rural highway. The operating speeds and differences, and the visual demand values are shown in Table 21.

As the maximum difference in operating speeds between the tangent and the curve was $7.1 \mathrm{~km} / \mathrm{h}$, which is just within the acceptable limit of $10 \mathrm{~km} / \mathrm{h}$, the proposed alignment was considered to be acceptable in terms of operating speed. After obtaining an acceptable critical threshold for visual demand, the VD consistency can also be evaluated by quantifying its difference. 
Table 21 Operating Speed and Visual Demand for 2D Test Alignment

\begin{tabular}{|c|c|c|c|c|c|c|c|c|}
\hline \multirow[b]{2}{*}{$\begin{array}{l}\text { Element } \\
\text { No. }\end{array}$} & \multirow{2}{*}{ Feature } & \multirow{2}{*}{$\mathrm{R}(\mathrm{m})$} & \multirow[b]{2}{*}{$\begin{array}{l}\text { Length } \\
\text { (m) }\end{array}$} & \multirow[b]{2}{*}{$\begin{array}{l}\text { Chainage } \\
\text { (m) }\end{array}$} & \multicolumn{2}{|c|}{$\begin{array}{l}\text { Operating Speed } \\
(\mathrm{km} / \mathrm{h})\end{array}$} & \multicolumn{2}{|c|}{ Visual Demand } \\
\hline & & & & & $V_{85}$ & $\begin{array}{l}\mathrm{V}_{85} 1- \\
\mathrm{V}_{85} 2 \\
(\mathrm{~km} / \mathrm{h})\end{array}$ & VDF & $\begin{array}{c}\text { Difference } \\
\times 100\end{array}$ \\
\hline 1 & h3 & 300 & 314.2 & 200 & 92.9 & - & 0.358 & \\
\hline 2 & Tangent & & 200 & 514.2 & 100 & 7.1 & 0.324 & 3.4 \\
\hline 3 & h1 & 600 & 628.3 & 714.2 & 98.9 & 1.1 & 0.311 & 1.3 \\
\hline 4 & Tangent & & 200 & 1342.5 & 100 & 1.1 & 0.305 & 0.6 \\
\hline 5 & $\mathrm{~h} 2$ & 400 & 418.9 & 1542.5 & 95.9 & 4.1 & 0.334 & 2.9 \\
\hline 6 & Tangent & & 200 & 1961.4 & 100 & 4.1 & 0.314 & 2 \\
\hline 7 & $\mathrm{~h} 3$ & 300 & 314.2 & 2161.4 & 92.9 & 7.1 & 0.358 & 4.4 \\
\hline 8 & Tangent & & 200 & 2475.6 & 100 & 7.1 & 0.324 & 3.4 \\
\hline 9 & h1 & 600 & 628.3 & 2675.6 & 98.9 & 1.1 & 0.311 & 1.3 \\
\hline
\end{tabular}

\subsubsection{Result for 3D Alignments}

The 3D test alignment was also analyzed using the methods based on speed consistency and the visual demand estimate. The radii, $\mathrm{K}$ values, grades, start distances and lengths of curves were computed and complied with TAC and AASHTO. The operating speeds on horizontal curves combined with vertical curves were calculated using the equations in Table 1 in Section 2.1.2. The operating speed on each tangent was $100 \mathrm{~km} / \mathrm{h}$.

A driver aged 30 was assumed to drive on the alignment. The results are shown in Table 22. These results show that in the overall alignment, the curve of c33 needs the highest visual demand because it has the sharpest radius and the smallest $\mathrm{K}$ value. Between curve c23 starting from the distance of 1804.3 meters and its following tangent, there is a speed difference of $12.3 \mathrm{~km} / \mathrm{h}$, which is outside the standard for good consistency. The design is considered to be fair rather than good and should be improved. 
Table 22 Operating Speed and Visual Demand for 3D Test Alignment

\begin{tabular}{|c|c|c|c|c|c|c|c|c|c|}
\hline \multirow[b]{2}{*}{ Feature } & \multirow[b]{2}{*}{$R$} & \multirow[b]{2}{*}{$\mathrm{K}$} & \multirow[b]{2}{*}{$\begin{array}{l}\text { Curve } \\
\text { Length } \\
\text { (m) }\end{array}$} & \multirow[b]{2}{*}{$\begin{array}{c}\text { Chainage } \\
\text { (m) }\end{array}$} & \multirow{2}{*}{$\begin{array}{c}\text { Equation } \\
\text { Type used } \\
\text { for } \\
\text { calculating } \\
\text { operating } \\
\text { speed }\end{array}$} & \multicolumn{2}{|c|}{$\begin{array}{l}\text { Operating Speed } \\
\qquad(\mathrm{km} / \mathrm{h})\end{array}$} & \multicolumn{2}{|c|}{ Visual Demand } \\
\hline & & & & & & $\begin{array}{c}\mathrm{V}_{85} \\
(\mathrm{~km} / \mathrm{h})\end{array}$ & $\begin{array}{l}\mathrm{V}_{85} 1- \\
\mathrm{V}_{85} 2 \\
(\mathrm{~km} / \mathrm{h})\end{array}$ & VDF & $\begin{array}{l}\text { Difference } \\
\times 100\end{array}$ \\
\hline $\begin{array}{c}\text { c11- } \\
\text { upgrade }\end{array}$ & 600 & 80 & 628.3 & 357.1 & Type 6 & 92.3 & - & \multirow[t]{2}{*}{0.327} & \\
\hline c11-downgrade & 600 & 80 & 628.3 & 671.3 & Type 6 & 97 & 4.7 & & \\
\hline Tangent & & & 200 & 985.4 & Long tangent & 100 & 3 & 0.305 & 2.2 \\
\hline s12 & 400 & 80 & 418.9 & 1185.4 & Type 5 & 96.7 & 3.3 & 0.346 & 4.1 \\
\hline Tangent & & & 200 & 1604.3 & Long tangent & 100 & 3.3 & 0.314 & 3.2 \\
\hline $\begin{array}{c}\text { c23- } \\
\text { upgrade }\end{array}$ & 300 & 60 & 314.2 & 1804.3 & Type 6 & 87.7 & 12.3 & \multirow{2}{*}{0.380} & \multirow{2}{*}{6.5} \\
\hline $\begin{array}{c}\text { C23- } \\
\text { downgrade }\end{array}$ & 300 & 60 & 314.2 & 1961.4 & Type 6 & 91.8 & 4.1 & & \\
\hline Tangent & & & 200 & 2118.4 & Long tangent & 100 & 8.2 & 0.324 & 5.6 \\
\hline s32 & 400 & 40 & 418.9 & 2318.4 & Type 5 & 96.7 & 3.3 & 0.358 & 3.5 \\
\hline Tangent & & & 200 & 2737.3 & Long tangent & 100 & 3.3 & 0.314 & 4.4 \\
\hline c33 & 300 & 40 & 314.2 & 2937.4 & Type 7 & 91.3 & 8.7 & 0.39 & 7.6 \\
\hline Tangent & & & 200 & 3251.5 & Long tangent & 100 & 8.7 & 0.324 & 6.7 \\
\hline s11 & 600 & 80 & 628.3 & 3451.5 & Type 5 & 99.6 & 0.4 & 0.323 & 0.12 \\
\hline Tangent & & & 200 & 4079.8 & Long tangent & 100 & 0.4 & 0.305 & 1.8 \\
\hline $\begin{array}{l}\text { c12- } \\
\text { upgrade }\end{array}$ & 400 & 80 & 418.9 & 4279.8 & Type 6 & 90 & 10 & \multirow{2}{*}{0.35} & \multirow{2}{*}{4.6} \\
\hline $\begin{array}{c}\text { C12- } \\
\text { downgrade }\end{array}$ & 400 & 80 & 418.9 & 4489.3 & Type 6 & 94.4 & 4.4 & & \\
\hline Tangent & & & 200 & 4698.7 & Long tangent & 100 & 5.6 & 0.314 & 3.6 \\
\hline s13 & 300 & 80 & 314.2 & 4898.7 & Type 5 & 93.9 & 6.1 & 0.37 & 5.6 \\
\hline Tangent & & & 200 & 5212.8 & Long tangent & 100 & 6.1 & 0.324 & 4.7 \\
\hline $\begin{array}{l}\text { c21- } \\
\text { upgrade }\end{array}$ & 600 & 60 & 628.3 & 5412.8 & Type 6 & 92.3 & 7.7 & \multirow{2}{*}{0.332} & \multirow{2}{*}{0.8} \\
\hline $\begin{array}{c}\text { C21- } \\
\text { downgrade }\end{array}$ & 600 & 60 & 628.3 & 5727 & Type 6 & 97 & 4.7 & & \\
\hline Tangent & & & 200 & 6041.2 & Long tangent & 100 & 3 & 0.305 & 2.7 \\
\hline s33 & 300 & 40 & 314.2 & 6241.2 & Type 5 & 93.9 & 6.1 & 0.382 & 7.7 \\
\hline
\end{tabular}




\subsection{Discussion}

For the 2D horizontal alignment, the results in Table 21 show that visual demand increases as the radius of the curvature decreases, and that visual demand increases linearly with the inverse of radius. In this case, the maximum visual demand requirement exists on the curve with the $300 \mathrm{~m}$ radius. Table 21 shows that operating speed increases from the curve to the following tangent, and decreases from the preceding tangent to the curve. In contrast, visual demand decreases from the curve to the following tangent, and increases from the preceding tangent to the curve. Obviously, the single and independent value of either operating speed or visual demand for individual element is not a good measure for evaluating the design quality of the highway.

Based on the design consistency concept, the differences in operating speed and VD were generated and compared, as shown in Figures 27 and 28. The two profiles, one for operating speed and the other for visual demand, are quite similar and well matched with each other. Although the threshold values for visual demand were not previously established, the new finding using the visual demand consistency evaluation can be supported by the speed consistency evaluation, and a similar result could be acquired. The findings show that visual demand measurement has very good potential as a design consistency rating measure if visual demand threshold values indicating limits are developed.

The results of the 3D alignment show that visual demand increases as the radius of the horizontal curvature becomes smaller and as the $\mathrm{K}$ value of the vertical curvature becomes smaller. With the same radius and $\mathrm{K}$ value, the visual demand for the horizontal overlapping with crest curve is higher than that for the horizontal overlapping with sag 


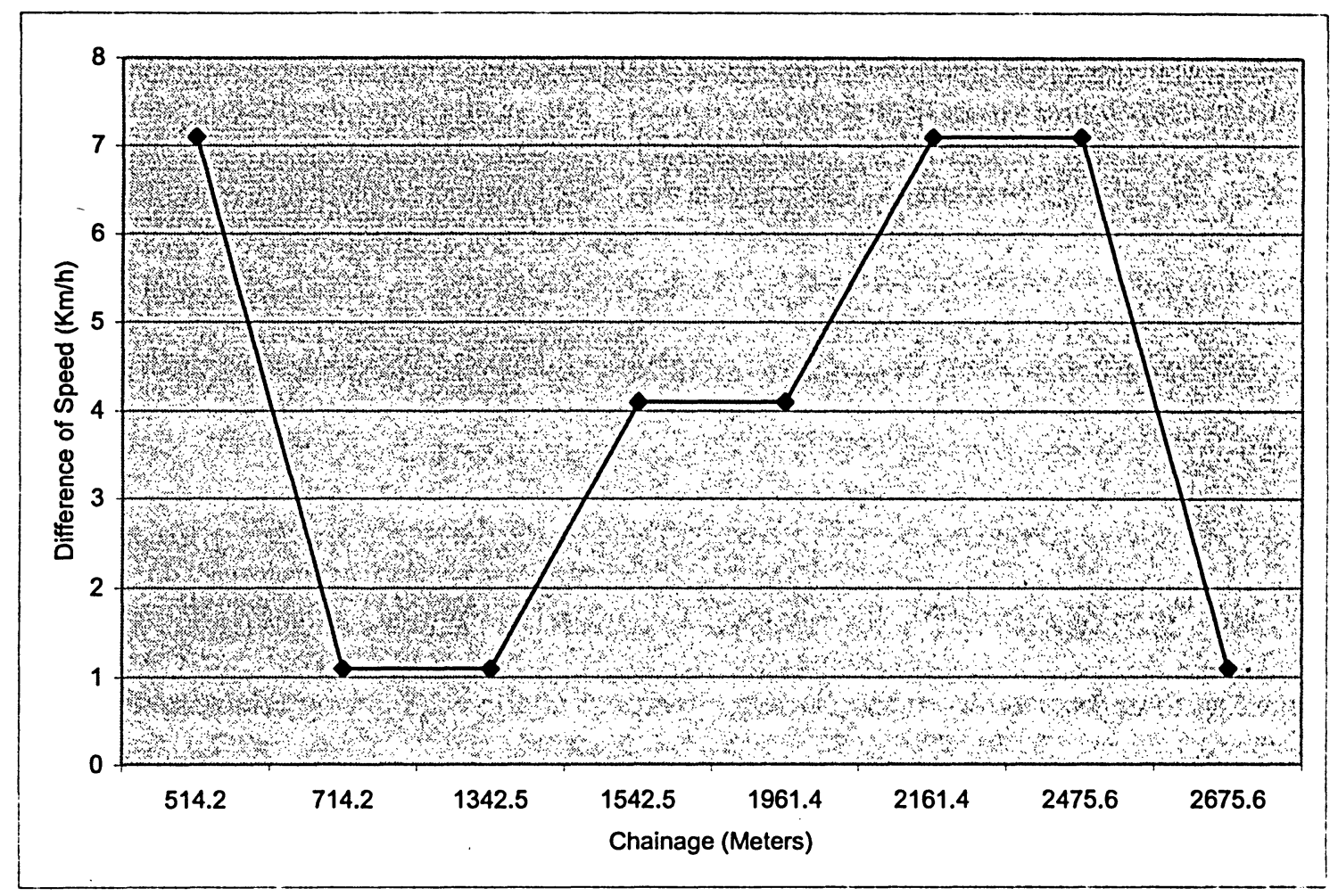

Figure 27 Difference of Speed Profile for 2D Test Alignment

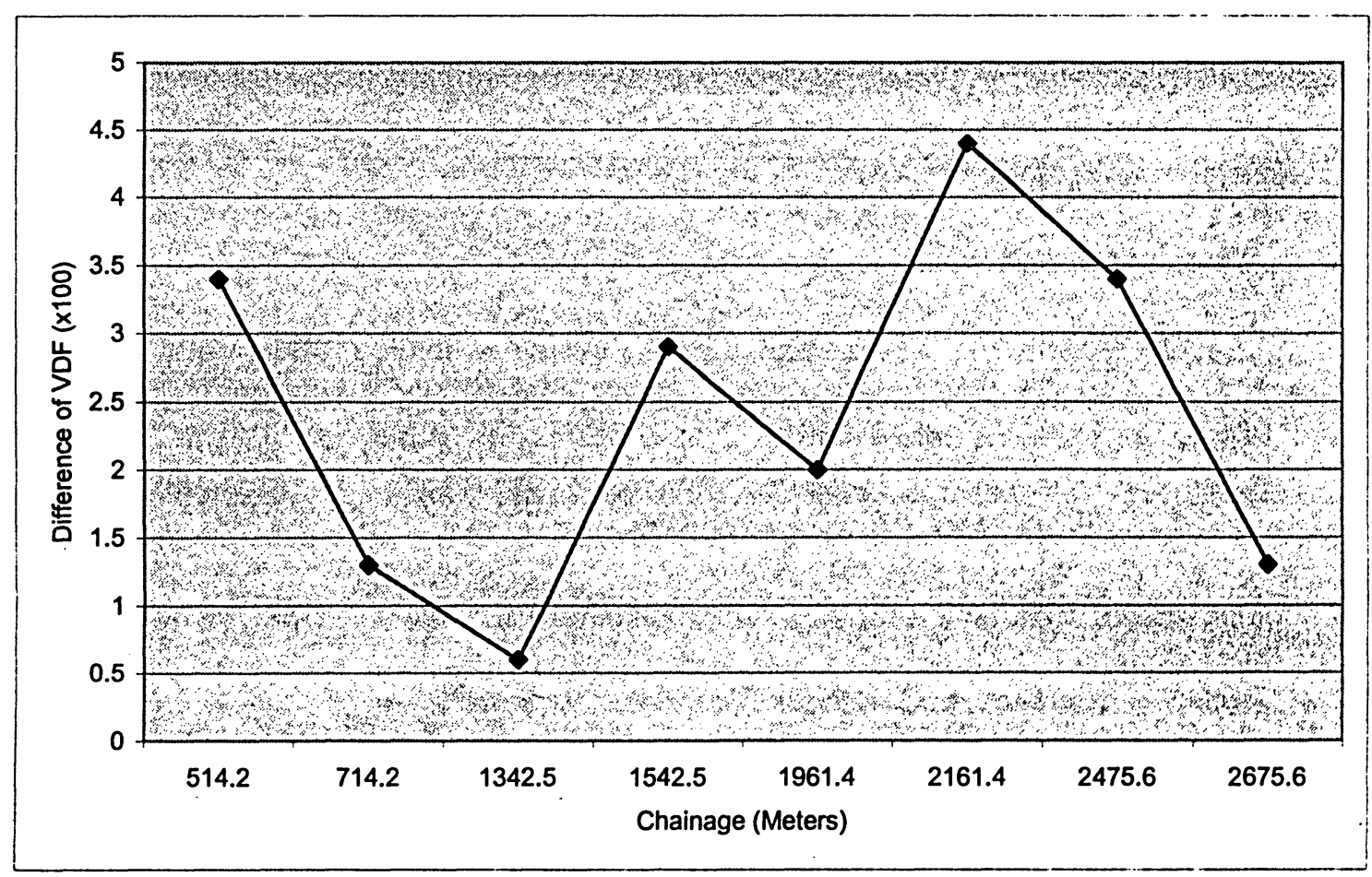

Figure 28 Difference of Visual Demand Profile for 2D Test Alignment 
curve. Since several previous driver workload studies have indicated that high driver workload results in an increased potential for accidents, the most dangerous location is on curve c33 at 2937.4 meters. This curve, has the smallest radius and $\mathrm{K}$ value and the largest difference in visual demand value.

Although the analysis for operating speed shows the opposite result from the analysis for visual demand, the consistency analysis with respect to the difference of value including speed and visual demand shows a similar trend in both profiles (Figures 29 and 30). For this point, the analysis for 3D test alignment clearly shows the same result as that obtained from the $2 \mathrm{D}$ test alignment analysis. A strong relationship between speed consistency and visual demand consistency could be established. A well-defined limit with respect to the acceptable variation of visual demand could then be produced for evaluating an acceptable design by using the visual demand determination method.

The driver workload models developed in this study produce more sensitive results than those produced by other models, because the models developed include more geometric features such as the vertical curvature.

The following important points arise from the above discussion:

- The visual demand method and model developed in this study highlight the 3D nature of highway alignments. These $3 \mathrm{D}$ issues were not addressed in earlier models used to evaluate design consistency.

- The speed difference and the visual demand difference are useful for evaluating design consistency, and both profiles match very well. 


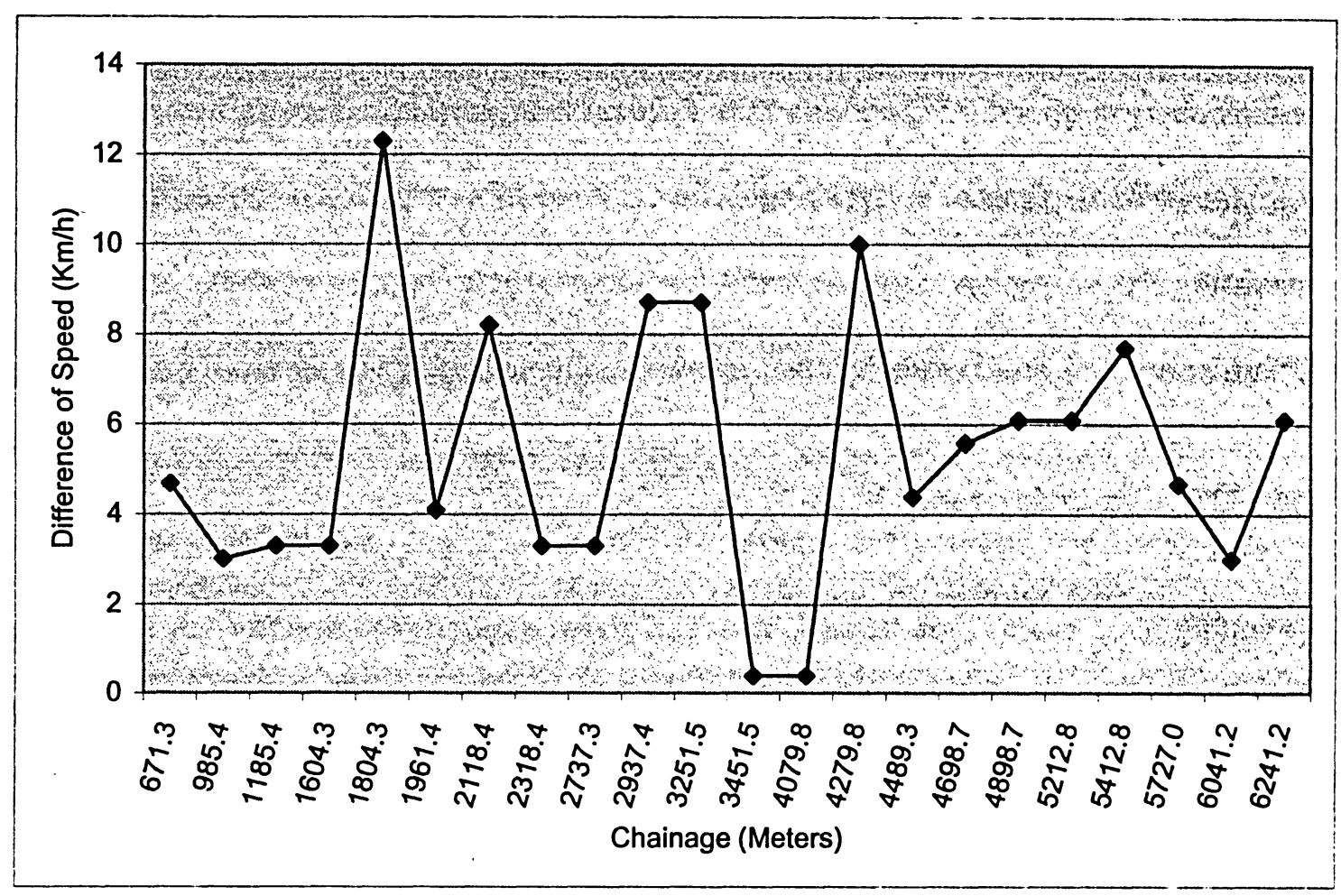

Figure 29 Difference of Speed Profile for 3D Test Alignment

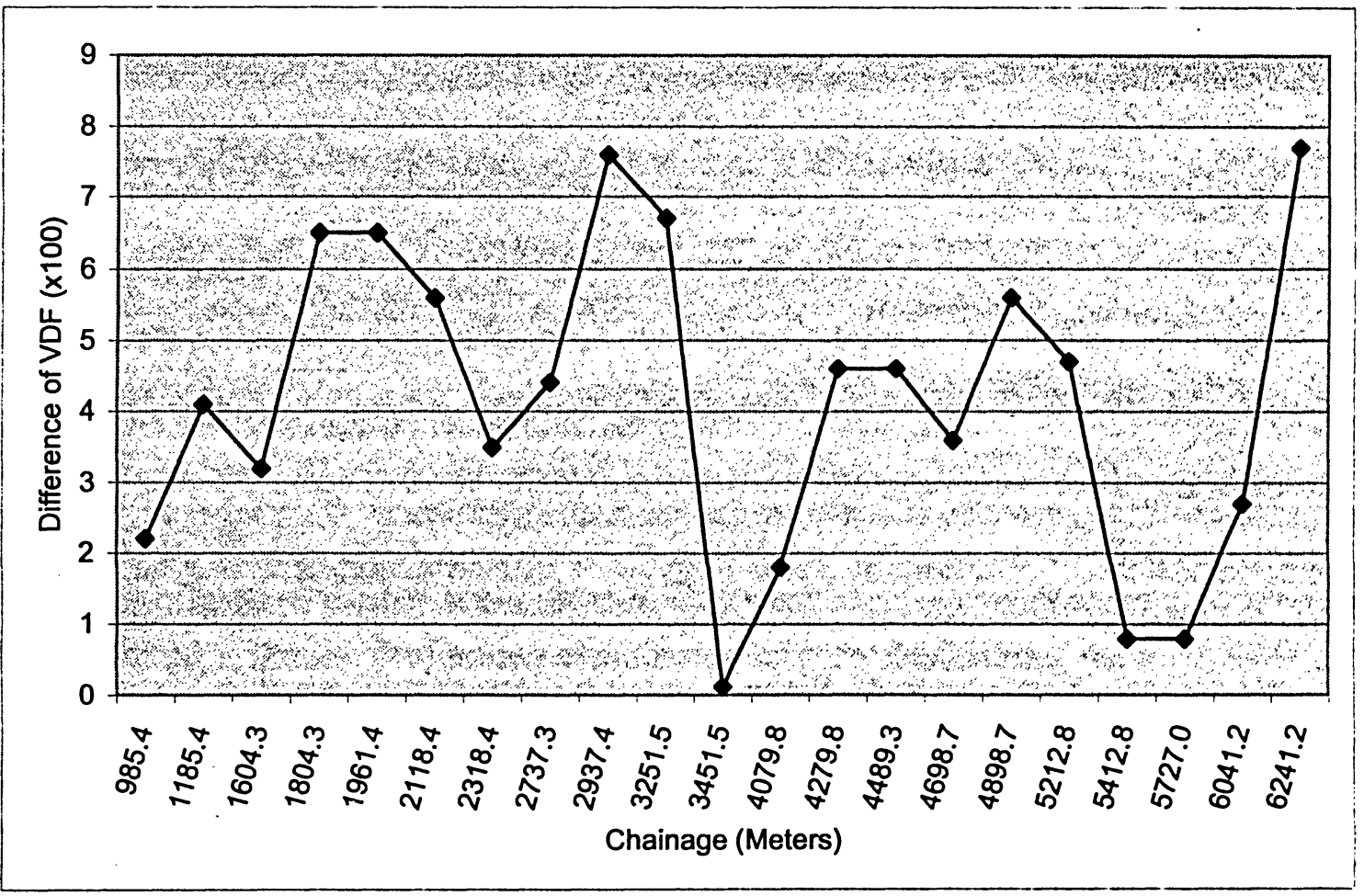

Figure 30 Difference of Visual Demand Profile for 3D Test Alignment 
In conclusion, the workload consistency results could be supported by comparing the difference in operating speeds and the difference in visual demand values. In the same way, the critical threshold for visual demand consistency could be established by comparing the changing trend in the difference of operating speeds with that of visual demand.

\subsection{GIS Visualization}

A limited number of techniques have been developed and applied to present highway alignments and relevant information such as vehicle speed, driver visual demand and vehicle operation stability. The most popular technique is a graphical presentation to show the $2 \mathrm{D}$ plan or vertical profile of a road, but this approach fails to present the $3 \mathrm{D}$ nature of location-based visual demand information. New techniques have been developed to present 3D highway alignments and related location-based information, such as driver visual demand and vehicle speed.

\subsubsection{Background}

Geographic Information Systems (GIS) is a computer system capable of assembling, storing, manipulating, and displaying geographically referenced information, i.e., data identified according to their locations (USGS 1997). Today, GIS has become an important field of information technology (IT) infrastructure, and has been broadly applied in many areas such as transportation, environment, military, agriculture and energy.

The object of visual data analysis is to use graphics to assist in data exploration and the development of ideas in scientific investigation (Unwin et al. 1994). The emphasis of 
visualization is on the exploratory analysis of information by means of symbolic-togeometric transformation, interactive data manipulation and display, graphical rendering, and so on (Jiang and $\mathrm{Li} 2001$ ). The objective of visualization is to produce visual images that can effectively utilize the ability of the human visual system to identify spatial patterns and processes in spatial problem solving and decision making (Robertson 1988). Human factors research has shown that 50 percent of the brain's neurons are involved in vision, and it is believed that 3D displays stimulate more neurons and involve a larger portion of the brain in the problem solving process (Albert and Yeung 2002). Thus a 3D spatial model suggests much more information than the 2D chart or graphic we are familiar with.

\subsubsection{Visualization of 3D Highway Alignments}

Compared with the CAD 3D technique, one of the main benefits of GIS 3D visualization is that it provides a simple, fast and accurate method to build the models of 3D highway alignments and relevant information such as visual demand. Using Adding Route Events (ESRI 1999), Extruding, and 3D analysis, the location information and especially the elevation and grade value controlled by the $\mathrm{K}$ value on vertical alignments, can be accurately presented in the GIS 3D system.

To introduce $3 \mathrm{D}$ visualization technology applied in a driver workload study, a PolylineM Shape file of a six-mile two-lane rural highway in the State of Georgia (U.S.A.) was obtained to present the visual demand information on the 3D highway network model. The GIS PolylineM Shape file of this highway was opened on a 2D View window. As the two-and-half dimensional spatial modeling system, GIS is unable to create the 3D line model directly. Fortunately, based on the Measured Polyline type, the 
Adding Route Events function can be applied to create a series of 2D location points along this. highway. If the density of the points is high enough, it will appear as a 3D spatial line, as shown in Figure 31.

\subsubsection{Visualization of Driver Visual Demand}

The visual demand data output from the driving simulator has been recorded based on the distance along the highway alignments, as shown in Table 23. The visual demand data with the distance information can be posted in ArcView-GIS 2D view by using the Adding Route Events function to create a series of location 2D points along the highway alignment. Then, the $2 \mathrm{D}$ points can be extruded to be the $3 \mathrm{D}$ columns, the heights of which represent the value of visual demand (Figure 32).

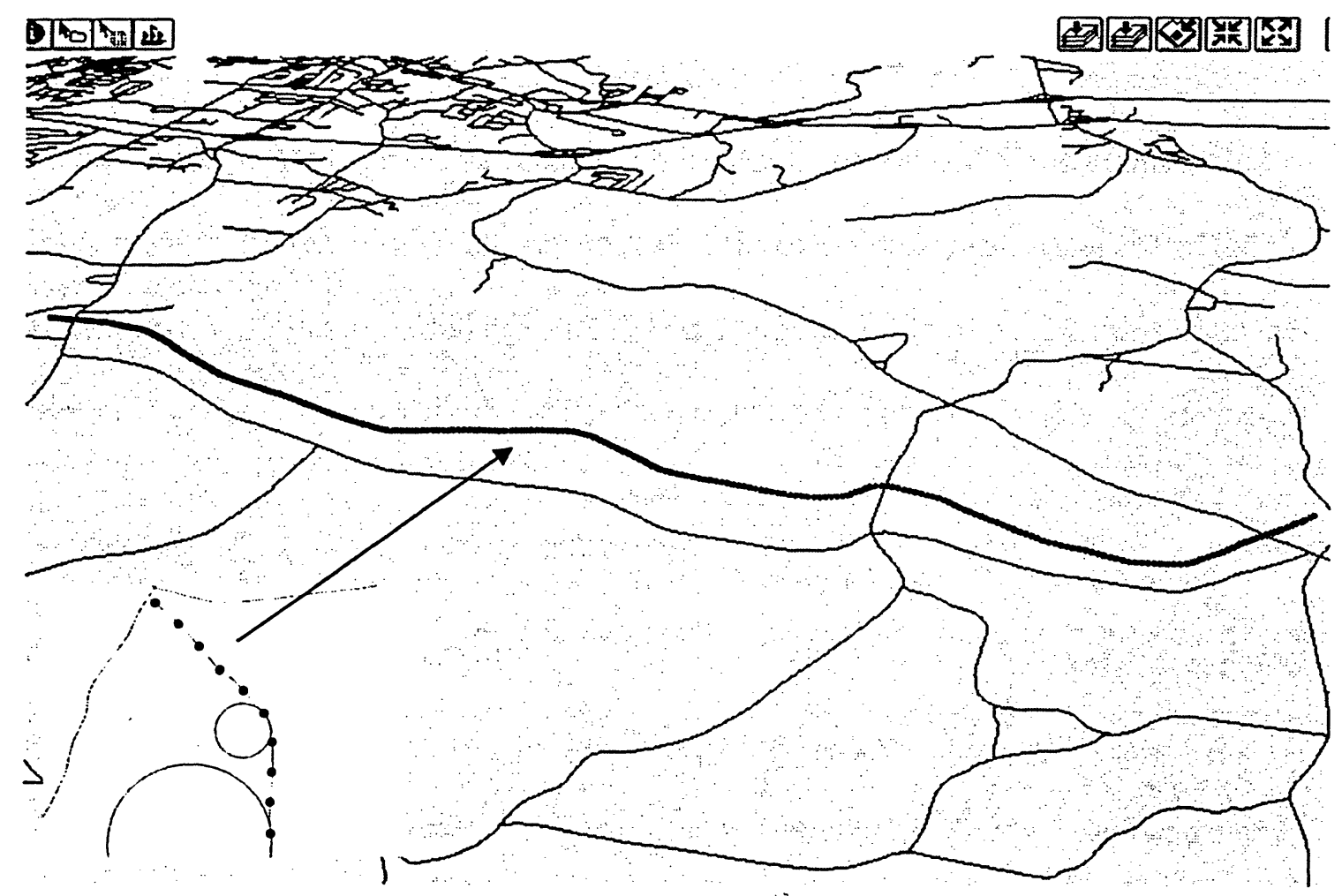

Figure 31 3D Visualization Model of Highway Alignment 
Table 23 Visual Demand Information along the Highway Alignment

\begin{tabular}{|c|c|c|}
\hline Time (s) & Distance $(\mathrm{m})$ & VD \\
\hline 0.6 & 12.96 & 0.1832 \\
\hline 3.3 & 72.95 & 0.185185 \\
\hline 5.9 & 130.72 & 0.192308 \\
\hline 8.7 & 192.94 & 0.178571 \\
\hline 11.3 & 250.71 & 0.192308 \\
\hline 12.7 & 281.84 & 0.357143 \\
\hline 14.3 & 317.69 & 0.3125 \\
\hline 16 & 355.75 & 0.294118 \\
\hline 17.9 & 398.25 & 0.263158 \\
\hline 19 & 422.81 & 0.454545 \\
\hline 20.5 & 456.32 & 0.333333 \\
\hline 22.2 & 494.34 & 0.294118 \\
\hline 23.9 & 532.4 & 0.294118 \\
\hline
\end{tabular}

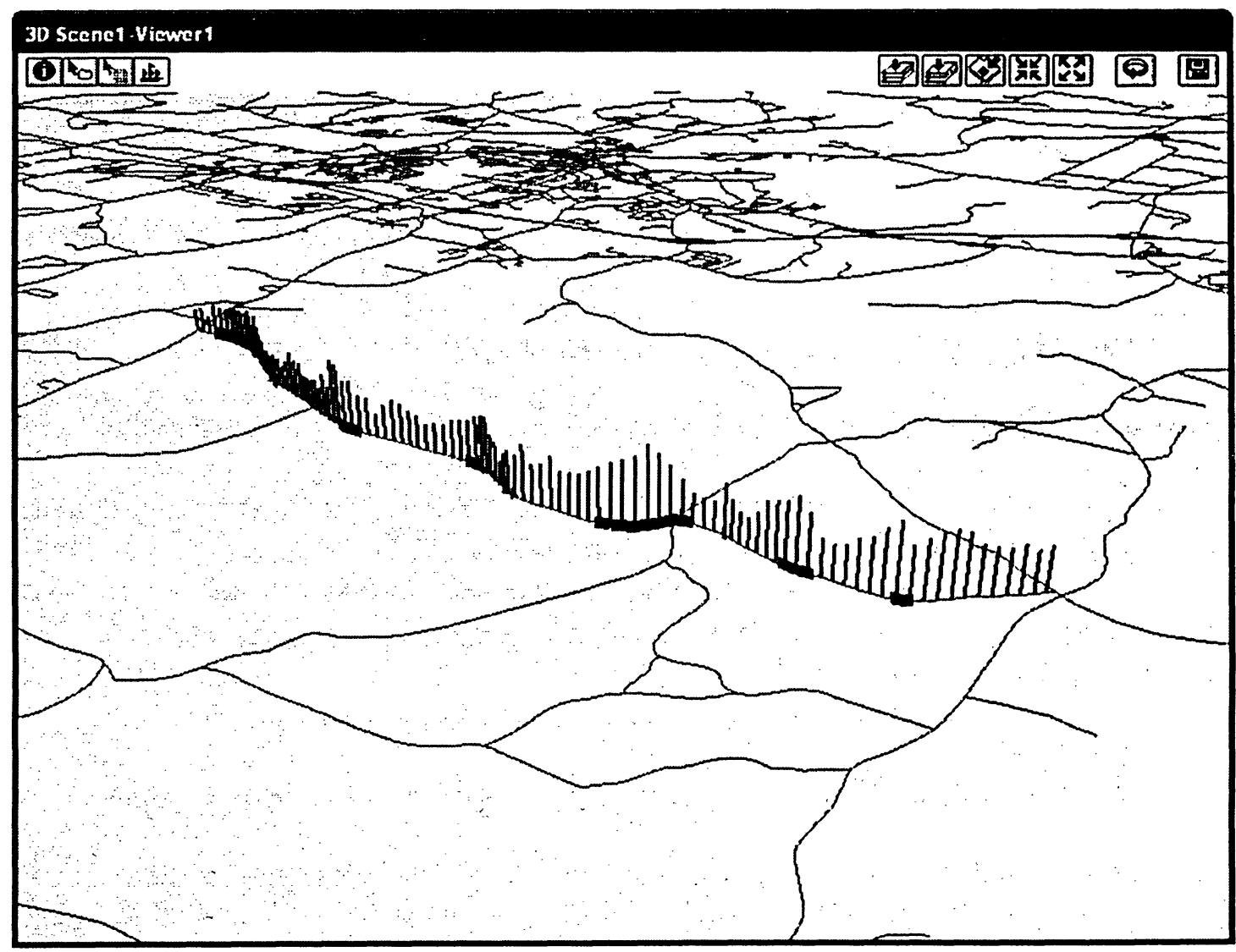

Figure 32 3D Visualization Model of Visual Demand on Highway Alignment 
Using GIS 3D modeling, the variation in visual demand can be posted on the highway network to examine the effects of the curve, curve combinations, tangents, intersections and other environmental elements contributing to visual demand. As shown in Figure 32, the dark sections of highway are curves on which the visual demand values are obviously higher than the visual demand values on tangents.

Another benefit of GIS 3D modeling is the improved management of visual demand information. It helps visualize, manipulate, analyze and present visual demand information or other information that is tied to a spatial location on 3D highway alignments, and gives one a better understanding of the 3D highway alignment and its relevant information. It links information about where things are with information about what things are like. A GIS can link data sets such as visual demand information and speed information together by common linear locations along the highway alignment. By creating a shared database one department can benefit from the work of another, data can be collected once and used many times.

Therefore, GIS and 3D visualization techniques can be applied to develop an advanced visual demand information management system, which includes the complete visual demand information and speed information database. The 2D mapping system and 3D visualization models are integrated to provide evaluation of visual demand consistency and operating speed consistency. 


\section{Chapter 7 CONCLUSIONS AND RECOMMENDATIONS}

\subsection{Conclusions}

The conventional methods for evaluating driver visual demand and workload can deal with only 2D horizontal alignments. The purpose of this research was to examine the effects of 3D alignments (combined horizontal and vertical alignments) on driver visual demand. The experimental design and evaluation procedure used were developed in this research. The simulation results have clearly shown that 3D alignments have a significant effect on visual demand. As Easa et al. (2002) have suggested, 3D highway alignment issues must be addressed using 3D modeling.

This research has shown that the effects of radius of horizontal curve and the $\mathrm{K}$ parameter of vertical curves on visual demand are statistically significant. The visual demand for the 3D alignments was linearly related to the inverse of $\mathrm{K}$ and the inverse of $R$. The results showed that the preceding grade of the 3D curve did not have a significant effect on visual demand. The following findings are highlighted:

- Current models of visual demand on 2D curves are not applicable to evaluate visual demand on 3D curves. Vertical curves (crest or sag) had a positive influence on visual demand. Visual demand linearly increases as the inverses of $\mathrm{K}$ or $\mathrm{R}$ increases, as expected. Meanwhile, the model developed in this study can be used for evaluating visual demand for 2D horizontal alignments, which can be considered a special case of $3 \mathrm{D}$ alignments with $1 / \mathrm{K}=0$. The visual demand resulting from this simulator experiment was very close to that of an on-road test and test track study reported in the literature. The driving simulator 
can be used to obtain objective measurements of driver visual demand on 3D highway alignments.

- The simulation results showed that age has a significant effect on visual demand. A driver older than 65 experiences $35-40 \%$ more workload on 3D alignments than a young driver does.

- In tangent models, the inverse of the preceding radius and age are two significant factors. The significant effect of the inverse of the preceding radius has been reported for complex horizontal alignments (Easa and Ganguly 2004).

- The application results showed that the workload consistency method can be supported by the operating speed consistency method. Therefore, driver visual demand has very good potential as a design consistency rating measure. The visual occlusion method is sensitive to changes in road geometry and is a promising measure of measuring driver workload.

- The GIS virtual reality technique should be applied to visualize the locationbased visual demand information on the $3 \mathrm{D}$ highway network, for the purpose of data query, consistency evaluation, road safety analysis, and decisionmaking.

\subsection{Recommendations}

The following recommendations are made based on this research:

- The visual demand models on 3D alignments have been developed for an operating speed of $80 \mathrm{~km} / \mathrm{h}$. Previous studies have indicated that the variation of operating speed has an immense impact on visual demand. Therefore, future research should evaluate the effect of operating speed on visual demand for 3D 
alignments by conducting similar experiments with different speeds.

- Lane width has played a significant role in modeling visual demand on 2D horizontal curves, so it is expected to have a similar effect on visual demand on 3D alignment. The visual demand model developed in this study is based on an environment of two-lane rural highway with a $3.6 \mathrm{~m}$ land width. Hence, visual demand models, incorporating various highway types, land width and shoulders width, should be developed.

- These research findings are a start at evaluating the effect of 3D highway alignments when considered alone as a geometric parameter, without traffic flow, pedestrians, intersections, signs and pavement markings. These factors are expected to affect visual demand. Thus a visual demand study for 3D highway alignments that include the preceding factors should be conducted.

- Features of the driving simulator in this study were set up to imitate the driving environment during daytime. Previous research has found that driver performance in daytime is different from that at nighttime. For this reason, an experiment could be conducted to evaluate visual demand on 3D alignments for driving at nighttime. 


\section{REFERENCES}

Albert, K. and Yeung, W. (2002). Concepts and Techniques of Geographic Information Systems. Prentice-Hall Inc., Upper Saddle River, New Jersey.

Blaauw, G.J. (1985). Vehicle Guidance by Delineation Systems at Night. Ergonomics, 28 (12), 1601-1615.

Choureiri, E.M., Lamm, R., Kloeckner, J.H., and Mailaender, T. (1994). Safety Aspects of Individual Design Elements and their interaction on Two-Lane Rural Highways: International perspective. Transportation Research Record 1445, 3446.

Cooper, G.E. and Harper, R.P. (1969). The Use of Pilot Rating in the Evaluation of Aircraft Handling Qualities. National Aeronautics and Space Administration, Ames Research Center, NASA TN-D-5153, Moffett Field, California.

Easa, S.M. (1991). Sight Distance Model for Unsymmetrical Sag Curves. Transportation Research Record 1303, 51-62.

Easa, S.M. (1994). Design Considerations of Highway Reverse Curves. Transportation Research Record 1445, 1-11.

Easa, S.M. (2003). Improved Speed Profile Model for Two-lane Highways. Canadian Journal of Civil Engineering, 30(6), 1055-1065.

Easa, S.M. and Dabbour, E. (2003). Design Radius Requirements for Simple Horizontal Curves on Three-dimensional Alignments. Canadian Journal of Civil Engineering, $30(6), 1022-1033$.

Easa, S.M. and Ganguly, C. (2004). Evaluation of Driver Mental Workload on Complex Highway Alignments. Journal of Transportation Engineering, ASCE, (in press). 
Easa, S.M. and He, W.L. (2004). Evaluation of Driver Visual Demand on ThreeDimensional Highway Alignments. Canadian Journal of Civil Engineering (under review).

Easa, S.M. (2004). Design Consistency. In Chapter 1.4, Geometric Design Guide for Canadian Roads, Transportation Association of Canada, Ottawa, Ontario.

Easa, S.M., Strauss, T.R., Hassan, Y., and Souleryette, R.R. (2002). Three-Dimensional Transportation Analysis: Planning and Design. Journal of Transportation Engineering, ASCE, 128(3), 250-258.

ESRI, (1999). Getting to know ArcView GIS: the Geographic Information System for Everyone. ESRI Press, Redlands, CA.

Farber, E. and Gallagher, V. (1972). Attentional Demand as a Measure of the Influence of Visibility Conditions on Driving Task Difficulty. Highway Research Record, No. 414, $1-5$.

Fitzpatrick, K., Wooldridge, M.D., Tsimhoni, O., Collins, J.M., Green, P., Bauer, K.M., Parma, K.D., Harwood, D.W. et al. (1999). Alternative Design Consistency Rating Methods for Two-Lane Rural Highways. FHWA-RD-99-173, Washington, D.C. Gibreel, G.M., Easa, S.M., Hassan, Y., and Al-Dimeery, I.A. (1999). State of the Art of Highway Geometric Design Consistency. Journal of Transportation Engineering, ASCE, 125, 305-313.

Glennon, J.C. and Harwood, D.W. (1978). Highway Design Consistency and Systematic Design Related to Highway Safety. Transportation Research Record 681, 77-88. Godthelp, J., Blaauw, G.J., and Milgram, P. (1984). Supervisory Behaviour in Automobile Driving: New Approaches in Modeling Vehicle Control. XX FISITA 
Congress, Society of Automotive Engineers, Warrendale, PA: 3.255-2.265.

Hassan, Y. and Easa, S.M. (1998). Sight Distance Red Zones on Combined Horizontal and Sag Vertical Curves. Canadian Journal of Civil Engineering, 25(4), 621-630.

Hassan, Y., Easa, S.M., and Abd El Halim, A.O. (1998). State-of-the-Art of ThreeDimensional Highway Geometric Design. Canadian Journal of Civil Engineering, 25(3), 500-511.

Hassan, Y., Gibreel, G., and Easa, S.M. (2000). Evaluation of Highway Consistency and Safety: Practical Application. Journal of Transportation Engineering, ASCE, 126, 193-201.

Hassan, Y. and Easa, S.M. (2003). Effect of Vertical Alignment on Driver Perception of Horizontal Curves. Journal of Transportation Engineering, ASCE, 129(4), 399407.

Hicks T.G. and Wierwille, W.W. (1979). Comparison of Five Mental Workload Assessment Procedures in a Moving Base Driving Simulation, Human Factors, 21 (2), 129-144.

Janikula, T. and Garrick, N. W. (2002). Three-Dimensional Visualization Approach to Illustrating Esthetic Concepts for Highway Design. Transportation Research Record 1796, 35-40.

Jiang, B. and Li, H. (2001). An Integration of GIS, Virtual Reality and the Internet for Visualization, Analysis and Exploration of Spatial Data. Geographical Information Science, 15, 439-456.

Knowles, W.B. (1963). Operator Loading Tasks. Human Factors, 5 (2), 155-161.

Krammes, R.A. and Glascock, S.W. (1992). Geometric Inconsistency and Accident 
Experience on Two-lane Rural Highways. Transportation Research Record 1356, $1-10$.

Krammes, R.A., Brackett, R.Q., and Shafer, M.A. (1995). Driver Mental Workload as a Measure of Geometric Design Consistency for Horizontal Curves. $74^{\text {th }}$ TRB Meeting, Washington, D.C.

Krammes, R., Brackett, R.O., Shafer, M., Ottesen, J., Anderson, I., Fink, K., Collins, K., Pendleton, O., and Messer, C. (1995). Horizontal Alignment Design Consistency for Rural Two-Lane Highways. Federal Highway Administration, Washington, , D.C.

Lamm, R., Chouerri, E.M., and Hayward, J.C (1988). Tangent as an independent Design Element. Transportation Research Record 1195, 123-131.

Lamm, R., Choueiri, E.M., and Soilemezoglou, G. (1995). A Practical Safety Approach to Highway Geometric Design. International Symposium on Highway Geometric Design Practices, Boston, Massachusetts.

Leisch, J.e. and Leisch, J.P. (1977). New Concepts in Design Speed Application. Transportation Research Record 631, 5-14.

McLean, J. R. and Hoffmann, E.R. (1975). Steering reversals as a measure of driver performance and steering task difficulty. Human Factors, 17(3), 248-256.

Messer, C.J. (1980). Methodology for Evaluating Geometric Design Consistency, Transportation Research Record 757, 7-14.

Milgram, P. and Horst, A. (1984). Field-sequential Colour Stereoscopy with Liquid Crystal Spectacles. Proceedings Fourth international Display Research Conference, Paris, France. 
Mori, Y., Kurihara, M., Hayama, A., and Ohkuma, S. (1995). A Study to Improve the Safety of Expressways by Desirable Combinations of Geometric Alignments. Proc., $1^{\text {st }}$ Int. Symp. On Highway Geometric Design Practices, Transportation Research Board, Washington, D.C.

Mourant, R.R. and Ge, Z. (1997). Measuring Attentional Demand in a Virtual Environments Driving Simulator. Proceedings of the Human Factors and Ergonomics Society $41^{\text {st }}$ Annual Meeting, Santa Monica, CA.

Passetti, K.A. and Fambro, D.B. (1999). Operating Speeds on Curves with and without Spiral Transitions. Transportation Research Record 1658, 9-16.

Polus, A. and Dagan, D (1978). Models for Evaluating the Consistency of Highway Alignment. Transportation Research Record 1122, 47-56.

Post, T. and Lunenfeld, H. (1981). A Users' Guide to Positive Guidance. FHWA-TO-811. Federal Highway Administration, Washington, D.C.

Robertson, P.K. (1988). Choosing Data Presentation for the Effective Visualization of Spatial Data. $3^{\text {rd }}$ International Symposium on Spatial Data Handling, Sydney, Australia.

Rockwell, T. (1972). Skills, Judgment and Information Acquisition in Driving. Human Factors in Highway Traffic Safety Research, Wiley, New York.

Schlegel, R.E. (1993). Driver Mental Workload in B. Peacock and W. Karwowski (Eds). Automotive Ergonomics, Taylor and Francis, London.

Senders, J.W., Kristofferson, A.B., Levison, W.H., Dietrich, C.W., and Ward, J.L. (1967). The Attentional Demand of Automobile Driving. Highway Research Record 195, 15-33. 
Senders, J.W. (1970). The Estimation of Operator Workload in Complex Systems. McGraw-Hill, New York.

Shafer, M.A., Brackett, R.Q., and Krammes, R.A. (1995). Driver Mental Workload as a Measure of Geometric Design Consistency for Horizontal Curves. $74^{\text {th }}$ TRB Meeting, Washington, D.C.

Smith, B.L. and Lamm, R. (1994). Coordination of Horizontal and Vertical Alignment with Regard to Highway Esthetics. Transportation Research Record 1445, 73-85.

Tsimhoni, O. and Green, A. (1999). Visual Demand of Driving Curves as Determined by Visual Occlusion. Vision in Vehicle 8 Conference, Boston, MA.

Tsimhoni, O. and Green, A. (2001). Visual Demand of Driving and the Execution of Display-intensive In-vehicle Tasks. Proceedings of the Human Factors and Ergonomics Society $45^{\text {th }}$ Annual Meeting, Santa Monica, CA.

Unwin, D., Dynes, J.A., Fisher, P. F., Stynes, K., and Wood, J. (1994). Visualization in the Spatial Sciences. Paper presented at AGI Conference, Birmingham, U.K.

USGS (1997) DEM Data User's Guide Version 5. Geological Survey, Reston, VA.

Wickens, C. D. and Hollands, J.G. (2000). Engineering Psychology and Human Performance (Third edition). Prentice-Hall Inc. Upper Saddle River, NJ.

Wierwille, W.W. and Gutmann, J. C. (1978). Comparison of Primary and Secondary Task Measures as a Function of Simulated Vehicle Dynamics and Driving Conditions. Human Factors 20(2), 233-244.

Wooldridge, M. D., Bauer, K., Green, P., and Fitzpatrick, K. (2000). Comparison of Driver Visual Demand in Test Track, Simulator, and On-Road Environments. The $79^{\text {th }}$ Annual Meeting, Transportation Research Board, Washington, D.C. 


\section{Appendix A}

CHARACTERISTICS OF TESTED ALIGNMENTS 
Table 24 Detail Geometric Information on Test Alignment - 1

\begin{tabular}{|c|c|c|c|c|c|c|c|c|}
\hline Element ID & $\mathrm{R}(\mathrm{m})$ & $\mathrm{K}$ & $\begin{array}{c}\text { Def } \\
\text { Angle } \\
(\text { degree })\end{array}$ & $\begin{array}{c}\text { Curve } \\
\text { Length } \\
(\mathrm{m})\end{array}$ & $\begin{array}{c}\text { Start } \\
\text { Distance } \\
(\mathrm{m})\end{array}$ & $\begin{array}{c}\text { End } \\
\text { Distance } \\
(\mathrm{m})\end{array}$ & $\begin{array}{c}\text { Start } \\
\text { Grade } \\
(\%)\end{array}$ & $\begin{array}{c}\text { End } \\
\text { Grade } \\
(\%)\end{array}$ \\
\hline $\begin{array}{c}\text { Vertical } \\
\text { Curve 1 }\end{array}$ & - & -40 & $\mathrm{NA}$ & 235.6 & 317.8 & 553.4 & 2.945 & -2.945 \\
\hline $\begin{array}{c}\text { Vertical } \\
\text { Curve 2 }\end{array}$ & - & 40 & $\mathrm{NA}$ & 235.6 & 553.4 & 789.1 & -2.945 & 2.945 \\
\hline $\begin{array}{l}\text { Vertical } \\
\text { Curve 3 }\end{array}$ & - & 80 & $\mathrm{NA}$ & 314.2 & 789.1 & 1103.2 & 2.945 & -0.982 \\
\hline $\begin{array}{c}\text { Vertical } \\
\text { Curve 4 }\end{array}$ & - & 60 & $\mathrm{NA}$ & 314.2 & 1103.2 & 1417.4 & -0.982 & 4.26 \\
\hline
\end{tabular}

* As a reference group, test alignment has not tangent connecting two curves

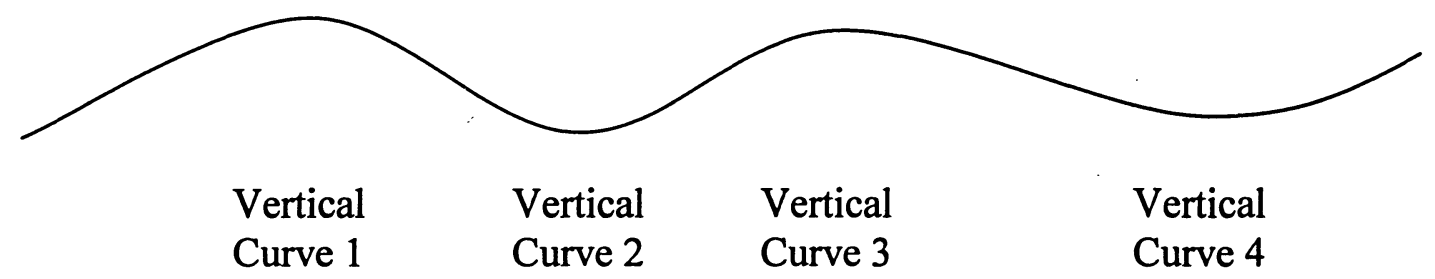

Figure 33 Sketches showing Vertical Profile of Test Alignment - 1 
Table 25 Detail Geometric Information on Test Alignment - 2

\begin{tabular}{|c|c|c|c|c|c|c|c|c|}
\hline $\begin{array}{c}\text { Element } \\
\text { ID }\end{array}$ & $\mathrm{R}(\mathrm{m})$ & $\mathrm{K}$ & $\begin{array}{c}\text { Def } \\
\text { Angle } \\
(\mathrm{degree})\end{array}$ & $\begin{array}{c}\text { Element } \\
\text { Length } \\
(\mathrm{m})\end{array}$ & $\begin{array}{c}\text { Start } \\
\text { Distance } \\
(\mathrm{m})\end{array}$ & $\begin{array}{c}\text { End } \\
\text { Distance } \\
(\mathrm{m})\end{array}$ & $\begin{array}{c}\text { Start } \\
\text { Grade } \\
(\%)\end{array}$ & $\begin{array}{c}\text { End } \\
\text { Grade } \\
(\%)\end{array}$ \\
\hline Curve-h1 & 600 & - & 60 & 628.3 & 200 & 828.3 & 0 & 0 \\
\hline Tangent-1 & - & - & - & 200 & 828.3 & 1028.3 & 0 & 0 \\
\hline Curve-h2 & 400 & - & 60 & 418.9 & 1028.3 & 1447.2 & 0 & 0 \\
\hline Tangent-2 & - & - & - & 200 & 1447.2 & 1647.2 & 0 & 0 \\
\hline Curve-h3 & 300 & - & 60 & 314.2 & 1647.2 & 1961.4 & 0 & 0 \\
\hline Tangent-3 & - & - & - & 200 & 1961.4 & 2161.4 & 0 & 0 \\
\hline Curve-h1 & 600 & - & 60 & 628.3 & 2161.4 & 2789.9 & 0 & 0 \\
\hline
\end{tabular}

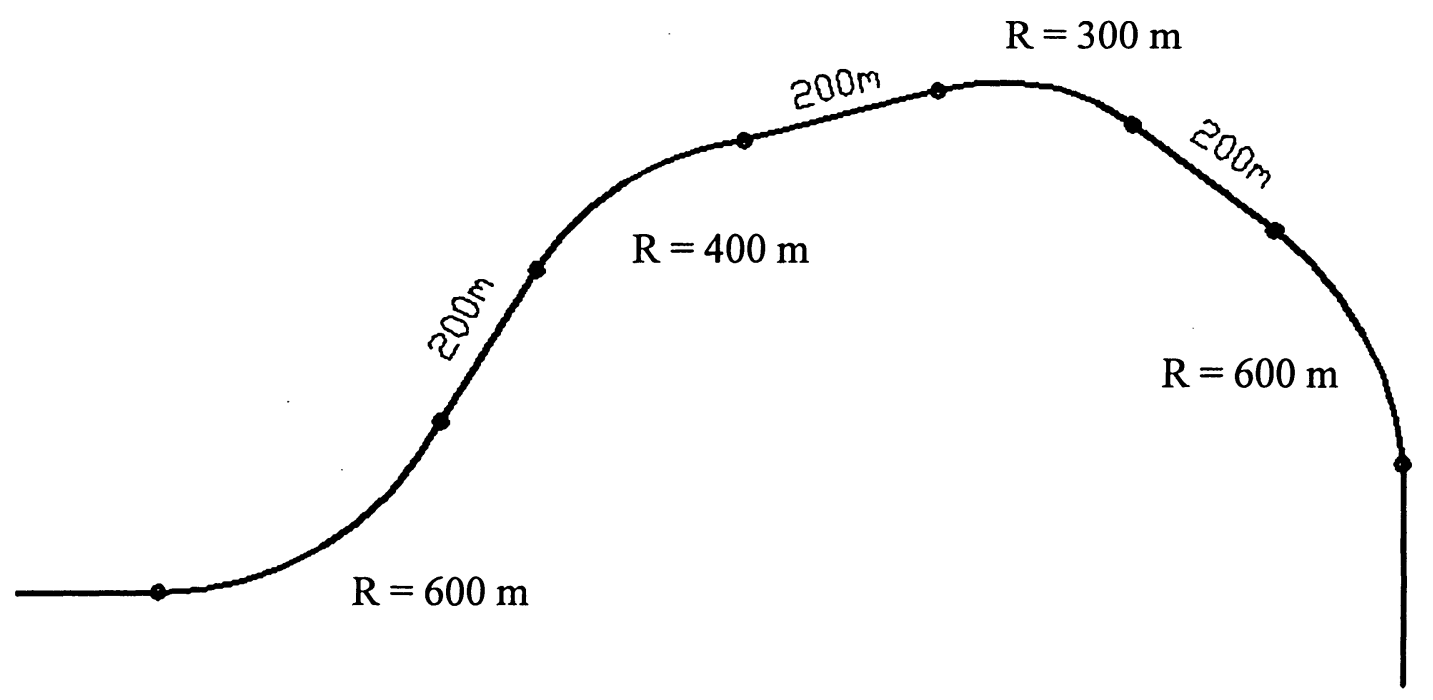

Figure 34 Sketches showing Horizontal Curves of Test Alignment - 2 
Table 26 Detail Geometric Information on Test Alignment - 3

\begin{tabular}{|c|c|c|c|c|c|c|c|c|}
\hline $\begin{array}{c}\text { Element } \\
\text { ID }\end{array}$ & $\begin{array}{c}\mathrm{R} \\
(\mathrm{m})\end{array}$ & $\mathrm{K}$ & $\begin{array}{c}\text { Def } \\
\text { Angle } \\
(\text { degree }\end{array}$ & $\begin{array}{c}\text { Element } \\
\text { Length } \\
(\mathrm{m})\end{array}$ & $\begin{array}{c}\text { Start } \\
\text { Distance } \\
(\mathrm{m})\end{array}$ & $\begin{array}{c}\text { End } \\
\text { Distance } \\
(\mathrm{m})\end{array}$ & $\begin{array}{c}\text { Start } \\
\text { Grade } \\
(\%)\end{array}$ & $\begin{array}{c}\text { End } \\
\text { Grade } \\
(\%)\end{array}$ \\
\hline Curve-c13 & 300 & -80 & 60 & 314.2 & 278.5 & 592.7 & 1.964 & -1.964 \\
\hline Tangent-1 & - & - & - & 200 & 592.7 & 792.7 & -1.964 & -1.964 \\
\hline Curve-s12 & 400 & 80 & 60 & 418.9 & 792.7 & 1211.6 & -1.964 & 3.273 \\
\hline Tangent-2 & - & - & - & 200 & 1211.6 & 1411.6 & 3.273 & 3.273 \\
\hline Curve-c21 & 600 & -60 & 60 & 628.3 & 1411.6 & 2039.9 & 3.273 & -7.2 \\
\hline Tangent-3 & - & - & - & 200 & 2039.9 & 2239.9 & -7.2 & -7.2 \\
\hline Curve-s33 & 300 & 40 & 60 & 314.2 & 2239.9 & 2554.1 & -7.2 & 0.655 \\
\hline
\end{tabular}

Horizontal Turning Direction: c13 --- Left

s12 --- Right

c21 -.- Left

s33 --- Right

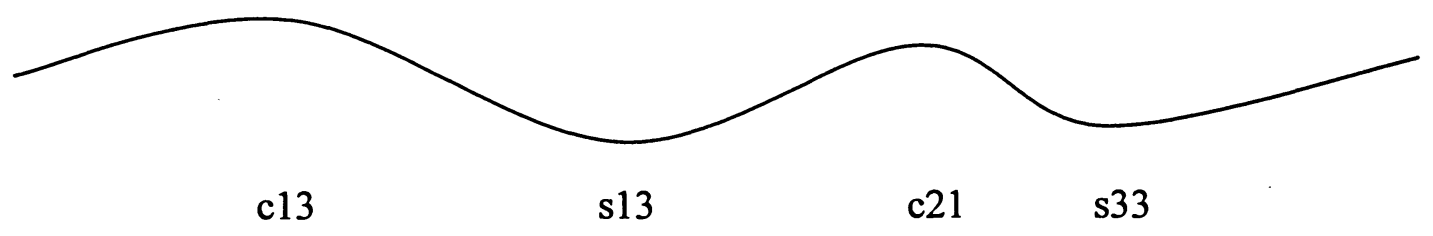

Figure 35 Sketches showing Vertical Profile of Test Alignment - 3 
Table 27 Detail Geometric Information on Test Alignment - 4

\begin{tabular}{|c|c|c|c|c|c|c|c|c|}
\hline $\begin{array}{c}\text { Element } \\
\text { ID }\end{array}$ & $\begin{array}{c}\mathrm{R} \\
(\mathrm{m})\end{array}$ & $\mathrm{K}$ & $\begin{array}{c}\text { Def } \\
\text { Angle } \\
(\text { degree})\end{array}$ & $\begin{array}{c}\text { Element } \\
\text { Length } \\
(\mathrm{m})\end{array}$ & $\begin{array}{c}\text { Start } \\
\text { Distance } \\
(\mathrm{m})\end{array}$ & $\begin{array}{c}\text { End } \\
\text { Distance } \\
(\mathrm{m})\end{array}$ & $\begin{array}{c}\text { Start } \\
\text { Grade } \\
(\%)\end{array}$ & $\begin{array}{c}\text { End } \\
\text { Grade } \\
(\%)\end{array}$ \\
\hline Curve-s13 & 300 & 80 & 60 & 314.1 & 278.5 & 592.7 & -1.964 & 1.964 \\
\hline Tangent-1 & - & - & - & 200 & 592.7 & 792.7 & 1.964 & 1.964 \\
\hline Curve-c11 & 600 & -80 & 60 & 628.3 & 792.7 & 1421 & 1.964 & -5.891 \\
\hline Tangent-2 & - & - & - & 200 & 1421 & 1621 & -5.891 & -5.891 \\
\hline Curve-s22 & 400 & 60 & 60 & 418.9 & 1621 & 2039.9 & -5.891 & 1.091 \\
\hline Tangent-3 & - & - & - & 200 & 2039.9 & 2239.9 & 1.091 & 1.091 \\
\hline Curve-c33 & 300 & -40 & 60 & 314.2 & 2239.9 & 2554.1 & 1.091 & -6.763 \\
\hline
\end{tabular}

Horizontal Turning Direction: s13 --- Right

c11 --- Left

s22 --- Right

c33 --- Left

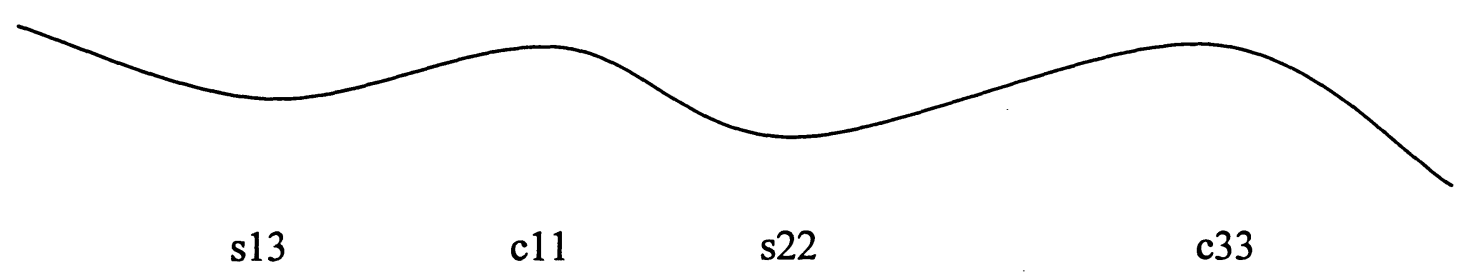

Figure 36 Sketches showing Vertical Profile of Test Alignment - 4 
Table 28 Detail Geometric Information on Test Alignment - 5

\begin{tabular}{|c|c|c|c|c|c|c|c|c|}
\hline $\begin{array}{c}\text { Element } \\
\text { ID }\end{array}$ & $\begin{array}{c}\mathrm{R} \\
(\mathrm{m})\end{array}$ & $\mathrm{K}$ & $\begin{array}{c}\text { Def } \\
\text { Angle } \\
(\text { degree })\end{array}$ & $\begin{array}{c}\text { Element } \\
\text { Length } \\
(\mathrm{m})\end{array}$ & $\begin{array}{c}\text { Start } \\
\text { Distance } \\
(\mathrm{m})\end{array}$ & $\begin{array}{c}\text { End } \\
\text { Distance } \\
(\mathrm{m})\end{array}$ & $\begin{array}{c}\text { Start } \\
\text { Grade } \\
(\%)\end{array}$ & $\begin{array}{c}\text { End } \\
\text { Grade } \\
(\%)\end{array}$ \\
\hline Curve-c33 & 300 & -40 & 60 & 314.2 & 357.1 & 671.2 & 3.927 & -3.927 \\
\hline Tangent-1 & - & - & - & 200 & 671.2 & 871.2 & -3.927 & -3.927 \\
\hline Curve-s12 & 400 & 80 & 60 & 418.9 & 871.2 & 1290.1 & -3.927 & 1.309 \\
\hline Tangent-2 & - & - & - & 200 & 1290.1 & 1490.1 & 1.309 & 1.309 \\
\hline Curve-c12 & 400 & -80 & 60 & 418.9 & 1490.1 & 1909 & 1.309 & -3.927 \\
\hline Tangent-3 & - & - & - & 200 & 1909 & 2109 & -3.927 & -3.927 \\
\hline Curve-s21 & 600 & 60 & 60 & 628.3 & 2109 & 2737.3 & -3.927 & 6.545 \\
\hline
\end{tabular}

Horizontal Turning Direction: c33 --- Left

s12 --- Left

c12 --- Right

s21 --. Right

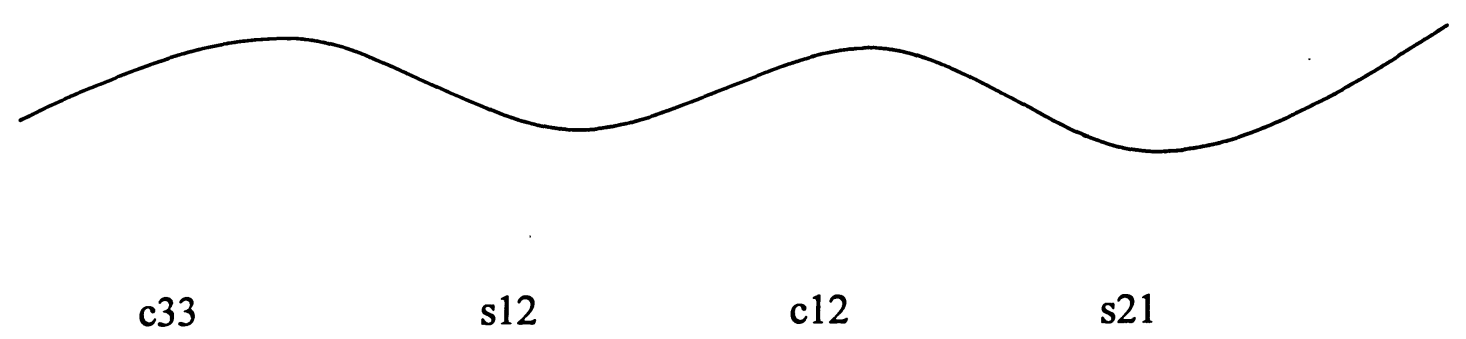

Figure 37 Sketches showing Vertical Profile of Test Alignment - 5 
Table 29 Detail Geometric Information on Test Alignment - 6

\begin{tabular}{|c|c|c|c|c|c|c|c|c|}
\hline $\begin{array}{c}\text { Element } \\
\text { ID }\end{array}$ & $\begin{array}{c}\mathrm{R} \\
(\mathrm{m})\end{array}$ & $\mathrm{K}$ & $\begin{array}{c}\text { Def } \\
\text { Angle } \\
(\text { degree})\end{array}$ & $\begin{array}{c}\text { Element } \\
\text { Length } \\
(\mathrm{m})\end{array}$ & $\begin{array}{c}\text { Start } \\
\text { Distance } \\
(\mathrm{m})\end{array}$ & $\begin{array}{c}\text { End } \\
\text { Distance } \\
(\mathrm{m})\end{array}$ & $\begin{array}{c}\text { Start } \\
\text { Grade } \\
(\%)\end{array}$ & $\begin{array}{c}\text { End } \\
\text { Grade } \\
(\%)\end{array}$ \\
\hline Curve-c12 & 400 & -80 & 60 & 418.9 & 304.72 & 723.6 & 2.618 & -2.618 \\
\hline Tangent-1 & - & - & - & 200 & 723.6 & 923.6 & -2.618 & -2.618 \\
\hline Curve-s13 & 300 & 80 & 60 & 314.2 & 923.6 & 1237.8 & -2.618 & 1.309 \\
\hline Tangent-2 & - & - & - & 200 & 1237.8 & 1437.8 & 1.309 & 1.309 \\
\hline Curve-c33 & 300 & -40 & 60 & 314.2 & 1437.8 & 1751.9 & 1.309 & -6.545 \\
\hline Tangent-3 & - & - & - & 200 & 1751.9 & 1951.9 & -6.545 & -6.545 \\
\hline Curve-s21 & 600 & 60 & 60 & 628.3 & 1951.9 & 2580.2 & -6.545 & 3.927 \\
\hline
\end{tabular}

$\begin{aligned} & \text { Horizontal Turning Direction: } \text { c12 --- Left } \\ & \text { s13 --- Right } \\ & \text { c33 --- Left } \\ & \text { s21 --- Right }\end{aligned}$

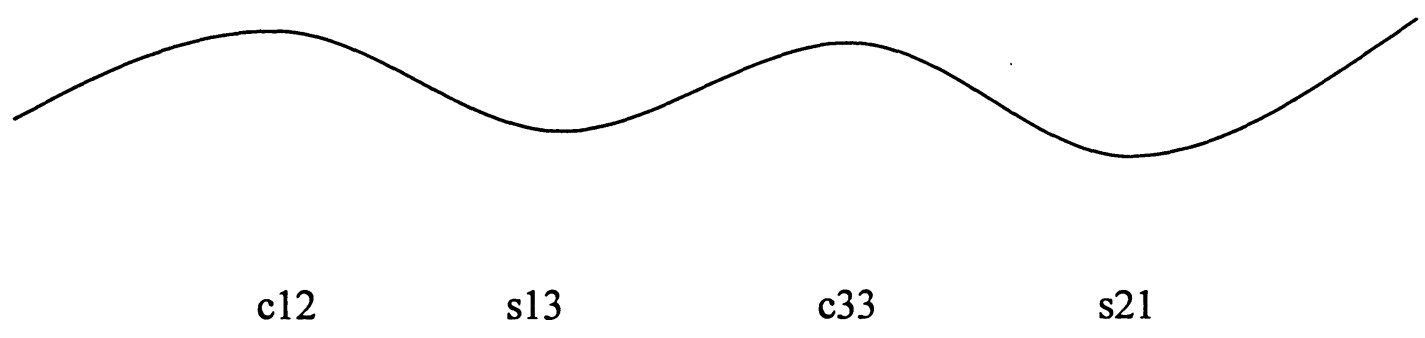

Figure 38 Sketches showing Vertical Profile of Test Alignment - 6 
Table 30 Detail Geometric Information on Test Alignment - 7

\begin{tabular}{|c|c|c|c|c|c|c|c|c|}
\hline $\begin{array}{c}\text { Element } \\
\text { ID }\end{array}$ & $\begin{array}{c}\mathrm{R} \\
(\mathrm{m})\end{array}$ & $\mathrm{K}$ & $\begin{array}{c}\text { Def } \\
\text { Angle } \\
(\text { degree })\end{array}$ & $\begin{array}{c}\text { Element } \\
\text { Length } \\
(\mathrm{m})\end{array}$ & $\begin{array}{c}\text { Start } \\
\text { Distance } \\
(\mathrm{m})\end{array}$ & $\begin{array}{c}\text { End } \\
\text { Distance } \\
(\mathrm{m})\end{array}$ & $\begin{array}{c}\text { Start } \\
\text { Grade } \\
(\%)\end{array}$ & $\begin{array}{c}\text { End } \\
\text { Grade } \\
(\%)\end{array}$ \\
\hline Curve-s13 & 300 & 80 & 60 & 314.2 & 278.5 & 592.7 & -1.964 & 1.964 \\
\hline Tangent-1 & - & - & - & 200 & 592.7 & 792.7 & 1.964 & 1.964 \\
\hline Curve-c33 & 300 & -40 & 60 & 314.2 & 792.7 & 1106.9 & 1.964 & -5.891 \\
\hline Tangent-2 & - & - & - & 200 & 1106.9 & 1306.9 & -5.891 & -5.891 \\
\hline Curve-s32 & 400 & 40 & 60 & 418.9 & 1306.9 & 1725.7 & -5.891 & 4.582 \\
\hline Tangent-3 & - & - & - & 200 & 1725.7 & 1925.7 & 4.582 & 4.582 \\
\hline Curve-c21 & 600 & -60 & 60 & 628.3 & 1925.7 & 2554.1 & 4.582 & -5.891 \\
\hline
\end{tabular}

Horizontal Turning Direction: s13 --- Right

c33 --- Left

s32 --- Right

c21 --- Left

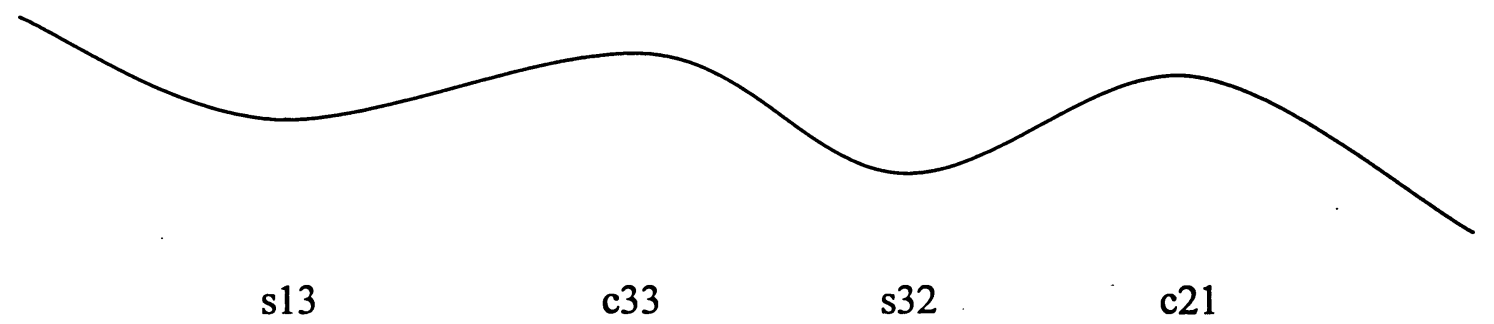

Figure 39 Sketches showing Vertical Profile of Test Alignment - 7 
Table 31 Detail Geometric Information on Test Alignment - 8

\begin{tabular}{|c|c|c|c|c|c|c|c|c|}
\hline $\begin{array}{c}\text { Element } \\
\text { ID }\end{array}$ & $\begin{array}{c}\mathrm{R} \\
(\mathrm{m})\end{array}$ & $\mathrm{K}$ & $\begin{array}{c}\text { Def } \\
\text { Angle } \\
(\text { degree })\end{array}$ & $\begin{array}{c}\text { Element } \\
\text { Length } \\
(\mathrm{m})\end{array}$ & $\begin{array}{c}\text { Start } \\
\text { Distance } \\
(\mathrm{m})\end{array}$ & $\begin{array}{c}\text { End } \\
\text { Distance } \\
(\mathrm{m})\end{array}$ & $\begin{array}{c}\text { Start } \\
\text { Grade } \\
(\%)\end{array}$ & $\begin{array}{c}\text { End } \\
\text { Grade } \\
(\%)\end{array}$ \\
\hline Curve-s11 & 600 & 80 & 60 & 628.3 & 357.1 & 985.4 & -3.927 & 3.927 \\
\hline Tangent-1 & - & - & - & 200 & 985.4 & 1185.4 & 3.927 & 3.927 \\
\hline Curve-c23 & 300 & -60 & 60 & 314.2 & 1185.4 & 1499.6 & 3.927 & -1.309 \\
\hline Tangent-2 & - & - & - & 200 & 1499.6 & 1699.6 & -1.309 & -1.309 \\
\hline Curve-s33 & 300 & 40 & 60 & 314.2 & 1699.6 & 2013.7 & -1.309 & 6.545 \\
\hline Tangent-3 & - & - & - & 200 & 2013.7 & 2213.7 & 6.545 & 6.545 \\
\hline Curve-c32 & 400 & -40 & 60 & 418.9 & 2213.7 & 2632.6 & 6.545 & -3.927 \\
\hline
\end{tabular}

$\begin{array}{ll}\text { Horizontal Turning Direction: } & \text { s11 --- Left } \\ \text { c23 --- Right } \\ \text { s33 --- Left } \\ \text { c32 --- Right }\end{array}$

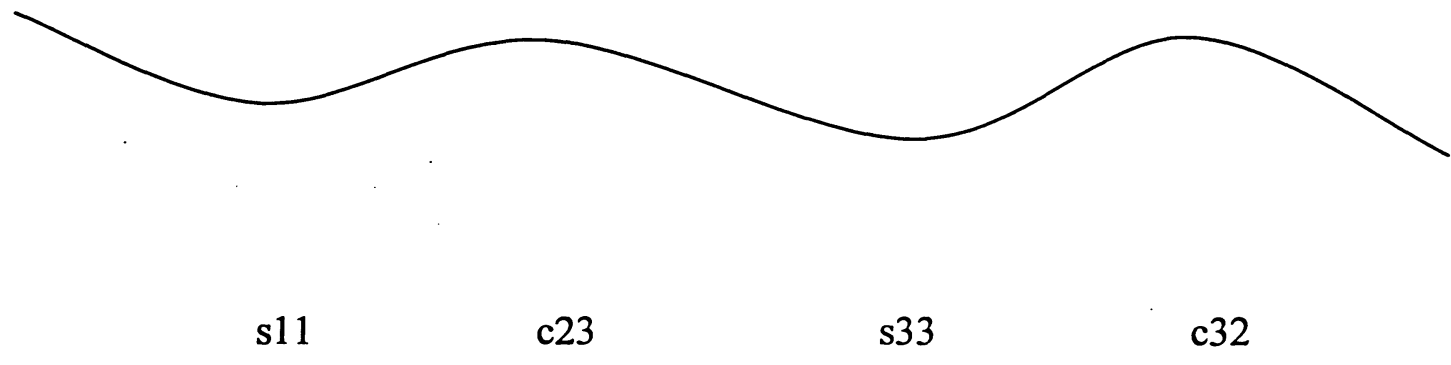

Figure 40 Sketches showing Vertical Profile of Test Alignment - 8 
Table 32 Detail Geometric Information on Test Alignment - 9

\begin{tabular}{|c|c|c|c|c|c|c|c|c|}
\hline $\begin{array}{c}\text { Element } \\
\text { ID }\end{array}$ & $\begin{array}{c}\mathrm{R} \\
(\mathrm{m})\end{array}$ & $\mathrm{K}$ & $\begin{array}{c}\text { Def } \\
\text { Angle } \\
(\text { degree })\end{array}$ & $\begin{array}{c}\text { Element } \\
\text { Length } \\
(\mathrm{m})\end{array}$ & $\begin{array}{c}\text { Start } \\
\text { Distance } \\
(\mathrm{m})\end{array}$ & $\begin{array}{c}\text { End } \\
\text { Distance } \\
(\mathrm{m})\end{array}$ & $\begin{array}{c}\text { Start } \\
\text { Grade } \\
(\%)\end{array}$ & $\begin{array}{c}\text { End } \\
\text { Grade } \\
(\%)\end{array}$ \\
\hline Curve-s23 & 300 & 60 & 60 & 314.2 & 304.7 & 618.9 & -2.618 & 2.618 \\
\hline Tangent-1 & - & - & - & 200 & 618.9 & 818.9 & 2.618 & 2.618 \\
\hline Curve-c22 & 400 & -60 & 60 & 418.9 & 818.9 & 1237.8 & 2.618 & -4.363 \\
\hline Tangent-2 & - & - & - & 200 & 1237.8 & 1437.8 & -4.636 & -4.363 \\
\hline Curve-s21 & 600 & 60 & 60 & 628.3 & 1437.8 & 2066.1 & -4.363 & 6.109 \\
\hline Tangent-3 & - & - & - & 200 & 2066.1 & 2266.1 & 6.109 & 6.109 \\
\hline Curve-c22 & 400 & -60 & 60 & 418.9 & 2266.1 & 2685 & 6.109 & -0.873 \\
\hline
\end{tabular}

Horizontal Turning Direction: s23 --- Right

c22 --- Right

s21 --- Left

c22 --- Left

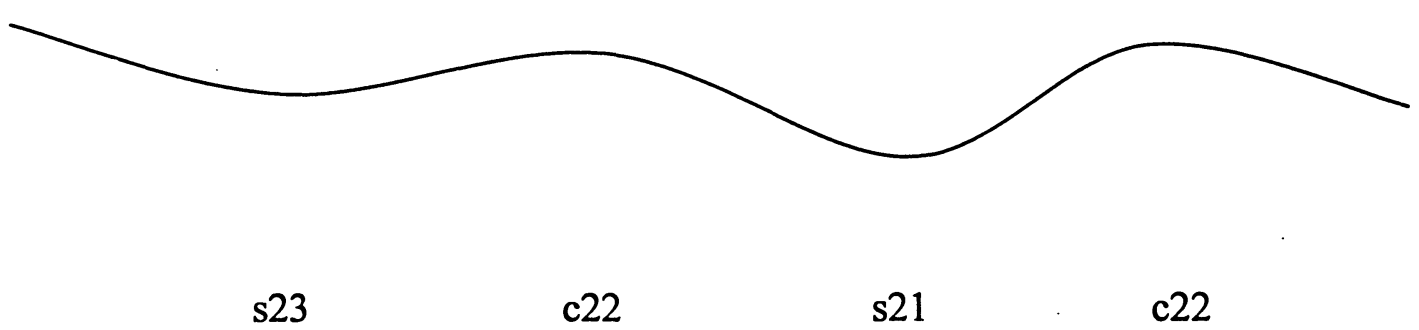

Figure 41 Sketches showing Vertical Profile of Test Alignment - 9 
Table 33 Detail Geometric Information on Test Alignment - 10

\begin{tabular}{|c|c|c|c|c|c|c|c|c|}
\hline $\begin{array}{c}\text { Element } \\
\text { ID }\end{array}$ & $\begin{array}{c}\mathrm{R} \\
(\mathrm{m})\end{array}$ & $\mathrm{K}$ & $\begin{array}{c}\text { Def } \\
\text { Angle } \\
(\text { degree })\end{array}$ & $\begin{array}{c}\text { Element } \\
\text { Length } \\
(\mathrm{m})\end{array}$ & $\begin{array}{c}\text { Start } \\
\text { Distance } \\
(\mathrm{m})\end{array}$ & $\begin{array}{c}\text { End } \\
\text { Distance } \\
(\mathrm{m})\end{array}$ & $\begin{array}{c}\text { Start } \\
\text { Grade } \\
(\%)\end{array}$ & $\begin{array}{c}\text { End } \\
\text { Grade } \\
(\%)\end{array}$ \\
\hline Curve-c31 & 600 & -40 & 60 & 628.3 & 514.2 & 1142.5 & 7.854 & -7.854 \\
\hline Tangent-1 & - & - & - & 200 & 1142.5 & 1324.5 & -7.854 & -7.854 \\
\hline Curve-s31 & 600 & 40 & 60 & 628.3 & 1324.5 & 1970.8 & -7.854 & 7.854 \\
\hline Tangent-2 & - & - & - & 200 & 1970.8 & 2170.8 & 7.854 & 7.854 \\
\hline Curve-c32 & 400 & -40 & 60 & 418.9 & 2170.8 & 2589.7 & 7.854 & -2.618 \\
\hline Tangent-3 & - & - & - & 200 & 2589.7 & 2789.7 & -2.618 & -2.618 \\
\hline Curve-s23 & 300 & 60 & 60 & 314.2 & 2789.7 & 3103.8 & -2.618 & 2.618 \\
\hline
\end{tabular}

Horizontal Turning Direction : c31 --- Left

s31 --- Left

c32 --- Right

s23 --- Right

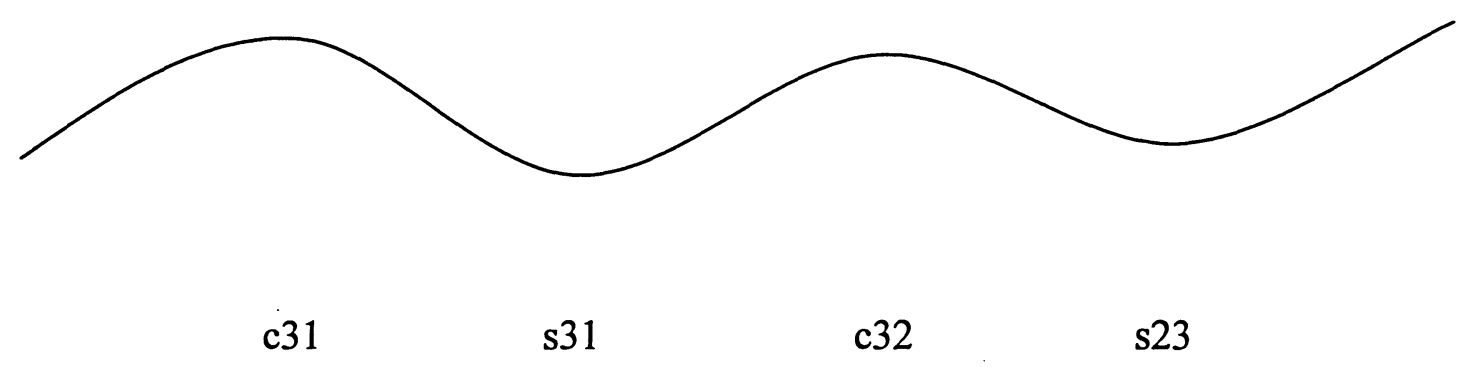

Figure 42 Sketches showing Vertical Profile of Test Alignment - 10 


\section{Appendix B}

DETAILS OF THE DRIVING SIMULATOR 


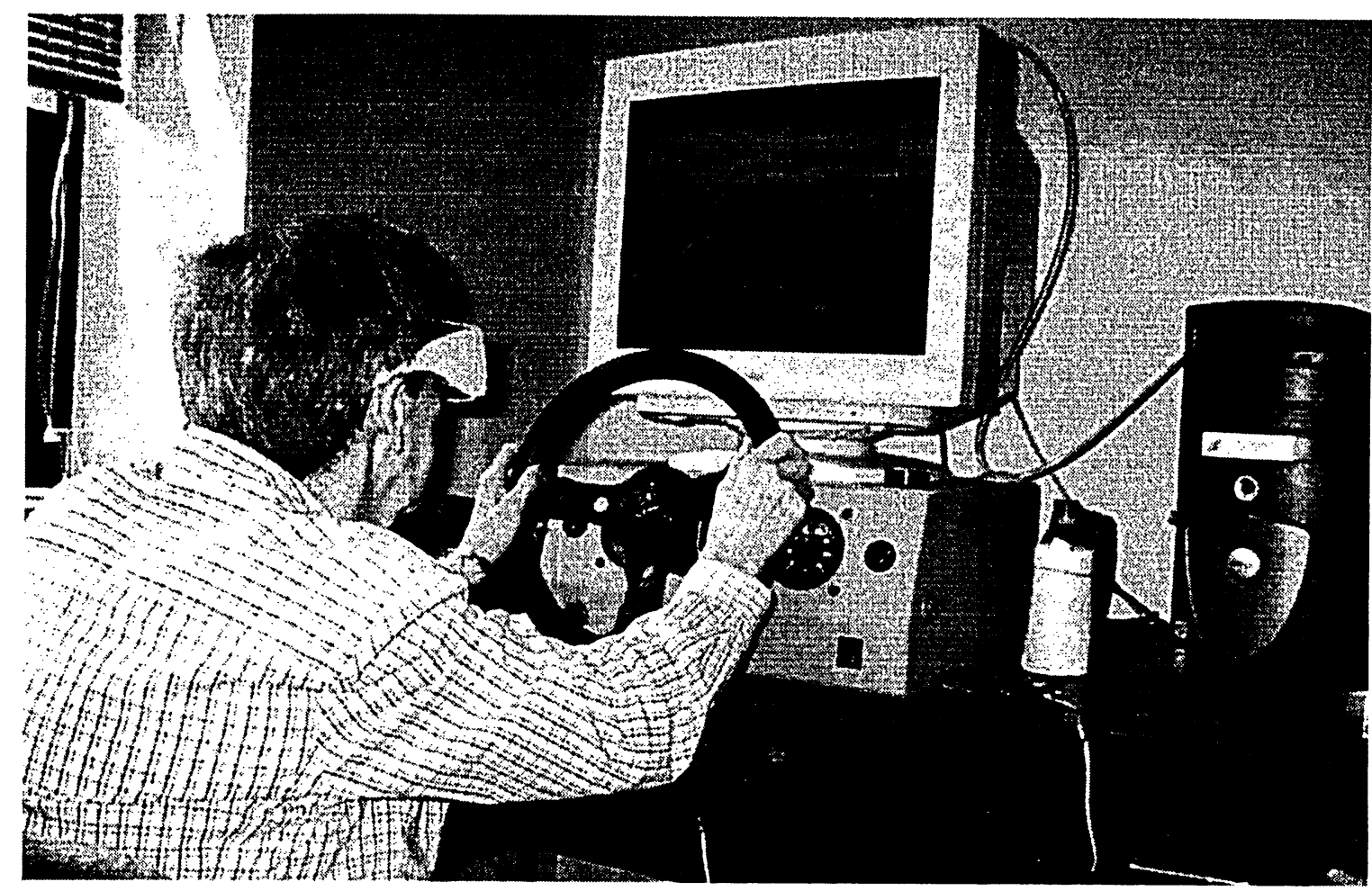

Figure 43 STISIM Simulator at Human Factors Lab in Ryerson University

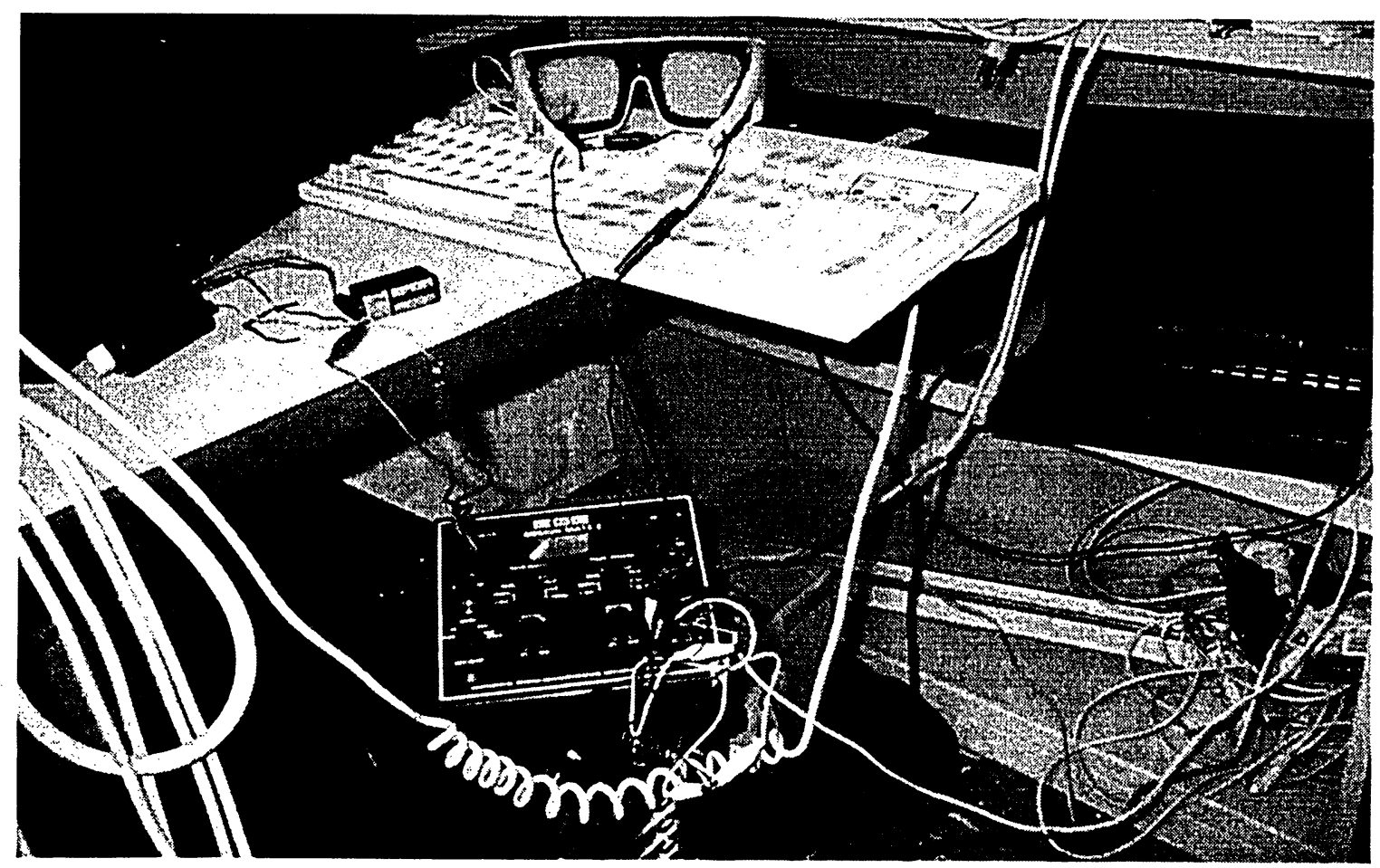

Figure 44 Visual Occlusion Spectacles, ToTal Control Computer, Pulse Generator and Black Control Box 


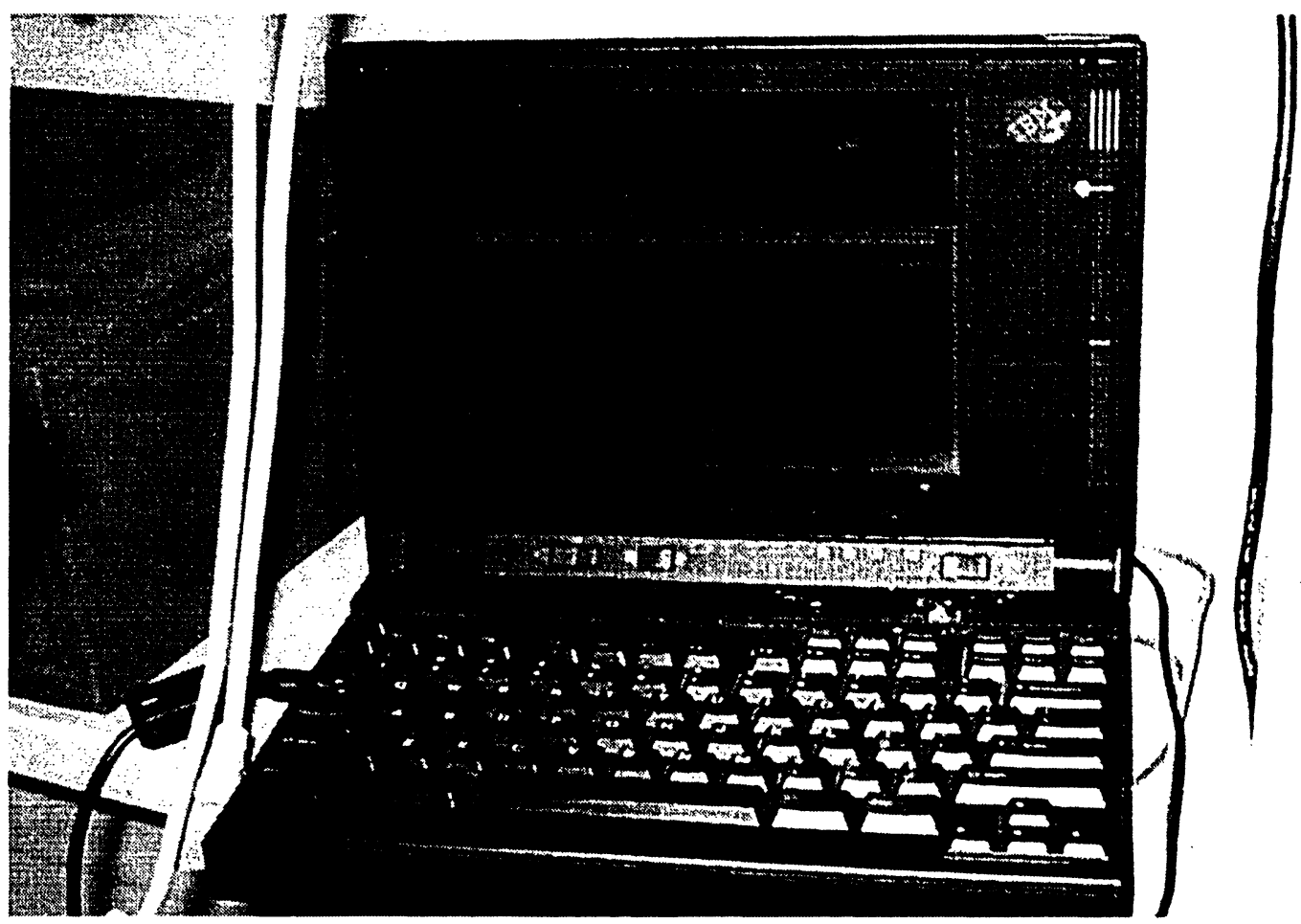

Figure 45 ToTal Control Computer for Visual Occlusion Control

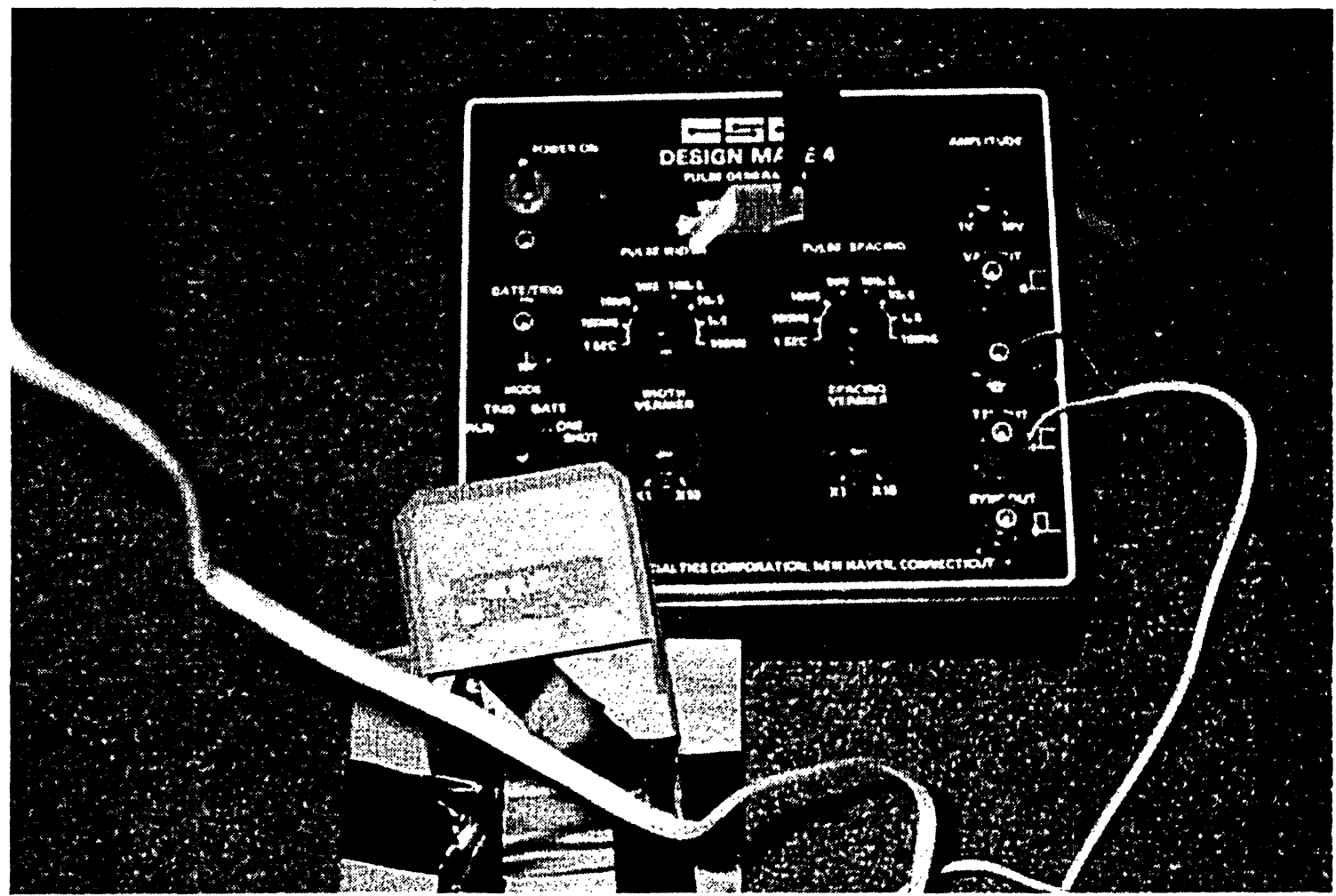

Figure 46 Switch Pedal and Pulse Generator 

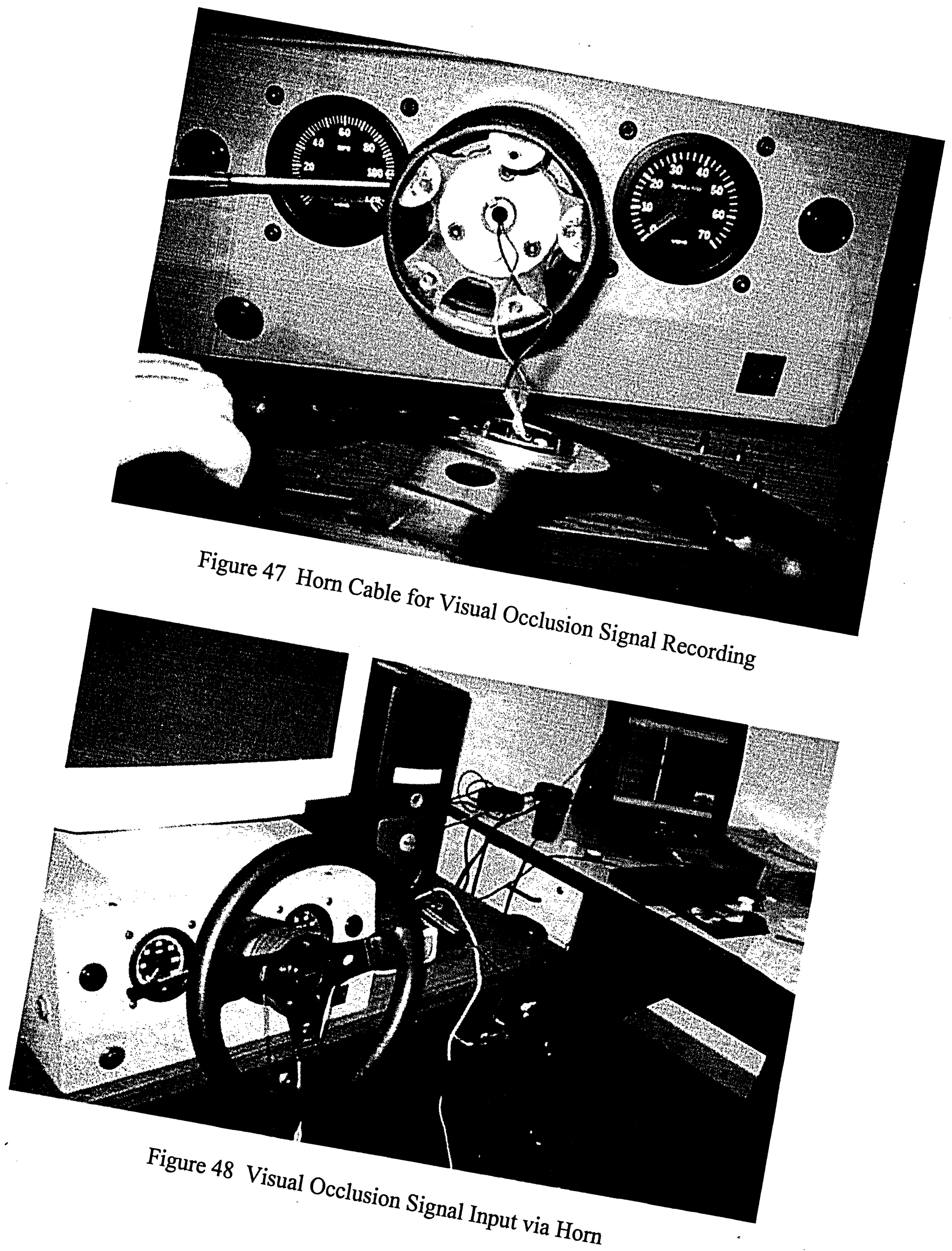


\section{Appendix C}

FORMS FOR PILOT STUDY AND EXPERIMENT 


\section{Experimental Explanatory Statement}

\section{Project Tile: Evaluation of Driver Visual Demand on Three-Dimensional}

\section{Rural Highway Alignments}

My name is Wen Long He and I am studying for my M.A.Sc. (Transportation Program, Civil Engineering) at Ryerson University. I am conducting this research project under the supervision of Dr. Said Easa, Chair of Civil Engineering Department at the Ryerson University in Toronto.

The aim of this research project is to investigate Consistency of existing or proposed highway design with respect to driver's visual demand and or mental workload. The findings of this research project will be highly important for the future of highway design and road safety in Canada and North America as well. The results will be used for my thesis and may be published in professional publications as well.

I am seeking people who have held a driving license for at least three years. Those people will drive a high-tech driving simulator in a safe and comfortable indoor environment. The procedure will take approximately one and half-hour of your time, and will be undertaken at the Human Factors laboratory in the Department of Civil Engineering at Ryerson University. For your time, you will be paid $\$ 10$ per hour.

The anonymity of your participation is assured by our procedure, in which your name and any other personal information will not be associated with your simulator data that is collected. In addition, participation in this research is entirely voluntary, and if you agree 
to participate, you may withdraw your consent at any time by indicating this to the experimenter.

If you have any queries, please contact Wen Long He. If you have any complaint concerning the manner in which this research is conducted, please feel free to contact Dr.

S Easa, my supervisor.

Dr. Said Easa, Chair, Civil Engineering Department,

Ryerson University,

350 Victory Street, Toronto, ON, M5B 2K3

Tele: $416-979-5000$ ext 6451

Thank you

Wen Long He

Tele: $416-979-5000$ ext 6463

E-mail: w2he@ryerson.ca 


\section{Information Form}

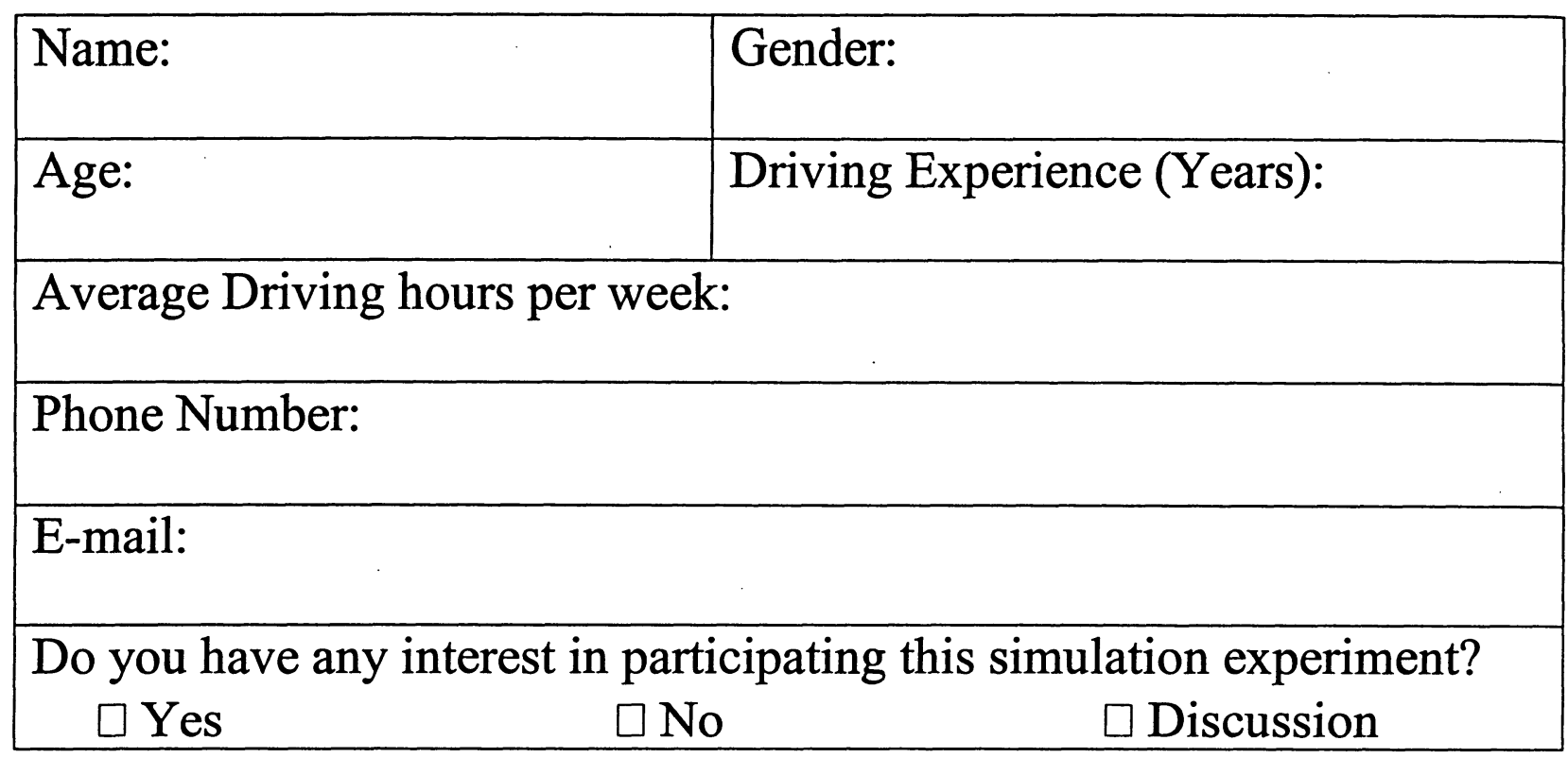

What time are you available?

$\square$ April

$\square$ May

June

$\square$ July

\begin{tabular}{|l|l|l|l|l|l|l|}
\hline Monday & Tuesday & Wednesday & Thursday & Friday & Saturday & Sunday \\
\hline$\square$ Morning & $\square$ Morning & $\square$ Morning & $\square$ Morning & $\square$ Morning & $\square$ Morning & $\square$ Morning \\
\hline$\square$ Afternoon & $\square$ Afternoon & $\square$ Afternoon & $\square$ Afternoon & $\square$ Afternoon & $\square$ Afternoon & $\square$ Afternoon \\
\hline$\square$ Evening & $\square$ Evening & $\square$ Evening & $\square$ Evening & $\square$ Evening & $\square$ Evening & $\square$ Evening \\
\hline
\end{tabular}

Wen Long He

Tele: $416-979-5000$ ext 6463

E-mail: w2he@,ryerson.ca 


\section{Appendix D}

SUMMARY OUTPUT AND RESULTS 
Table 34 Model developed on Average VD during Pilot Study (for 2D horizontal curves, only considering 1/R)

\begin{tabular}{|c|c|c|c|c|c|c|}
\hline SUMMARY OUTPUT & & & & & & \\
\hline & & & & & & \\
\hline \multicolumn{7}{|c|}{ Regression Statistics } \\
\hline Multiple R & 0.998519965 & & & & & \\
\hline R Square & 0.99704212 & & & & & \\
\hline Adjusted R Square & 0.99408424 & & & & & \\
\hline Standard Error & 0.002041241 & & & & & \\
\hline \multicolumn{7}{|l|}{ Observations } \\
\hline & & & & & & \\
\hline \multicolumn{7}{|l|}{ ANOVA } \\
\hline & $\mathrm{df}$ & SS & MS & $\mathrm{F}$ & Significance F & \\
\hline Regression & 1 & 0.0014045 & 0.001405 & 337.08 & 0.034640545 & \\
\hline Residual & 1 & 4. $16667 \mathrm{E}-06$ & 4. $17 \mathrm{E}-06$ & & & \\
\hline \multirow[t]{2}{*}{ Total } & 2 & 0.001408667 & & & & \\
\hline & Coefficients & Standard Error & t Stat & P-value & Lower $95 \%$ & Upper 95\% \\
\hline Intercept & 0.282833333 & 0.004487637 & 63.025 & 0.01010022 & 0.225812739 & 0.339853928 \\
\hline Inverse of Radius & 31.8 & 1.732050808 & 18.35974 & 0.03464054 & 9.79230211 & 53.80769789 \\
\hline
\end{tabular}

Visual Demand $=0.283+31.8 / \mathrm{R}$ 
Table 35 Model developed on Average VD during Pilot Study (for 2D curves, and 3D horizontal overlapping sag curves, only considering $1 / \mathrm{R})$

\begin{tabular}{|c|c|c|c|c|c|c|}
\hline SUMMARY OUTPUT & & & & & & \\
\hline & & & & & & \\
\hline \multicolumn{7}{|c|}{ Regression Statistics } \\
\hline Multiple R & 0.9022073 & & & & & \\
\hline R Square & 0.813978012 & & & & & \\
\hline Adjusted R Square & 0.795375814 & & & & & \\
\hline Standard Error & 0.011099351 & & & & & \\
\hline Observations & 12 & & & & & \\
\hline & & & & & & \\
\hline \multicolumn{7}{|l|}{ ANOVA } \\
\hline & $\mathrm{df}$ & SS & MS & $\mathrm{F}$ & Significance $\mathrm{F}$ & \\
\hline Regression & 1 & 0.005390681 & 0.005391 & 43.75709 & $5.96555 \mathrm{E}-05$ & \\
\hline Residual & 10 & 0.001231956 & 0.000123 & & & \\
\hline Total & 11 & 0.006622637 & & & & \\
\hline & & & & & & \\
\hline & Coefficients & Standard Error & t Stat & P-value & Lower 95\% & Upper 95\% \\
\hline Intercept & 0.293722222 & 0.012200875 & 24.07387 & $3.48 \mathrm{E}-10$ & 0.266536974 & 0.320907471 \\
\hline Inverse of Radius & 31.15 & 4.709055992 & 6.614914 & $5.97 \mathrm{E}-05$ & 20.65756757 & 41.64243243 \\
\hline
\end{tabular}

Visual Demand $=0.294+31.15 / \mathrm{R}$ 
Table 36 Model developed on Average VD during Pilot Study (for 2D horizontal curves, and 3D horizontal overlapping sag curves, considering $1 / \mathrm{R}$ and $1 / \mathrm{K}$ )

\begin{tabular}{|c|c|c|c|c|c|c|}
\hline SUMMARY OUTPUT & & & & & & \\
\hline & & & & & & \\
\hline \multicolumn{7}{|c|}{ Regression Statistics } \\
\hline Multiple R & 0.925645143 & & & & & \\
\hline R Square & 0.856818931 & & & & & \\
\hline Adjusted R Square & 0.825000916 & & & & & \\
\hline Standard Error & 0.009404445 & & & & & \\
\hline Observations & 12 & & & & & \\
\hline & & & & & & \\
\hline \multicolumn{7}{|l|}{ ANOVA } \\
\hline & $\mathrm{df}$ & SS & MS & $\mathrm{F}$ & Significance $\mathrm{F}$ & \\
\hline Regression & 2 & 0.004763348 & 0.002382 & 26.92874 & 0.000159032 & \\
\hline Residual & 9 & 0.000795992 & $8.84 \mathrm{E}-05$ & & & \\
\hline \multirow[t]{3}{*}{ Total } & 11 & 0.00555934 & & & & \\
\hline & & & & & & \\
\hline & Coefficients & Standard Error & t Stat & P-value & Lower $95 \%$ & Upper 95\% \\
\hline Intercept & 0.292121296 & 0.011112024 & 26.28876 & $8.05 \mathrm{E}-10$ & 0.266984133 & 0.31725846 \\
\hline Inverse of $\mathrm{K}$ & 0.704888888 & 0.300942242 & 2.342273 & 0.043857 & 0.024109721 & 1.385668057 \\
\hline Inverse of Radius & 27.75 & 3.98996813 & 6.954943 & $6.65 \mathrm{E}-05$ & 18.72405814 & 36.77594186 \\
\hline
\end{tabular}

Visual Demand $=0.292+0.704 / \mathrm{K}+27.75 / \mathrm{R}$ 
Table 37 Model developed on Average VD during Pilot Study (for 2D curves, and 3D horizontal overlapping crest curves, considering $1 / \mathrm{R}$ )

\begin{tabular}{|c|c|c|c|c|c|c|}
\hline SUMMARY OUTPUT & & & & & & \\
\hline \multicolumn{7}{|c|}{ Regression Statistics } \\
\hline Multiple R & 0.824482944 & & & & & \\
\hline R Square & 0.679772124 & & & & & \\
\hline Adjusted R Square & 0.647749337 & & & & & \\
\hline Standard Error & 0.017297722 & & & & & \\
\hline Observations & 12 & & & & & \\
\hline & & & & & & \\
\hline \multicolumn{7}{|l|}{ ANOVA } \\
\hline & $\mathrm{df}$ & SS & MS & $\mathrm{F}$ & Significance $\mathrm{F}$ & \\
\hline Regression & 1 & 0.006351584 & 0.006352 & 21.22776 & 0.00096914 & \\
\hline Residual & 10 & 0.002992112 & 0.000299 & & & \\
\hline Total & 11 & 0.009343696 & & & & \\
\hline & Coefficients & Standard Error $t$ & Stat & P-value & Lower 95\% & Upper 95\% \\
\hline Intercept & 0.302447917 & 0.019014386 & 15.90627 & $1.99 \mathrm{E}-08$ & 0.260081218 & 0.344814616 \\
\hline Inverse of Radius & 33.8125 & 7.338802057 & 4.60736 & 0.000969 & 17.46062718 & 50.16437282 \\
\hline
\end{tabular}

Visual Demand $=0.302+33.8 / \mathrm{R}$ 
Table 38 Model developed on Average VD during Pilot Study (for 2D curves, and 3D horizontal overlapping crest curves, considering $1 / \mathrm{R}$ and $1 / \mathrm{K}$ )

\begin{tabular}{|c|c|c|c|c|c|c|}
\hline \multicolumn{2}{|l|}{ SUMMARY OUTPUT } & & & & & \\
\hline & & & & & & \\
\hline \multicolumn{2}{|c|}{ Regression Statistics } & & & & & \\
\hline Multiple R & 0.98369309 & & & & & \\
\hline R Square & 0.96765209 & & & & & \\
\hline Adjusted R Square & 0.96046367 & & & & & \\
\hline Standard Error & 0.0057951 & & & & & \\
\hline Observations & 12 & & & & & \\
\hline \multicolumn{7}{|l|}{. } \\
\hline \multicolumn{7}{|l|}{ ANOVA } \\
\hline & $\mathrm{df}$ & SS & MS & $\mathrm{F}$ & Significance $\mathrm{F}$ & \\
\hline Regression & 2 & 0.009041447 & 0.004520724 & 134.6126 & $1.96928 \mathrm{E}-07$ & \\
\hline Residual & 9 & 0.000302249 & $3.35832 \mathrm{E}-05$ & & & \\
\hline \multirow[t]{2}{*}{ Total } & 11 & 0.009343696 & & & & \\
\hline & Coefficients & Standard Error & t Stat & P-value & Lower 95\% & Upper 95\% \\
\hline Intercept & 0.27997356 & 0.006847329 & 40.88799809 & $1.56 \mathrm{E}-11$ & 0.264483819 & 0.29546331 \\
\hline Inverse of $\mathrm{K}$ & 1.65964444 & 0.185443308 & 8.949605469 & $8.94 \mathrm{E}-06$ & 1.240142217 & 2.07914667 \\
\hline Inverse of Radius & 33.8125 & 2.458654138 & 13.75244264 & $2.39 \mathrm{E}-07$ & 28.25063369 & 39.3743663 \\
\hline
\end{tabular}

Visual Demand $=0.28+1.66 / \mathrm{K}+33.8 / \mathrm{R}$ 
Table 39 Model developed on Individual VD during Pilot Study (for horizontal overlapping sag curves, considering Age, $1 / \mathrm{K}$ and $1 / \mathrm{R})$

\begin{tabular}{|c|c|c|c|c|c|c|}
\hline \multicolumn{2}{|l|}{ SUMMARY OUTPUT } & & & & & \\
\hline Multiple R & 0.875339412 & & & & & \\
\hline R Square & 0.766219086 & & & & & \\
\hline Adjusted R Square & 0.744302126 & & & & & \\
\hline Standard Error & 0.042848235 & & & & & \\
\hline Observations & 36 & & & & & \\
\hline & & & & & & \\
\hline \multicolumn{7}{|l|}{ ANOVA } \\
\hline & $\mathrm{df}$ & SS & MS & $\mathrm{F}$ & Significance $\mathrm{F}$ & \\
\hline Regression & 3 & 0.192557199 & 0.064186 & 34.96009771 & $3.2468 \mathrm{E}-10$ & \\
\hline Residual & 32 & 0.058751079 & 0.001836 & & & \\
\hline \multirow[t]{2}{*}{ Total } & 35 & 0.251308278 & & & & \\
\hline & Coefficients & Standard Error & t Stat & P-value & Lower 95\% & Upper 95\% \\
\hline Intercept & 0.10833594 & 0.034473638 & 3.142574 & 0.003597287 & 0.038115498 & 0.178556382 \\
\hline Age & 0.004935502 & 0.000503019 & 9.811762 & $3.60162 \mathrm{E}-11$ & 0.003910887 & 0.005960117 \\
\hline Inverse of $\mathrm{K}$ & 0.721066667 & 0.791630074 & 0.910863 & 0.36917816 & -0.891429661 & 2.333562995 \\
\hline Inverse of $\mathrm{R}$ & 29.275 & 10.49563113 & 2.789256 & 0.008824099 & 7.896117097 & 50.6538829 \\
\hline
\end{tabular}

Visual Demand $=0.108+0.00494$ Age $+0.721 / K+29.3 / R$ 
Table 40 Model developed on Individual VD during Pilot Study (for horizontal overlapping crest curves, considering Age, $1 / \mathrm{K}$ and $1 / \mathrm{R})$

\begin{tabular}{|c|c|c|c|c|c|c|}
\hline \multicolumn{2}{|l|}{ SUMMARY OUTPUT } & & & & & \\
\hline & & & & & & \\
\hline \multicolumn{7}{|c|}{ Regression Statistics } \\
\hline \begin{tabular}{|l|} 
Multiple R \\
\end{tabular} & 0.901135949 & & & & & \\
\hline R Square & 0.812045998 & & & & & \\
\hline Adjusted R Square & 0.79442531 & & & & & \\
\hline Standard Error & 0.038453961 & & & & & \\
\hline Observations & 36 & & & & & \\
\hline & & & & & & \\
\hline \multicolumn{7}{|l|}{ ANOVA } \\
\hline & $\mathrm{df}$ & SS & MS & $\mathrm{F}$ & Significance $\mathrm{F}$ & \\
\hline Regression & 3 & 0.204437795 & 0.068146 & 46.08481 & $1.01632 \mathrm{E}-11$ & \\
\hline Residual & 32 & 0.047318627 & 0.001479 & & & \\
\hline \multirow[t]{3}{*}{ Total } & 35 & 0.251756422 & & & & \\
\hline & & & & & & \\
\hline & Coefficients & Standard Error & t Stat & P-value & Lower $95 \%$ & Upper 95\% \\
\hline Intercept & 0.100371696 & 0.030938215 & 3.244263 & 0.002757 & 0.037352668 & 0.163390725 \\
\hline Age & 0.004942151 & 0.000451432 & 10.94772 & $2.36 \mathrm{E}-12$ & 0.004022615 & 0.005861688 \\
\hline Inverse of $\mathrm{K}$ & 1.668533333 & 0.710444947 & 2.348575 & 0.025187 & 0.221405558 & 3.115661109 \\
\hline Inverse of $\mathrm{R}$ & 33.8125 & 9.419258239 & 3.58972 & 0.001092 & 14.62611507 & 52.99888493 \\
\hline
\end{tabular}

Visual Demand $=0.1+0.00494$ Age $+1.669 / \mathrm{K}+33.8 / \mathrm{R}$ 
Table 41 Correlation Coefficient Analysis Result for Curve Models

D RIWW RIHW E1 Age VD : RIFW KIHW E1 AEe VD

\begin{tabular}{|c|c|c|c|c|c|}
\hline \multicolumn{6}{|c|}{$5+i c 5$} \\
\hline Verieble & $\mathbf{H}$ & Mean & std Dev & Jinimum & Ya \\
\hline $\begin{array}{l}\text { RIFV } \\
\text { KIFV } \\
\text { E1 } \\
\text { AEe } \\
\text { VD } \\
\text { RIFW } \\
\text { KIHW } \\
\text { E1 } \\
\text { AEe } \\
\text { VD }\end{array}$ & $\begin{array}{l}540 \\
540 \\
540 \\
540 \\
540 \\
540 \\
540 \\
540 \\
540 \\
540\end{array}$ & $\begin{array}{r}0.0026 \\
0.0162 \\
-0.1575 \\
38.7333 \\
0.3788 \\
0.0026 \\
0.0162 \\
-0.1575 \\
38.7333 \\
0.3788\end{array}$ & $\begin{array}{r}0.0007 \\
0.0075 \\
4.1538 \\
17.8471 \\
0.0694 \\
0.0007 \\
0.0075 \\
4.1538 \\
17.8471 \\
0.0694\end{array}$ & $\begin{array}{r}0.001 T \\
0 \\
-T .8540 \\
19.0000 \\
0.2506 \\
0.0017 \\
0 \\
- \text { T. } 8540 \\
19.0000 \\
0.2506\end{array}$ & $\begin{array}{r}0.0033 \\
0.0250 \\
T .8540 \\
\text { T1. } 0000 \\
0.5853 \\
0.0033 \\
0.0250 \\
\text { T. } 8540 \\
\text { T1. } 0000 \\
0.5853\end{array}$ \\
\hline
\end{tabular}

\begin{tabular}{|c|c|c|c|c|c|}
\hline \multirow[t]{2}{*}{ DI. } & \multicolumn{5}{|c|}{ Correletion Satriz } \\
\hline & RIMU & KIHS & E1 & AEe & WD \\
\hline $\begin{array}{l}\text { RINW } \\
\text { KIHV } \\
\text { E1 } \\
\text { AEe } \\
\text { VD }\end{array}$ & $\begin{array}{r}1.0000 \\
0.1916 \\
0.0267 \\
0.3285\end{array}$ & $\begin{array}{r}0.1916 \\
1.0000 \\
0.0906 \\
0.1911\end{array}$ & $\begin{array}{r}0.026 T \\
0.0906 \\
1.0000 \\
0.0520\end{array}$ & $\begin{array}{r}0 \\
0 \\
0 \\
1.0000 \\
0.8190\end{array}$ & $\begin{array}{l}0.3285 \\
0.1911 \\
0.0520 \\
0.8190 \\
1.0000\end{array}$ \\
\hline
\end{tabular}


Table 42 Model developed on VḌF for 2D \& 3D Curves during Experimentation

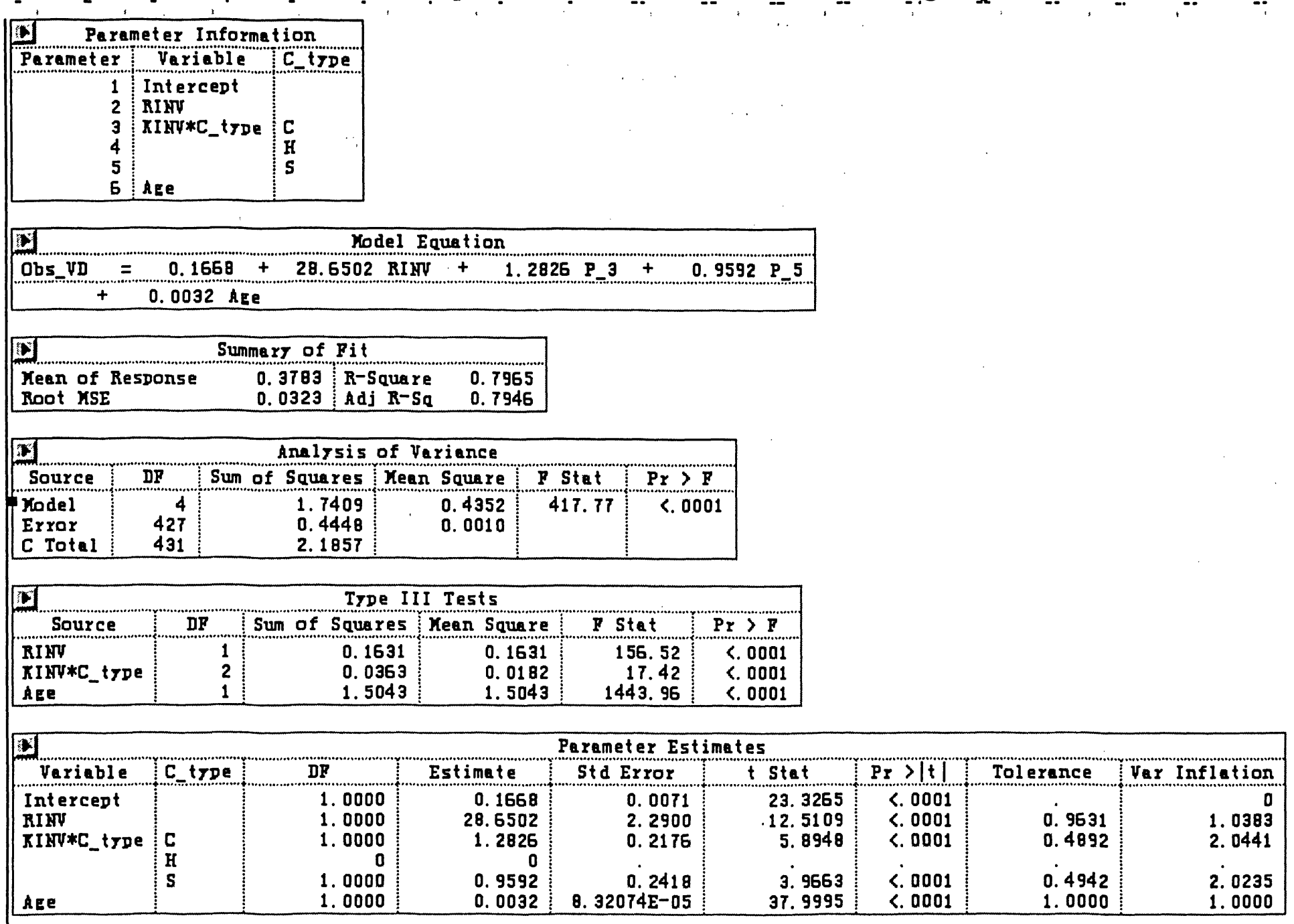

RINV: Inverse of Radius, KINV: Inverse of K, g1: Preceding grade 
Table 43 Model developed on VDH for 2D \& 3D Curves during Experimentation

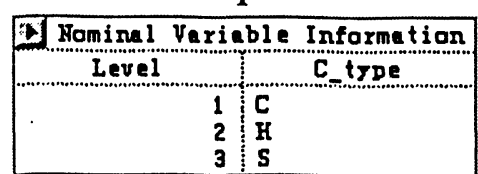

\begin{tabular}{|c|c|c|}
\hline \multicolumn{3}{|c|}{ Perameter Information } \\
\hline Peremeter & Variable & C-trpe \\
\hline $\begin{array}{l}1 \\
2 \\
3 \\
4 \\
5 \\
6\end{array}$ & $\begin{array}{l}\text { Intercept } \\
\text { RINW } \\
\text { RINW*C_trpe } \\
\text { AEE }\end{array}$ & $\begin{array}{l}\mathrm{C} \\
\mathrm{H} \\
\mathrm{S}\end{array}$ \\
\hline
\end{tabular}

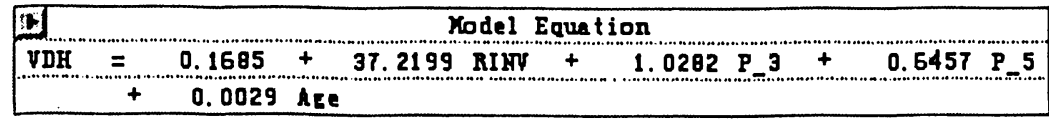

\begin{tabular}{|c|c|c|c|}
\hline 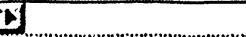 & Summer 7 of & Fit & \\
\hline $\begin{array}{l}\text { Xeen of Response } \\
\text { Root XSE }\end{array}$ & $\begin{array}{l}0.3905 \\
0.0515 \\
\end{array}$ & $\begin{array}{l}\text { R-Squere } \\
\text { Adj R-Sq }\end{array}$ & $\begin{array}{l}0.5699 \\
0.5667\end{array}$ \\
\hline
\end{tabular}

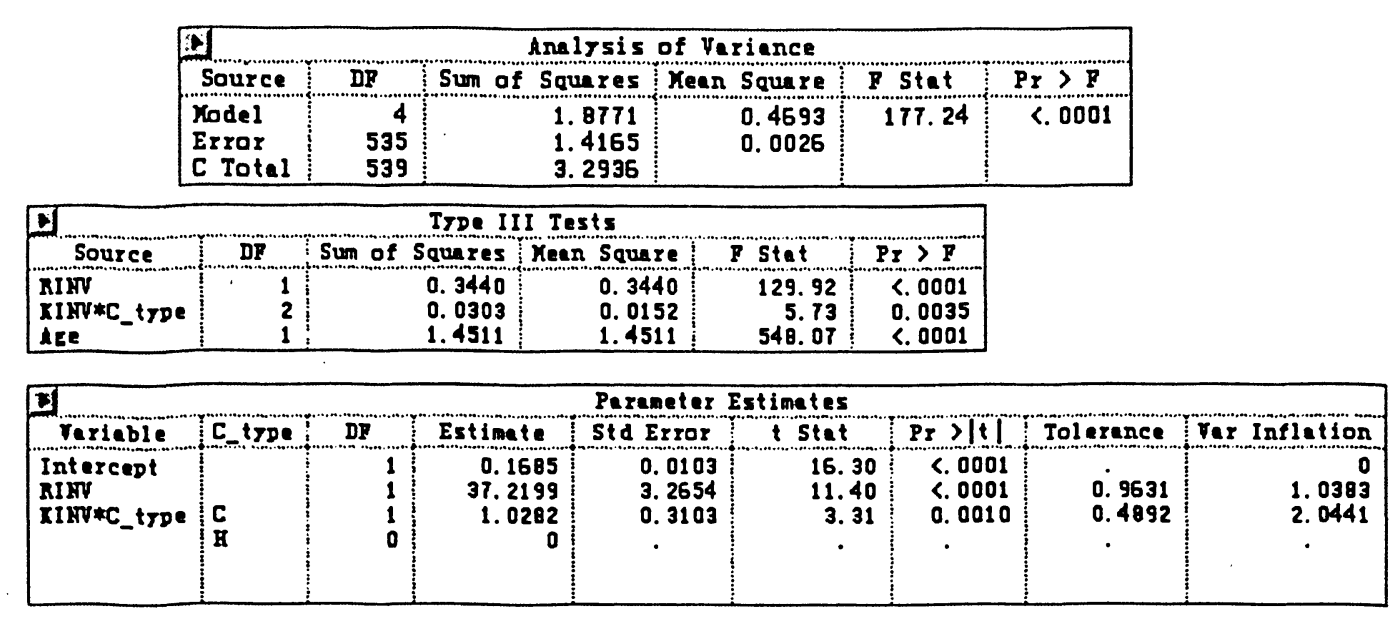


Table 44 Model developed on VD30 for 2D \& 3D Curves during Experimentation

ND30 $=$ RINY Age
Response Distribution: Hormel
Link Function:
Loe

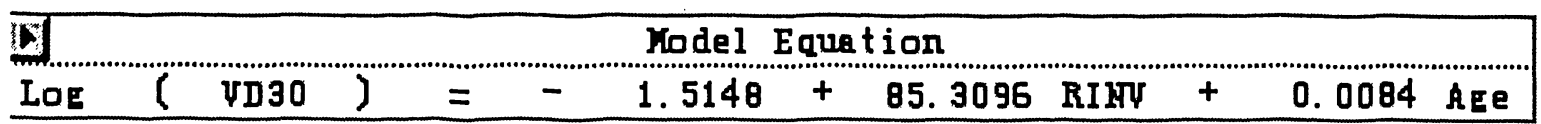

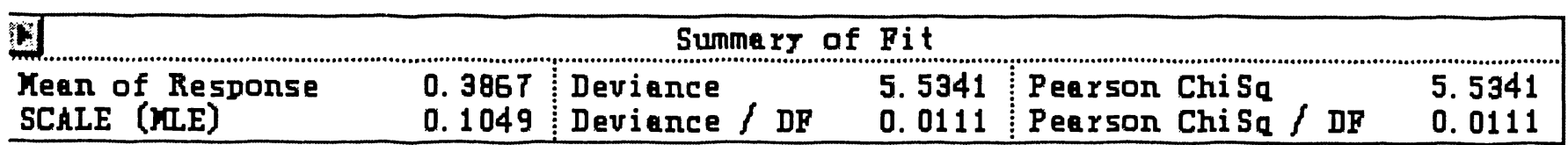

\begin{tabular}{|c|c|c|c|}
\hline \multicolumn{4}{|c|}{ Anelysis of Deviance } \\
\hline Source & $\mathrm{DF}$ & Deviance & Deviance / DF \\
\hline $\begin{array}{l}\text { Yodel } \\
\text { Error } \\
\text { C Totel }\end{array}$ & $\begin{array}{r}2 \\
500 \\
502\end{array}$ & $\begin{array}{l}\text { 2. } 0097 \\
5.5341 \\
\text { T. } 5438\end{array}$ & $\begin{array}{l}1.0049 \\
0.0111\end{array}$ \\
\hline
\end{tabular}

\begin{tabular}{|c|c|c|c|}
\hline D & Trpe & $(F, 1 d) T$ & ests \\
\hline Source & $D F$ & Chisa & $P_{r}>$ Chisq \\
\hline $\begin{array}{l}\text { RI HW } \\
\text { AEe }\end{array}$ & $\begin{array}{l}1 \\
1\end{array}$ & $\begin{array}{r}23.4783 \\
162.5985\end{array}$ & $\begin{array}{l}\text { <. } 0001 \\
\text { <. } 0001\end{array}$ \\
\hline
\end{tabular}

\begin{tabular}{|c|c|c|c|c|c|}
\hline \multicolumn{6}{|c|}{ Parameter Estimates } \\
\hline Yariable & DF & Estimete & Std Error & Chiso & $P Y>C h i S a$ \\
\hline $\begin{array}{l}\text { Intercept } \\
\text { RIWW } \\
\text { AEe }\end{array}$ & $\begin{array}{l}1 \\
1 \\
1\end{array}$ & $\begin{array}{r}-1.5148 \\
85.3096 \\
0.0084\end{array}$ & $\begin{array}{r}0.0567 \\
17.6062 \\
0.0007\end{array}$ & $\begin{array}{r}712.9921 \\
23.4783 \\
162.5985\end{array}$ & $\begin{array}{l}<.0001 \\
<.0001 \\
<.0001\end{array}$ \\
\hline
\end{tabular}


Table 45 Model developed on VDF for Tangents during Experimentation

\begin{tabular}{|c|c|c|c|c|}
\hline \multicolumn{5}{|c|}{ D tangent YD = PIFVR AEe } \\
\hline \multicolumn{5}{|c|}{ Response Distribution: Ho } \\
\hline & nk Function & & I dent $i$ & 7 \\
\hline
\end{tabular}

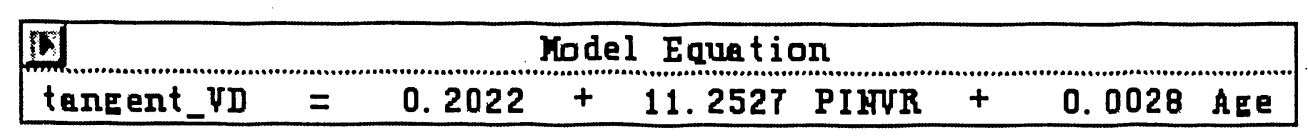

\begin{tabular}{|lll:l}
\hline D & SummerT of Pit & \\
\hline Kean of Response & 0.3403 & $\mathrm{R}-\mathrm{Square}$ & 0.3465 \\
Root KSE & 0.0698 & Adj R-SQ & 0.3433 \\
\hline
\end{tabular}

\begin{tabular}{|c|c|c|c|c|c|c|c|}
\hline \multicolumn{8}{|c|}{ Analysis of Veriance } \\
\hline Source & $\mathrm{DF}$ & Sum o & of Squares & Near & Squere & F Stat & $P Y>F$ \\
\hline $\begin{array}{l}\text { Yodel } \\
\text { Errar } \\
\text { C Tatel }\end{array}$ & $\begin{array}{r}2 \\
402 \\
404\end{array}$ & & $\begin{array}{l}\text { 1. } 0380 \\
\text { 1. } 9577 \\
\text { 2. } 9958\end{array}$ & & $\begin{array}{l}0.5190 \\
0.0049\end{array}$ & 106.58 & <. 0001 \\
\hline
\end{tabular}

\begin{tabular}{|c|c|c|c|c|c|}
\hline IN & & Trg & III Tests & & \\
\hline Source & $\mathrm{DP}$ & Sum of Squares & Yean Squa $\mathrm{Ye}$ & Pstat & $P r>P$ \\
\hline $\begin{array}{l}\text { PI WVR } \\
\text { Age }\end{array}$ & $\begin{array}{l}1 \\
1\end{array}$ & $\begin{array}{l}0.0219 \\
1.0161\end{array}$ & $\begin{array}{l}0.0219 \\
1.0161\end{array}$ & $\begin{array}{r}4.50 \\
208.65\end{array}$ & $\begin{array}{l}0.0345 \\
<.0001\end{array}$ \\
\hline
\end{tabular}

\begin{tabular}{|c|c|c|c|c|c|c|c|}
\hline \multicolumn{8}{|c|}{ Parameter Estimates } \\
\hline Verieble & $\mathrm{DP}$ & Estimete & Std Error & $t$ stet & $P r>1 t \mid$ & Tolerance & Ver Infletion \\
\hline $\begin{array}{l}\text { Intercept } \\
\text { PINVR } \\
\text { AEe }\end{array}$ & $\begin{array}{l}1 \\
1 \\
1\end{array}$ & $\begin{array}{r}0.2022 \\
11.2527 \\
0.0028\end{array}$ & $\begin{array}{l}0.0161 \\
5.3048 \\
0.0002\end{array}$ & $\begin{array}{r}12.52 \\
2.12 \\
14.44\end{array}$ & $\begin{array}{l}\text { <. } 0001 \\
0.0345 \\
<.0001\end{array}$ & $\begin{array}{l}1.0000 \\
1.0000\end{array}$ & $\begin{array}{r}0 \\
1.0000 \\
1.0000\end{array}$ \\
\hline
\end{tabular}


Table 46 Model developed on VDH for Tangents during Experimentation

\begin{tabular}{|c|c|c|c|}
\hline VD100T & $=$ & PIHUR & Age \\
\hline \multicolumn{4}{|c|}{ Response Distribution: } \\
\hline Link Func & n: & I den & ity \\
\hline
\end{tabular}

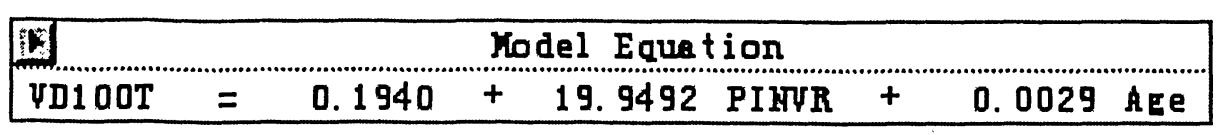

\begin{tabular}{|lc:ccc|}
\hline & SummerT of $\mathrm{Fit}$ & \\
\hline Keen of Response & 0.3571 & $\mathrm{R}-\mathrm{Square}$ & 0.3476 \\
Root KSE & 0.0725 & Adj R-SQ & 0.3443 \\
\hline
\end{tabular}

\begin{tabular}{|c|c|c|c|c|c|c|}
\hline \multicolumn{7}{|c|}{ Anelrsis of Yeriance } \\
\hline Source & $\mathrm{DF}$ & Sum o & of Squares & Mean Square & Pstet & $P \boldsymbol{P}>\mathbf{P}$ \\
\hline $\begin{array}{l}\text { Kodel } \\
\text { Error } \\
\text { C Totel }\end{array}$ & $\begin{array}{r}2 \\
402 \\
404 \\
\end{array}$ & & $\begin{array}{l}1.1251 \\
\text { 2. } 1120 \\
\text { 3. } 2372\end{array}$ & $\begin{array}{l}0.5626 \\
0.0053\end{array}$ & 107.08 & <. 0001 \\
\hline
\end{tabular}

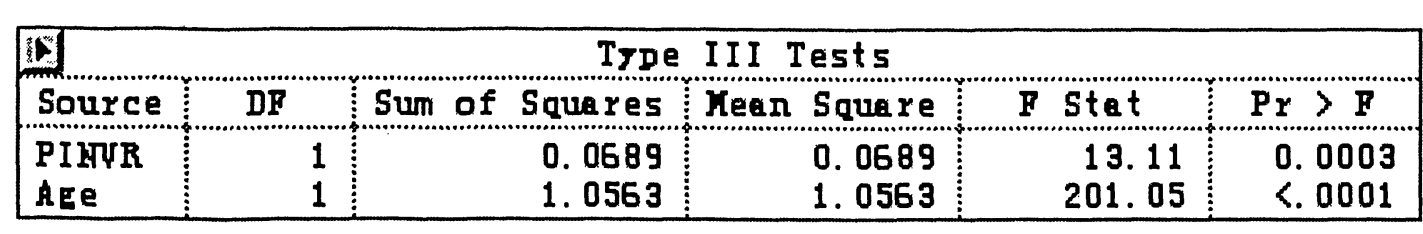

\begin{tabular}{|c|c|c|c|c|c|c|c|}
\hline \multicolumn{8}{|c|}{ Perameter Estimates } \\
\hline Variable & DF & Estimete & Std Error & $t s t a t$ & $P x>|t|$ & Tolerence & Ver Infletion \\
\hline $\begin{array}{l}\text { Intercept } \\
\text { PINWR } \\
\text { AEe }\end{array}$ & $\begin{array}{l}1 \\
1 \\
1 \\
\end{array}$ & $\begin{array}{r}0.1940 \\
19.9492 \\
0.0029 \\
\end{array}$ & $\begin{array}{l}0.0168 \\
5.5099 \\
0.0002 \\
\end{array}$ & $\begin{array}{r}11.57 \\
3.62 \\
14.18 \\
\end{array}$ & $\begin{array}{l}\text { S. } 0001 \\
0.0003 \\
<.0001 \\
\end{array}$ & $\begin{array}{l}1.0000 \\
1.0000 \\
\end{array}$ & $\begin{array}{r}0 \\
1.0000 \\
1.0000 \\
\end{array}$ \\
\hline
\end{tabular}


Table 47 Model developed on VD30 for Tangents during Experimentation

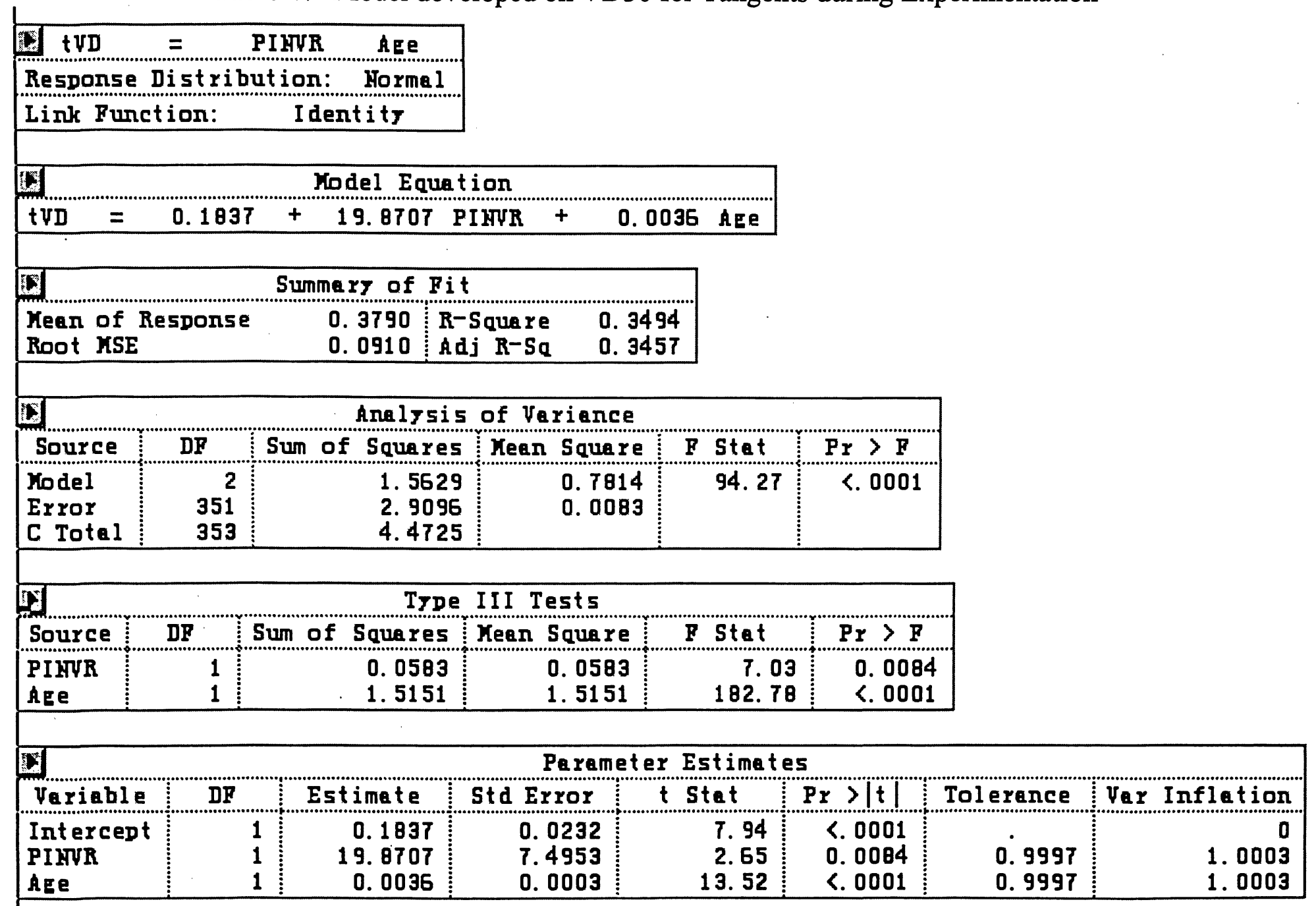

